\title{
Xenia: um sistema de segurança para grades computacionais baseado em cadeias de confiança
}

\author{
José de Ribamar Braga Pinheiro Júnior
}

\author{
TESE APRESENTADA \\ $\mathrm{AO}$ \\ Instituto de Matemática e Estatística \\ DA \\ Universidade DE SÃo Paulo \\ PARA \\ OBTENÇÃO DO TÍTULO \\ $\mathrm{DE}$ \\ Doutor EM CIÊNCIAS
}

\begin{abstract}
Área de Concentração: Ciência da Computação
Orientador: Prof. Dr. Fabio Kon
\end{abstract}

Durante o desenvolvimento deste trabalho o autor recebeu auxílio financeiro da CAPES

São Paulo, Março de 2008 


\section{Xenia: um sistema de segurança para grades computacionais baseado em cadeias de confiança}

Este exemplar corresponde à redação final da tese devidamente corrigida e defendida por

José de Ribamar Braga Pinheiro Júnior e aprovada pela Comissão Julgadora.

Banca Examinadora:

- Prof. Dr. Fabio Kon - IME-USP.

- Prof. Dr. Routo Terada - IME-USP.

- Prof. Dr. Luciano Paschoal Gaspary - UFRGS.

- Prof. Dr. Joni da Silva Fraga - UFSC.

- Prof. Dr. Renato Fontoura de Gusmão Cerqueira - PUC-Rio. 


\section{Agradecimentos}

Aos meus pais, à minha mulher Sandra, aos meus amados filhos Thaís, Thales e Caio Victor e ao meu padrinho Rui Braga. Aos meus amigos da lista de discussão aabalados e do LCPD. 


\section{Resumo}

Os Sistemas de Grades Computacionais são intrinsecamente mais vulneráveis às ameaças de segurança que os Sistemas tradicionais, uma vez que abrangem um grande número de usuários e os recursos e as aplicações são geridas por diferentes domínios administrativos. A autenticação e a autorização são fatores imperativos para os Sistemas de Grade Computacional. Da mesma forma, a escalabilidade e a distribuição de dados vêm também sendo objeto de estudo de vários pesquisadores da área. Os serviços providos pelas Grades Computacionais devem evitar implementações centralizadas pela dificuldade do gerenciamento global. Outro importante requisito das Grades Computacionais é prover mecanismos para a delegação de direitos de acesso aos recursos. O proprietário do recurso deve ser capaz de delegar permissões para outro usuário, talvez por um tempo limitado, com base na confiança que possui neste. No entanto, a delegação deve ser usada com cuidado, pois uma longa cadeia de delegações poderia conduzir a uma utilização abusiva dos recursos pelos usuários maliciosos.

Para tratar os principais requisitos de segurança das Grades Computacionais, desenvolvemos uma Arquitetura de Segurança denominada Xenia. Esta arquitetura é baseada em SPKI/SDSI, um modelo de segurança flexível, extensível e descentralizado que fornece autenticação, confidencialidade e controle de acesso. Propusemos uma extensão ao modelo SPKI/SDSI baseada em lógica subjetiva para representar relações de confiança entre indivíduos.

Palavras-chave: Segurança computacional, Grades computacionais, Cadeias de Confiança. 


\section{Abstract}

Grid Computing Systems are inherently more vulnerable to security threats than traditional systems, since they potentially encompass a large number of users, resources, and applications managed by different administrative domains. Authentication and authorization are imperative for grid systems. Since scalability and distribution are major concerns on grid environments, those services implementations should avoid centralized solutions. Another relevant requirement to consider is the provision of mechanisms for delegating access rights, since they minimize the overhead of grid administrators on providing access rights to grid resources. The owner of an access right should be able to delegate permissions to another user, maybe for a limited time, based on his trust on that user. However, delegation must be used with care. A long chain of delegations could lead to improper use of resources by malicious users. Confidentiality and integrity are also important security requirements for many grid applications. To address these problems, we designed a Security Architecture for Grid Systems named Xenia. This architecture is based on SPKI/SDSI, a flexible and extensible decentralized security model that provides authentication, confidentiality, and access control. We proposed an extension to the SPKI/SDSI model to represent trust relations between subjects based on subjective logic.

Keywords: Computational Security, Computational Grids, Trust Chains. 


\section{Sumário}

Lista de Abreviaturas $\quad$ xi

Lista de Figuras $\quad$ xiii

Lista de Tabelas $\quad$ Xv

1 Introdução $\quad 1$

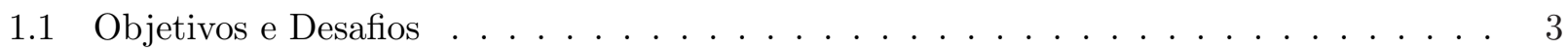

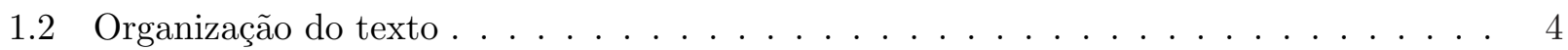

2 Segurança em Grades Computacionais $\quad 5$

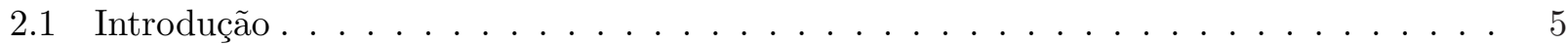

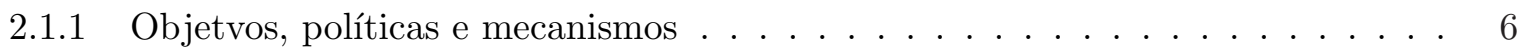

2.1.2 Vulnerabilidades, ameaças e ataques . . . . . . . . . . . . 7

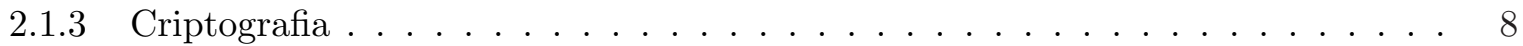

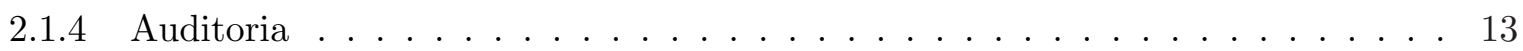

2.2 Grades Computacionais . . . . . . . . . . . . . . . . . . . . . . . 14

2.2 .1 Requisitos de segurança . . . . . . . . . . . . . . . . 17

3 Trabalhos Relacionados $\quad 19$ 
3.1 Globus . . . . . . . . . . . . . . . . . . . . . 19

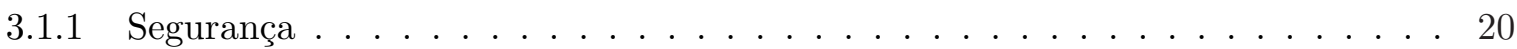

3.2 Legion/Avaki . . . . . . . . . . . . . . . . . . . . 26

3.2 .1 Segurança . . . . . . . . . . . . . . . . . . . 27

3.3 Condor . . . . . . . . . . . . . . . . . . . . . . . 29

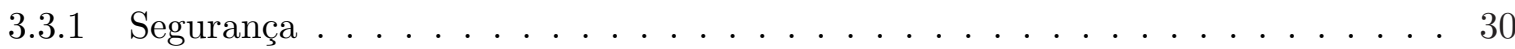

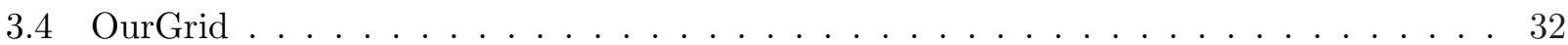

3.4 .1 Segurança . . . . . . . . . . . . . . . . . . 33

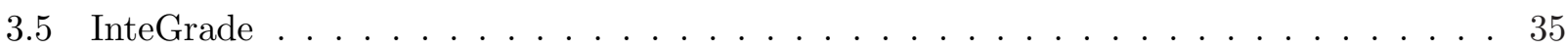

3.5.1 O Repositório de Aplicações . . . . . . . . . . . . . . . . . . . . . 37

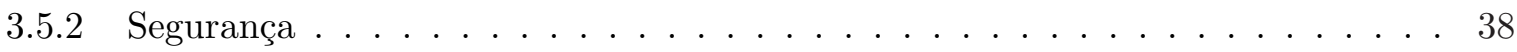

3.6 Conclusão . . . . . . . . . . . . . . . . . . . . . . . . . 41

4 Opiniões em Cadeias de Confiança SPKI/SDSI 43

4.1 Introdução . . . . . . . . . . . . . . . . . . . . . . . . . . . 43

4.2 Modelo de cadeias de confiança SPKI/SDSI . . . . . . . . . . . . . . . 45

4.3 Exprimindo opiniões em uma rede SPKI/SDSI . . . . . . . . . . . . . . . 46

4.3 .1 Modelo de Jøsang . . . . . . . . . . . . . . . . . . . . . . 47

4.3 .2 Aplicando o modelo de Jøsang no SPKI/SDSI . . . . . . . . . . . . . . . . . . 49

4.3 .3 Extensão do Modelo SPKI/SDSI . . . . . . . . . . . . . . . . . . . . . 51

5 Xenia: Uma Arquitetura de Segurança Baseada em Opiniões 55

5.1 Introdução . . . . . . . . . . . . . . . . . . . . . . 55

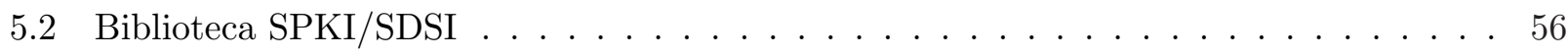

5.3 Módulos de Segurança . . . . . . . . . . . . . . . . . . . . . 58 
5.4 Autenticação na grade . . . . . . . . . . . . . . . . . . . . . . . . . 61

5.5 Autorização e Controle de Acesso . . . . . . . . . . . . . . . . . . . . . . . . 62

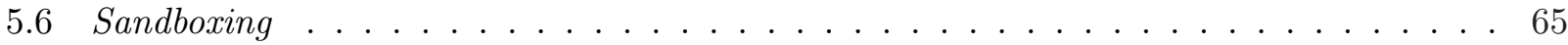

6 Avaliação do Modelo do Xenia $\quad 69$

6.1 Simulações . . . . . . . . . . . . . . . . . . . . . . . . . 69

6.1 .1 Inicialização . . . . . . . . . . . . . . . . . . . . . 69

6.1 .2 Ambiente de Simulação . . . . . . . . . . . . . . . . . . . . . 70

6.1 .3 Resultados Obtidos . . . . . . . . . . . . . . . . . . . 72

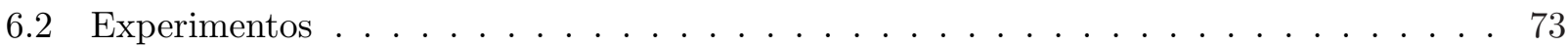

6.2.1 Cenário 1: Usuários Maliciosos na Grade . . . . . . . . . . . . . . 75

6.2.2 Cenário 2: Medida de Desempenho . . . . . . . . . . . . . . 76

7 Considerações Finais $\quad 79$

7.1 Publicações durante o doutorado . . . . . . . . . . . . . . . . . . . . . 80

7.2 Contribuições do Trabalho . . . . . . . . . . . . . . . . . . . . . . . 80

7.2.1 Sob o ponto de vista tecnológico . . . . . . . . . . . . . . . . 80

7.2 .2 Sob o ponto de vista científico f . . . . . . . . . . . . . 81

7.3 Trabalhos futuros . . . . . . . . . . . . . . . . . . . 81

Referências Bibliográficas $\quad 83$ 


\section{Lista de Abreviaturas}

$\begin{array}{ll}\text { ACL } & \text { Access Control List } \\ \text { AR } & \text { Application Repository } \\ \text { ARSC } & \text { Application Repository Security Client } \\ \text { ARSM } & \text { Application Repository Security Manager } \\ \text { ASCT } & \text { Application Submission and Control Tool } \\ \text { CA } & \text { Certificate Authority } \\ \text { CAS } & \text { Comunity Authorization Server } \\ \text { DAP } & \text { Data Access Point } \\ \text { GRM } & \text { Global Resource Manager } \\ \text { GSI } & \text { Globus Security Infrastructure } \\ \text { GSM } & \text { Global Security Manager } \\ \text { GT } & \text { Globus Toolkit } \\ \text { GUPA } & \text { Global Usage Pattern Analyzer } \\ \text { ICP } & \text { Infra-estrutura de Chave Pública } \\ \text { IDL } & \text { Interface Definition Language } \\ \text { KCA } & \text { Kerberos Certificate Authority } \\ \text { LRM } & \text { Local Resource Manager } \\ \text { LSM } & \text { Local Security Manager } \\ \text { LUPA } & \text { Local Usage Pattern Analyzer } \\ \text { OGSA } & \text { Open Grid Services Architecture } \\ \text { OGSI } & \text { Open Grid Service Infrasctructure } \\ \text { OPA } & \text { Object Persistent Address } \\ \text { OPR } & \text { Object Persistent Representation } \\ \text { P2P } & \text { Peer to Peer }\end{array}$


P2PSLF Peer-to-Peer Security Layer Framework

RC Resource Controller

SAML Security Assertions Markup Language

SDSI Simple Distributed Security Infrastructure

SOAP Simple Object Access Protocol

SPKI Simple Distributed Security Infrastructure

SSL Secure Socket Layer

TCL Trader Constraint Language

TLS Transport Layer Security

WSRF Web Service Resource Framework

XKISS XML Key Information Service Specification

XMKS XML Key Management Specification 


\section{Lista de Figuras}

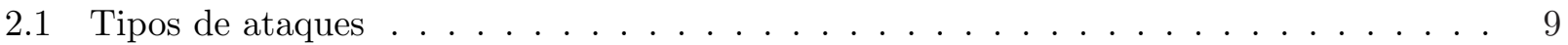

2.2 Tabela de substituição para cifração . . . . . . . . . . . . . . . . . . . . . 10

2.3 Modelo simplificado de chave secreta [57]. . . . . . . . . . . . . . . . . . . 11

2.4 Modelo simplificado de chave pública $[57] \ldots \ldots \ldots \ldots \ldots$. . . . . . . . . . 12

2.5 Assinatura através de uma chave pública. . . . . . . . . . . . . . . . . . . 13

2.6 Arquitetura de uma Grade computacional. . . . . . . . . . . . . . . . . . 16

3.1 Arquitetura do GSI. . . . . . . . . . . . . . . . . . . . . 20

3.2 Protocolo de Autenticação Única. . . . . . . . . . . . . . . . . . . . . . 22

3.3 Delegação de Certificado Proxy . . . . . . . . . . . . . . . . . . . . . . 23

3.4 Usuário faz uma requisição de capacidade ao servidor CAS. . . . . . . . . . . . . . . 25

3.5 Cliente requisitando uso de recurso . . . . . . . . . . . . . . . . 26

3.6 Arquitetura de Segurança do Condor. . . . . . . . . . . . . . . . . 30

3.7 Arquitetura do OurGrid. . . . . . . . . . . . . . . . . 33

3.8 Arquitetura do P2PSL . . . . . . . . . . . . . . . . . . . . 34

3.9 Arquitetura do InteGrade com os módulos de segurança. . . . . . . . . . . . . . . 36

3.10 Visão do Repositório de Aplicações via ASCTGui. . . . . . . . . . . . . . . . 38

3.11 Protocolo de armazenamento do executável de uma aplicação no repositório. . . . . . . 39 
3.12 Protocolo de recuperação do executável de uma aplicação. . . . . . . . . . . . . . . . . 40

4.1 Delegação de um Certificado . . . . . . . . . . . . . . . . . . . . . . . . 47

4.2 Cadeia de certificação com o nó C não muito confiável . . . . . . . . . . . . . . . . 47

4.3 Cadeia de certificação com o nó C não muito confiável . . . . . . . . . . . . . . . 50

4.4 Mudança de opinião . . . . . . . . . . . . . . . . . . . . . 51

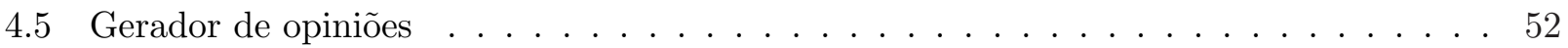

4.6 Um certificado de opinião SPKI/SDSI . . . . . . . . . . . . . . . . . . 53

5.1 Usuário Alice recebe uma opinião. . . . . . . . . . . . . . . . . . 57

5.2 Módulos de Segurança do InteGrade . . . . . . . . . . . . . . . . . . . 58

5.3 Arquitetura do InteGrade incluindo os módulos de segurança . . . . . . . . . . . . . 59

5.4 Logon na Grade . . . . . . . . . . . . . . . . . . . . . . . . . . 61

5.5 Autorizações e delegações no Xenia. . . . . . . . . . . . . . . 63

5.6 Dinâmica do controle de acesso do Xenia . . . . . . . . . . . . . . . . . . . 64

5.7 Exemplo de lista de controle de acesso no Xenia. . . . . . . . . . . . . . 66

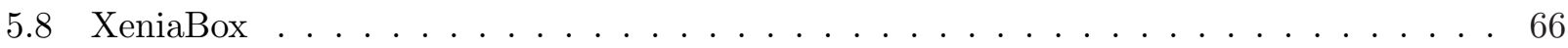

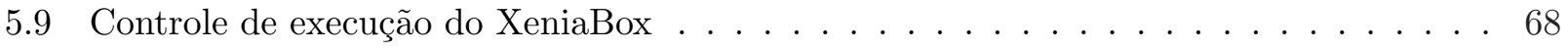

6.1 Resultados das simulações . . . . . . . . . . . . . . . . . . . . 73

6.2 Caminhada segura pelas cadeias . . . . . . . . . . . . . . . . 74

6.3 Topologia para os experimentos que medem a performance do Xenia $\ldots$. . . . . . . 75

6.4 Tempo de execução versus Numero de Multiplicações . . . . . . . . . . . . . . . . . . . 77 


\section{Lista de Tabelas}

3.1 Comparação entre X.509 padrão e X.509 proxy estendido pelo Globus Toolkit. . . . 21

3.2 Características dos mecanismos de segurança dos sistemas de grade. . . . . . . . . . . 41

4.1 Sistemas de créditos para o modelo de opinião. . . . . . . . . . . . . . . . . 52

6.1 Sistemas de créditos para o modelo de opinião. . . . . . . . . . . . . . . 70 


\section{Capítulo 1}

\section{Introdução}

A preocupação com a segurança de dados surgiu no meio militar, onde proteger as informações era o principal objetivo, pois delas dependiam os resultados das batalhas. Historicamente sabe-se que muitas das vitórias ocorridas durante a segunda guerra mundial deveram-se à criptografia de dados. Esconder uma ordem que indicava um movimento das tropas poderia salvar centenas de vidas.

Nos dias atuais, os problemas com a proteção dos dados são mais discretos, mas nem por isso menos importantes. Com a grande participação das tecnologias de redes de computadores nas empresas, nas instituições governamentais e até mesmo nos lares de milhões de pessoas, o perigo de uma possível ameaça às informações privilegiadas se faz presente a todo momento. Já faz parte da rotina diária das empresas a realização de negócios utilizando redes privadas ou a Internet como meio de comunicação. Bancos disponibilizam suas transações financeiras através de redes públicas de dados e a interceptação ou modificação de informações pode levar a resultados desastrosos. Diante deste contexto, assim como num ambiente de guerra real, existe a preocupação crescente em proteger informações que podem ser uma questão de sobrevivência das instituições.

As redes de computadores, em especial a Internet, no entanto, foram criadas sem a preocupação com a segurança na transmissão de dados [31]. Quando surgiram as tecnologias de redes de computadores, as relações de segurança entre as partes envolvidas, que eram confiáveis e conhecidas, não obtiveram a preocupação necessária dos seus projetistas. Mais recentemente, a partir do momento em que a arquitetura da Internet firmou-se como o padrão das redes de computadores, suas vulnerabilidades foram expostas e técnicas adicionais tiveram que ser usadas para manter a segurança das informações.

A sociedade em que vivemos é cada vez mais dependente das novas tecnologias. A computação, 
em particular, surgiu para automatizar muitas tarefas que eram executadas de forma árdua em um tempo não muito distante. A ciência, em todas suas áreas de conhecimento, é, sem sombra de dúvida, uma das beneficiadas pelas tecnologias emergentes oriundas da Computação. Biólogos, físicos, matemáticos, engenheiros, químicos, por exemplo, utilizam os computadores em suas simulações, otimizações, mineração de dados, entre outras atividades. A indústria, por sua vez, é favorecida, direta ou indiretamente, por resultados conseguidos através da informática para melhorar os seus processos, obtendo maior qualidade em seus produtos e, conseqüentemente, maiores lucros. O comércio, além das vantagens conseguidas naturalmente pela automatização de suas informações, utiliza-se da Internet para aumentar a venda de seus produtos, colocando-os disponíveis diretamente na casa ou no local de trabalho de seus clientes.

Todas essas facilidades fizeram surgir uma crescente necessidade de poder computacional. Problemas já existentes, ou mesmo novos, ainda não experimentados pela sociedade, demandam grande tempo de processamento. Altos investimentos em equipamentos são feitos para resolver problemas computacionais nas áreas de prospecção de petróleo, simulação metereológica, seqüenciamento de DNA e previsão do tempo. A importância estratégica destas atividades nos dão a idéia da importância da computação dentro da sociedade contemporânea. Os altos custos envolvidos na aquisição de computadores de alto desempenho os tornam inacessíveis para uma grande quantidade de potenciais usuários. Por outro lado, os computadores pessoais de hoje possuem a mesma capacidade de processamento dos supercomputadores de uma década atrás. A possibilidade de que estas máquinas disponibilizem seus recursos computacionais para solucionar os problemas de outros usuários e instituições em uma rede de computadores fez surgir a idéia da Computação em Grade (Grid Computing $)^{1}[13,26,28]$.

Um sistema de Computação em Grade pode ser definido como uma infra-estrutura capaz de interligar e gerenciar diversos recursos computacionais distribuídos por uma rede de computadores de maneira a oferecer, ao usuário, uso intensivo de recursos [8]. As grades permitem o compartilhamento de recursos geograficamente dispersos tais como processamento, memória, periféricos (por exemplo, instrumentos científicos e hardware especializado), componentes de software, entre outros.

Os computadores que participam de grades computacionais são particularmente vulneráveis a problemas com a segurança. Em um sistema de grade, os recursos a serem protegidos estão localizados em domínios administrativos diferentes, implicando em um controle de acesso mais difícil.

\footnotetext{
${ }^{1}$ A origem do termo Grid Computing é uma analogia com a rede elétrica (Power Grid).
} 
A Computação em Grade exige que as soluções de segurança sejam interoperáveis para permitir a integração com os sistemas de segurança já existentes. Finalmente, os sistemas operacionais e o middleware da Grade, por sua vez, podem não ser seguros o bastante, permitindo o acesso indevido a recursos.

Existem diversos mecanismos de segurança utilizados em sistemas distribuídos convencionais. Estes, no entanto, não se adequam totalmente às condições específicas das grades computacionais. A principal motivação deste trabalho é contribuir para o desenvolvimento de mecanismos de segurança que atendam aos requisitos mais abrangentes das grades computacionais.

\subsection{Objetivos e Desafios}

O objetivo deste trabalho é investigar o uso de uma arquitetura de segurança descentralizada baseada em cadeias de confiança (Trust Chains) em sistemas de grades computacionais. Esta arquitetura deve atender os principais requisitos de segurança dos sistemas de grade computacional que diferem em alguns pontos dos sistemas distribuídos convencionais.

Os desafios que cercam este trabalho são diversos. Inicialmente, devemos considerar que em um ambiente onde a segurança seja totalmente descentralizada, cada participante deve ser responsável pelo gerenciamento de seu próprio espaço de nomes. Isto siginifica que deve-se prover serviços de localização de usuários e seus recursos. Estes serviços devem ser capazes de resolver qualquer nome associado a uma chave criptográfica.

Deve-se ainda considerar a dificuldade de, dada uma cadeia que representa as relações de confiança entre elementos da grade, verificar se esta é segura. Porém, deve-se atentar que nem sempre todos os elementos de uma determinada cadeia de confiança podem ser considerados confiáveis, particularmente, em um ambiente de grade onde, na maior parte das vezes, têm-se domínios administrativos diferentes. Utilizar conceitos de confiança subjetiva entre pares associado a lógica subjetiva (Subjective Logic) pode ser uma abordagem que minimiza o problema, necessitando porém que seja demonstrado a qualidade da solução.

Em seguida, devemos supor que, além dos elementos que compõem a grade, devemos ter aplicações confiáveis. Poderíamos supor assim que as aplicações se comportam sempre como o esperado e ainda, se não o fizerem, que não executem um código malicioso ou simplesmente defeituoso. Neste caso, a definição de um ambiente de confinamento para execução de aplicações, conhecido como SandBoxing, é uma opção considerada neste trabalho. 
Finalmente, devemos considerar a heterogeneidade das máquinas em cada sítio. Além da diversidade da arquitetura, domínios administrativos diferentes podem ser compostos de diferentes ferramentas de segurança. Uma arquitetura de segurança para grades computacionais deve prover soluções que permitam a interação entre ambientes diversos.

Dentro de um contexto bem fundamentado busca-se o desenvolvimento de uma arquitetura de segurança genérica e flexível para sistemas em grade. Esta arquitetura será utilizada no Projeto InteGrade contribuindo desta forma com o desenvolvimento de um middleware para grades oportunistas que se tornará disponível a diversas instituições. O suporte desta arquitetura ao middleware InteGrade permitirá um menor risco de segurança aos recursos disponíveis.

\subsection{Organização do texto}

Este trabalho foi organizado como segue. O Capítulo 2 apresenta os conceitos gerais referentes a segurança de dados, seus objetivos, ameaças e mecanismos existentes. Em particular, neste capítulo tratamos dos aspectos de segurança relativos as Grades computacionais. O Capítulo 3 apresenta os trabalhos relacionados a segurança de dados em Grades computacionais; apresentamos as grades computacionais existentes, a forma que cada uma trata da segurança e suas deficiências. No capítulo seguinte, o Capítulo 4, apresentamos as cadeias de confiança como solução para segurança em grades computacionais. Neste capítulo propomos uma extensão para um modelo de cadeias de confiança existente de forma que este represente valores subjetivos de opiniões. A implementação de uma arquitetura de segurança para grades computacionais baseado em cadeias de confiança com opiniões, denominada Xenia, é apresentada no Capítulo 5. Por fim, no Capítulo 6, avaliamos a arquitetura através de simulações e de experimentos. 


\section{Capítulo 2}

\section{Segurança em Grades Computacionais}

Neste capítulo apresentamos uma pequena introdução dos conceitos gerais sobre segurança computacional. Tratamos brevemente dos objetivos, mecanismos e ameaças de um sistema de segurança. Apresentamos e discutimos os conceitos iniciais sobre grades computacionais.

\subsection{Introdução}

A implementação de sistemas seguros deve ser uma preocupação constante das equipes de desenvolvimento de sistemas de software. Um sistema computacional é seguro se pudermos depender dele e seu software tiver um comportamento esperado [36]. Sabemos, no entanto, que criar um sistema computacional totalmente seguro é muito difícil (se não impossível) e devemos definir os limites de risco aceitáveis. Respondendo a questões como: qual o perímetro da rede a ser considerada, quais serviços serão disponibilizados externamente, quais são os controles necessários para o sistema e o nível de segurança pretendido, estaremos delineando o escopo de nosso problema.

Cada sistema computacional tem valores associados aos recursos que devem ser protegidos, alguns tangíveis, outros intangíveis [51]. Recursos tangíveis são aqueles aos quais podemos associar valores diretos, ou seja, podemos quantificar um preço por ele (ohardware, por exemplo). Recursos intangíveis (uma informação, por exemplo) são mais difíceis de avaliar pela dificuldade que temos em definir o quanto vale a informação. Lang [51] sugere que devemos quantificar o custo da perda, pois é mais apropriado quantificar o impacto negativo do recurso comprometido, assim como: custo da troca, danos à reputação, perda de competitividade, entre outros.

A relação entre o custo da implementação e o custo da perda do recurso nos proporciona o que chamamos de análise de risco. O objetivo da segurança é minimizar o risco. Os custos da 
implementação de segurança tais como custo com pessoal,hardware, software e o tempo gasto não devem ser maior do que o custo associado ao risco potencial de cada possível ataque. É fácil imaginar que os requisitos de segurança necessários para um ambiente bancário devem ser diferentes daqueles esperados para um ambiente educacional. Encontrar um ponto de equilíbrio entre os custos associados à implementação de segurança e o benefício causado por essa implementação é um dos grandes desafios durante o projeto de sistemas de segurança. A seguir trataremos dos objetivos, das políticas e dos mecanismos disponíveis em um sistema de segurança.

\subsubsection{Objetvos, políticas e mecanismos}

Quando se projeta sistemas de segurança temos que estar atentos aos objetivos a serem alcançados. Os objetivos são definidos pelas políticas e os métodos utilizados para alcançá-los são chamados de mecanismos de segurança [65].

A política de segurança define as regras gerais pelas quais é fornecido acesso aos recursos. A política serve para avaliar a segurança de um sistema e definir regras e práticas que regulamentam como devemos proteger e distribuir os recursos. As políticas de segurança não devem conter detalhes técnicos relacionados às suas proposições, mas especificar o que deve ser feito e o motivo. Escrevese esta política de forma amigável e com uma linguagem clara e precisa. Uma política sempre é específica para um determinado ambiente e não pode ser definida de forma generalizada.

Os mecanismos de segurança são os meios através dos quais garantimos que uma determinada política está sendo cumprida; os mecanismos são as ferramentas disponíveis para implementar uma política de segurança. Os mecanismos de segurança podem ser desde procedimentos físicos (como impedir a entrada de usuários em uma determinada sala) ou implementados emhardware ou software (como algoritmos de criptografia ou controle de acesso).

Um sistema de segurança deve possuir propriedades que permitam que a comunicação seja a mais protegida possível. Vamos supor, por exemplo, que alice deseja se comunicar com Bob. Primeiramente, Alice quer que somente Bob compreenda a mensagem que ela enviou. Bob, por sua vez, quer ter certeza que a mensagem foi enviada por Alice e de alguma forma que esta não negue a sua autoria. Finalmente, Alice e Bob necesssitam que as mensagens enviadas não sejam modificadas e tampouco que alguém as impeça de chegar ao seu destino. Dessa forma, as seguintes propriedades desejáveis podem ser percebidas em uma comunicação segura [50]: 
- Autenticação

A autenticação é o processo de estabelecer a validade de uma identidade reivindicada [59]. A autenticação é o primeiro passo na segurança de um sistema computacional; junto à confidencialidade e à integridade, forma os pilares da segurança.

- Irretratabilidade

A irretratabilidade consiste em obter provas (ou fortes indícios) de ações realizadas no passado de forma que um indivíduo não possa negar ações que tenha realizado no sistema.

- Confidencialidade

A confidencialidade impede que os dados sejam lidos ou copiados por usuários que não possuem o direito de fazê-lo.

- Integridade de Dados

A integridade de dados protege a informação de ser removida ou alterada sem a autorização do dono.

- Disponibilidade

A disponibilidade é a proteção dos serviços para que eles não sejam degradados ou fiquem inacessíveis sem autorização. Isto implica em dados e sistemas prontamente disponíveis e confiáveis.

\subsubsection{Vulnerabilidades, ameaças e ataques}

Uma vulnerabilidade é um ponto onde o sistema é suscetível a um ataque e uma ameaça pode ser definida como um possível perigo que pode explorar uma vulnerabilidade do sistema computacional. Uma vulnerabilidade geralmente surge de forma não intencional; por exemplo, para aumentar o desempenho é comum programadores evitarem a verificação de dados de entrada em programas, o que pode levar a vulnerabilidades. Um exemplo comum de vulnerabilidade é o estouro de buffer que tem sido muito explorado nos últimos anos [53]. Esta vulnerabilidade consiste em utilizar a falta de verificação do tamanho e do tipo dos dados de entrada de um programa, alterando o seu estado através da inserção de código malicioso, resultando num desvio para executar o código inserido. Uma ameaça pode ser definida como um possível perigo que pode explorar uma vulnerabilidade do sistema computacional [51]. Uma vulnerabilidade é um ponto onde o sistema é suscetível a um 
ataque. Uma ameaça pode explorar uma vulnerabilidade para concretizar um ataque a um sistema. Uma vulnerabilidade geralmente surge de forma não intencional; por exemplo, para aumentar o desempenho é comum programadores evitarem a verificação de dados de entrada em programas, o que pode levar a vulnerabilidades. Um exemplo comum de vulnerabilidade é o estouro de buffer que tem sido muito explorado nos últimos anos [53]. Esta vulnerabilidade consiste em utilizar a falta de verificação do tamanho e do tipo dos dados de entrada de um programa, alterando o seu estado através da inserção de código malicioso, resultando num desvio para executar o código inserido.

O ataque é a efetivação de uma ameaça através de uma vilnerabilidade. O termo intruso ou atacante é comumente usado para representar aquele que tenta obter um acesso não autorizado. Os ataques podem ser passivos ou ativos [65]. Os ataques passivos ocorrem quando um intruso tenta obter informações de um sistema computacional sem interferir diretamente no funcionamento deste sistema. Os ataques ativos interferem diretamente no funcionamento normal do sistema, geralmente ocasionando algum prejuízo.

O representante mais expressivo dos ataques ativos é conhecido como vírus de computador. Fred Cohen [12], um dos primeiros pesquisadores que estudou o vírus de computador, o definiu inicialmente como um programa que infecta outro, modificando-o para incluir-se. Devido à facilidade de troca de arquivos pela rede, os vírus passaram a ser um problema constante de segurança. Através da rede, a contaminação por vírus de computador não mais depende do contato direto de dispositivos de armazenamento dos programas. Os vírus atuais propagam-se com velocidade extrema, através dos diversos serviços oferecidos pela Internet e suas vulnerabilidades, dentre os quais destacam-se o correio eletrônico e a $W e b$.

Os dados, ao trafegarem pela rede, podem sofrer ataques do tipo interceptação, interrupção, modificação ou fabricação [66], como pode ser visto na Figura 2.1. Na interceptação, os dados são copiados e assim perdem sua confidencialidade. A interrupção ocorre quando os dados são perdidos ou corrompidos. Na modificação, os dados são obtidos, modificados e então reenviados ao seu destino. Finalmente, na fabricação, dados e atividades são criados sem sequer terem saído da sua verdadeira origem.

\subsubsection{Criptografia}

A criptografia tem como objetivo esconder informações sigilosas de qualquer pessoa que não seja autorizada a lê-las [67]. A criptologia é o estudo de técnicas matemáticas relacionadas com a segu- 

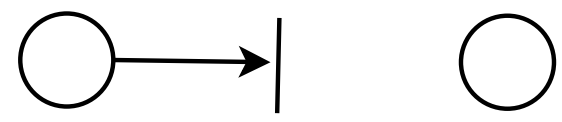

Interrupção
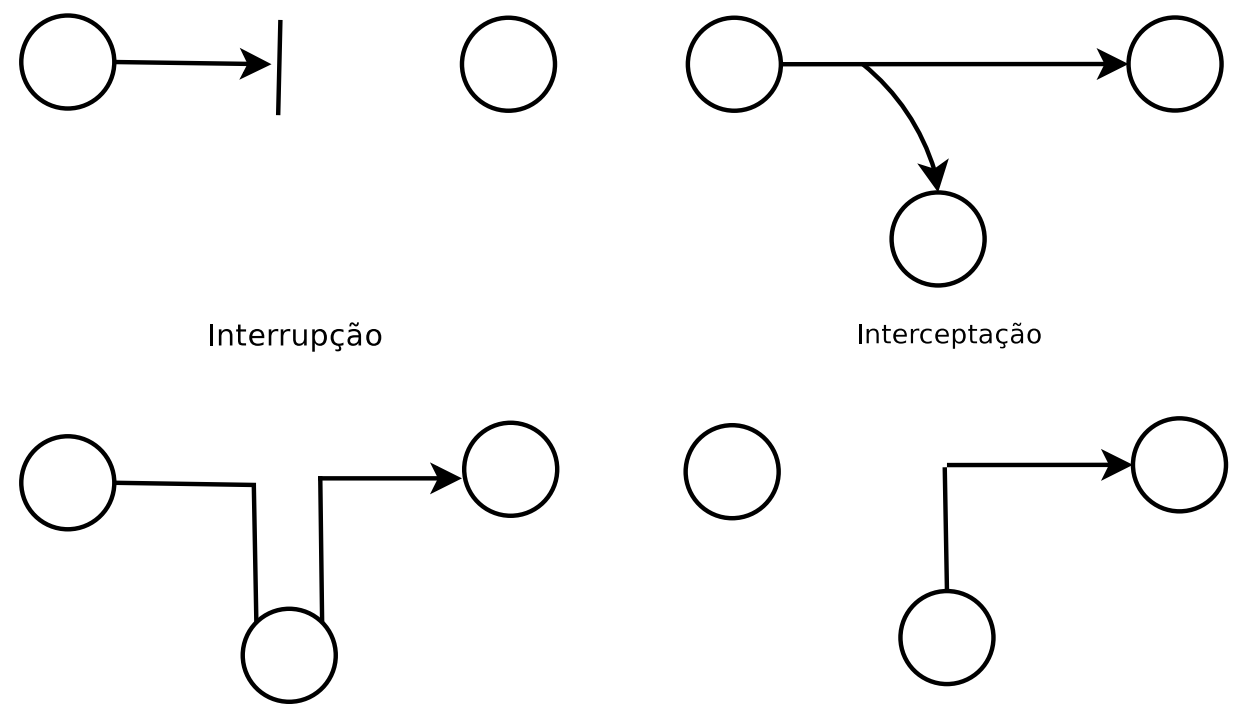

Modificação

Interceptação
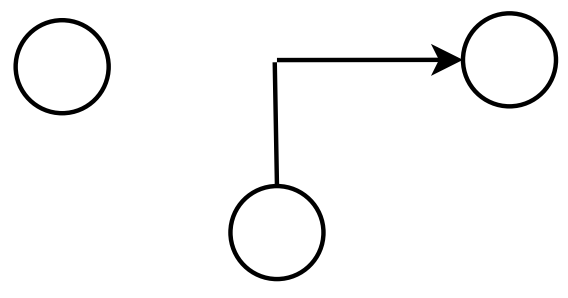

Fabricação

Figura 2.1: Tipos de ataques

rança da informação tais como confidencialidade, integridade dos dados, autenticação das entidades e autenticação da origem [55]. A criptografia é então um mecanismo que ajuda a implementar os principais objetivos de segurança de um sistema computacional.

Historicamente, a criptografia vem sendo usada pelo ser humano há mais de 2000 anos [67]. A Cifra de César, por exemplo, foi usada pelo Império Romano para esconder informações que eram transmitidas por mensageiros. A cifra de César consistia em deslocar de forma circular em $n$ posições, as letras do alfabeto.

Outro algoritmo usado nos primóridos da criptografia é a Cifra da Substituição. Na Figura 2.2 podemos visualizar um exemplo de uma tabela utilizada para cifrar uma mensagem usando este algoritmo. A primeira linha é o alfabeto na sua seqüência original, enquanto a segunda representa a permutação das letras. Dessa forma duas pessoas que compartilhassem esta tabela poderiam saber que a mensagem "DQJBCM" significa na verdade "GRADES “. O ato de procurar a letra trocada na tabela para embaralhar a mensagem é conhecida como criptografar, enquanto a ação contrária correspondente é conhecida como descriptografar. A informação que é compartilhada entre os dois participantes (a tabela) é conhecida como chave criptográfica. 


\section{\begin{tabular}{|l|l|l|l|l|l|l|l|l|l|l|l|l|}
\hline $\mathbf{A}$ & $\mathbf{B}$ & $\mathbf{C}$ & $\mathbf{D}$ & $\mathbf{E}$ & $\mathbf{F}$ & $\mathbf{G}$ & $\mathbf{H}$ & $\mathbf{I}$ & $\mathbf{J}$ & $\mathbf{K}$ & $\mathbf{L}$ & $\mathbf{M}$ \\
\hline $\mathbf{J}$ & $\mathbf{A}$ & $\mathbf{I}$ & $\mathbf{B}$ & $\mathbf{C}$ & $\mathbf{G}$ & $\mathbf{D}$ & $\mathbf{F}$ & $\mathbf{H}$ & $\mathbf{E}$ & $\mathbf{N}$ & $\mathbf{X}$ & $\mathbf{Z}$ \\
\hline
\end{tabular}}

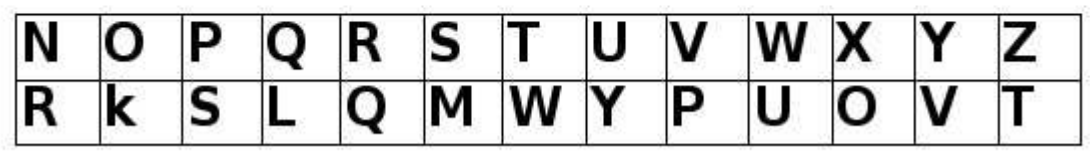

Figura 2.2: Tabela de substituição para cifração.

\section{Algoritmos criptográficos}

Os algoritmos criptográficos são responsáveis pela implementação dos mecanismos de segurança. Existem dois tipos de algoritmos de criptografia: os de chave secreta e os de chave pública (também conhecidos como simétricos e assimétricos, respectivamente). Os algoritmos de chave secreta utilizam uma chave que é compartilhada pelos participantes. Nesse tipo de algoritmo, existe o problema de como fazer para compartilhar a chave sem que ela fique exposta a roubo por intrusos. Nos algoritmos de chave pública cada participante possui um par de chaves: uma privada, conhecida somemente pelo detentor, e outra pública, que pode ser distribuída livremente.

A Figura 2.3 mostra como funciona um esquema de chave secreta. As duas partes, A e B, compartilham uma chave secreta $\mathrm{K}$ e desejam se comunicar de maneira que a informação a ser transmitida seja protegida. A utiliza a chave que possui e um algoritmo de criptografia para cifrar ${ }^{1}$ a mensagem e envia a mensagem no meio de transmissão que estiver disponível. Ao receber o texto cifrado, B, com a chave que compartilha com seu par, utiliza uma função inversa a usada por A e obtém o texto decifrado, igual ao original.

Os algoritmos de chave pública foram propostos por Diffie e Hellman em 1976 no seu famoso artigo New Directions in cryptography [19]. No modelo de chave pública, cada usuário possui um par de chaves (S, P), sendo S uma chave secreta e P uma chave pública [67]. Essas duas chaves são relacionadas matematicamente de tal forma que as seguintes propriedades são verdadeiras:

1. $\mathrm{S}(\mathrm{x})$ denota a aplicação da chave $\mathrm{S}$ no texto x e $\mathrm{P}(\mathrm{y})=\mathrm{x}$, ou seja, $\mathrm{P}$ é a função inversa de $\mathrm{S}$;

\footnotetext{
${ }^{1} \mathrm{O}$ verbo cifrar é usado no sentido de escrever em cifra, esconder.
} 


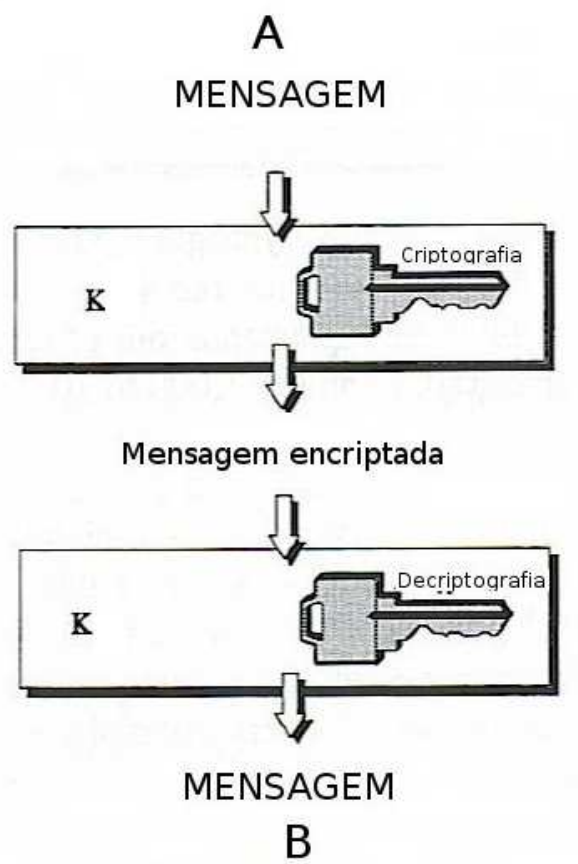

Figura 2.3: Modelo simplificado de chave secreta [57].

2. O cálculo de $\mathrm{S}$ e $\mathrm{P}$ é computacionalmente fácil;

3. É computacionalmente difícil calcular S a partir de P;

4. Os cálculos de $\mathrm{P}()$ e $\mathrm{S}()$ são computacionalmente fáceis;

5. É computacionalmente difícil calcular $\mathrm{S}()$ sem conhecer a chave $\mathrm{S}$.

A Figura 2.4 representa a utilização de um algoritmo de criptografia de chave pública. "A" deseja enviar uma mensagem criptografada para "B"; para fazer isso "A" utiliza a chave pública de "B" e transmite a mensagem. "B", quando recebe a mensagem de "A", é o único que consegue recuperar a mensagem por possuir a chave privada correspondente.

\section{Assinatura digital}

Uma assinatura digital é um mecanismo criptográfico que tem função similar a uma assinatura escrita à mão [57]. A assinatura possui duas funções primordiais: a integridade e a autenticação da 


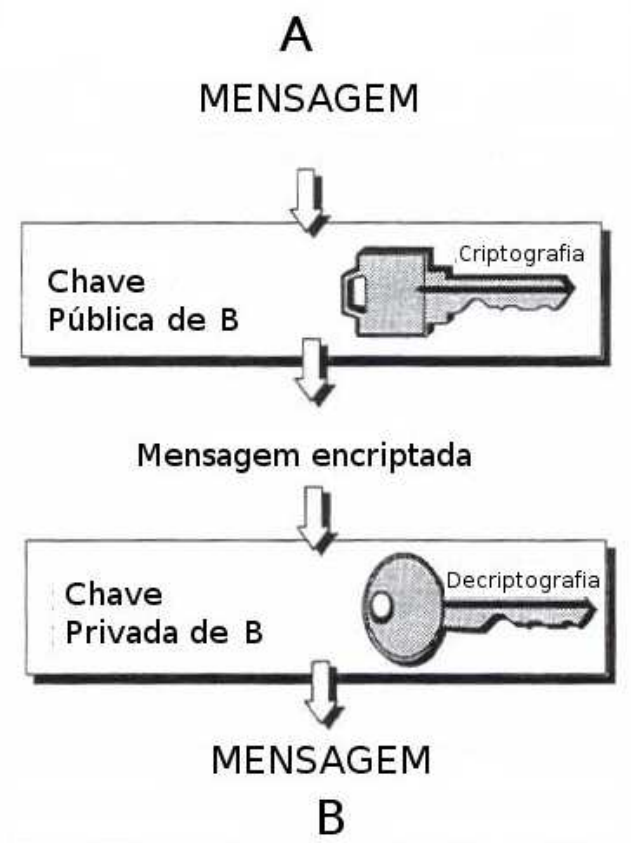

Figura 2.4: Modelo simplificado de chave pública [57].

mensagem. Suponha que dois usuários desejam se comunicar utilizando um meio de comunicação de acesso público. A integridade impediria que um usuário mal intencionado alterasse parte da mensagem antes de ela chegar ao seu verdadeiro destino. A autenticação garantiria que a mensagem enviada tenha sido gerada verdadeiramente pelo usuário legítimo. Uma terceira função da assinatura seria a irretratabilidade. A irretratabilidade evita que, depois da assinatura de uma mensagem, um usuário negue que tenha feito tal ação.

A Figura 2.5 mostra um processo de assinatura utilizando chaves públicas. Inicialmente o usuário "A" usa sua chave privada para assinar a mensagem a ser enviada para "B". Uma vez recebida a mensagem, "B" utiliza a chave pública de "A" para verificar sua origem. Para diminuir o tempo necessário para a execução do processo é possível utilizar um resumo criptográfico ${ }^{2}$ na mensagem e logo depois aplicar o algoritmo de criptografia sobre essa saída, executando o processo inverso no destinatário.

\footnotetext{
${ }^{2}$ Um resumo critptográfico (ou hashing) é uma função matemática que gera uma saída de tamanho fixo e que possui algumas propriedades interessantes entre elas o fato de ser impraticável determinar a entrada a partir de sua saída.
} 


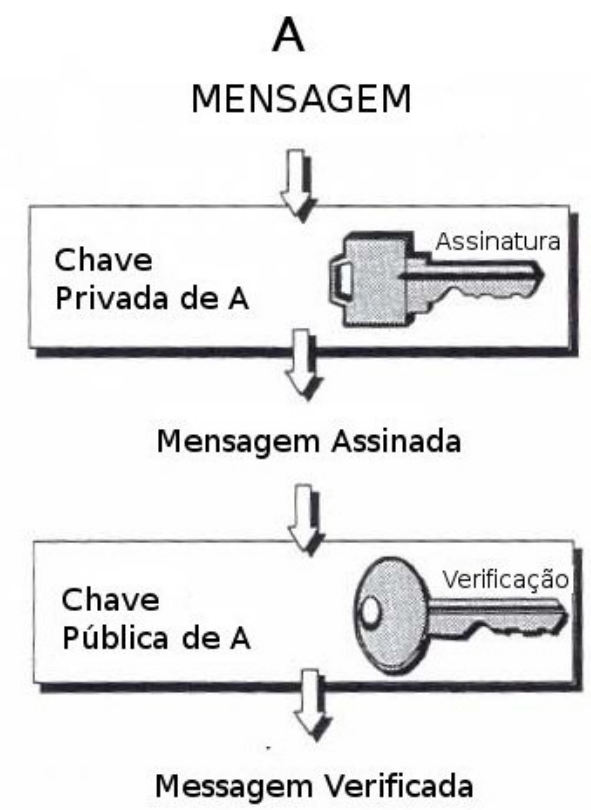

B

Figura 2.5: Assinatura através de uma chave pública.

\section{Certificados digitais}

Os certificados digitais são utilizados para garantir que uma determinada chave pública pertença ao seu suposto proprietário. Um certificado é um tipo especial de assinatura digital, ele é um documento que contém a chave pública de um determinado usuário e outras informações adicionais. Este documento é assinado por um terceiro elemento, uma autoridade confiável, atestando a autenticidade da identidade de um usuário.

\subsubsection{Auditoria}

A auditoria é um mecanismo de segurança que tem como objetivo o registro e a análise de atividades relevantes de segurança. A auditoria pode ajudar na detecção de violações de segurança, análise de desempenho ou falhas em aplicações. Manter um registro de eventos é importante pois é muito difícil garantir que uma determinada política de segurança está correta ou até mesmo que foi 
implementada com exatidão através dos mecanismos de segurança disponíveis.

A auditoria pode fornecer benefícios como o acompanhamento de ações de um usuário, reconstrução de eventos e análise de problemas. Com o acompanhamento de um usuário (ou um processo), as ações ficam associadas com quem as executou, de forma que passa a ser possível realizar uma prestação de contas. Através da reconstrução de eventos, podemos verificar em quais circunstância uma situação relevante ocorreu e quem foi o verdadeiro responsável pela sua ocorrência. Uma análise minuciosa dos problemas de segurança ocorridos facilita a manutenção do sistema de segurança, permitindo que políticas, mecanismos de segurança, o software e ohardware sejam revisados de forma pró-ativa ou preventiva.

A escolha correta dos eventos que deverão ser registrados é um passo importante em um projeto de sistemas de segurança. Escolher o registro de mais eventos do que seria necessário tem um custo computacional muito alto, influenciando no desempenho do sistema e no uso de seus recursos. Caso a quantidade de eventos escolhidos seja insuficiente, os registros dos eventos podem ser considerados ineficazes em trazer informações que possam ser utilizadas.

A auditoria é um dos alvos preferenciais dos usuários que tentam atacar um sistema. Paralisando, destruindo ou compremetendo a integridade do sistema de auditoria, o atacante dificulta ou impossibilita ao administrador do sistema que ele e/ou seus atos indevidos sejam descobertos. Políticas de segurança como o uso de mecanismos de criptografia, cópia rotineira dos arquivos de eventos e proteção física das máquinas devem ser consideradas sempre que um sistema de segurança for implementado e isso for relevante.

\subsection{Grades Computacionais}

Hoje em dia, apesar de todo avanço da computação nos últimos anos, ainda existe uma necessidade desproporcional de recursos computacionais para resolver alguns problemas específicos. Como exemplo destas necessidades podemos citar: as simulações econômicas e os estudos de viabilidade de prospecção de petróleo nas áreas industriais e as simulações de redes de grande escala, as otimizações e a mineração nas áres da computação, biologia e física. O custo de máquinas poderosas que possuam os recursos necessários para resolver estes problemas ainda é demasiadamente alto, particularmente para instituições de pequeno e médio porte. As grades computacionais surgiram para tentar dar alento a esta questão; elas são sistemas distribuídos que permitem escalonar processos em máquinas espalhadas por diversas organizações e domínios administrativos. 
As grades computacionais estão atualmente em evidência; diversos pesquisadores no mundo todo, nas mais diversas áreas da Computação, investem recursos humanos e financeiros em pesquisas sobre o tema. A indústria já começa a investir no desenvolvimento de sistemas que viabilizem este modelo. Grandes empresas como IBM, Microsoft, NEC, Sun e Oracle investem tempo e dinheiro para desenvolver padrões e sistemas de Grades Computacionais. Algumas questões ainda necessitam de muito trabalho para considerarmos que o desenvolvimento de sistemas de grades esteja totalmente consolidado, sobretudo a Segurança. Entre as forças relacionadas ao desenvolvimento de Grades computacionais [13] podemos destacar:

- Executar em diversas plataformas sobre os diversos sistemas operacionais pré-existentes, não exigindo assim nenhum tipo de substituição;

- permitir o compartilhamento eficiente de recursos computacionais, tais como processador, memória, disco, outros tipos dehardware e software;

- oferecer qualidade de serviço tanto aos usuários das aplicações quanto aos proprietários dos recursos;

- prover suporte a aplicações paralelas;

- oferecer autonomia para usuários e administradores, evitando impor políticas rígidas de utilização e oferecimento dos recursos;

- ser escalável, podendo englobar de poucas máquinas até possivelmente milhões;

- possuir baixo custo de instalação;

- não causar sobrecarga perceptível ao usuário; e

- ser fácil de usar, permitindo que aplicações pré-existentes sejam facilmente adaptadas ao novo contexto.

O padrão arquitetural Grid [13] apresenta uma arquitetura genérica para grades computacionais (Figura 2.6). Este padrão arquitetural tem como usos conhecidos os sistemas Globus [25], Condor [22], InteGrade [35] e OurGrid [4] descritos no próximo capítulo. Nesse padrão, o agente de acesso é o ponto de acesso primário do usuário à Grade e deve ser executado em cada nó onde os usuários submeterão aplicações à Grade. Através dele o usuário pode, ao submeter aplicações, definir seus 
requisitos, monitorar e coletar os resultados das execuções. O serviço de provisão de recursos deve ser executado em cada nó que disponibiliza seus recursos para a Grade; ele gerencia e provê informações sobre a disponibilidade destes recursos. O serviço de provisão de recursos é responsável por permitir a execução de aplicações no nó, reportar erros e devolver os resultados do processamento ao usuário ou a outros nós da aplicação distribuída. O serviço de monitoramento de recursos é responsável por monitorar os estados dos recursos e prover informação sobre o estado destes recursos a outros serviços da Grade. O serviço de escalonamento gerencia os recursos disponíveis na Grade e é responsável, baseado nas informações recebidas do serviço de monitoramento, por escolher nós aptos a executar uma aplicação cuja execução foi solicitada.

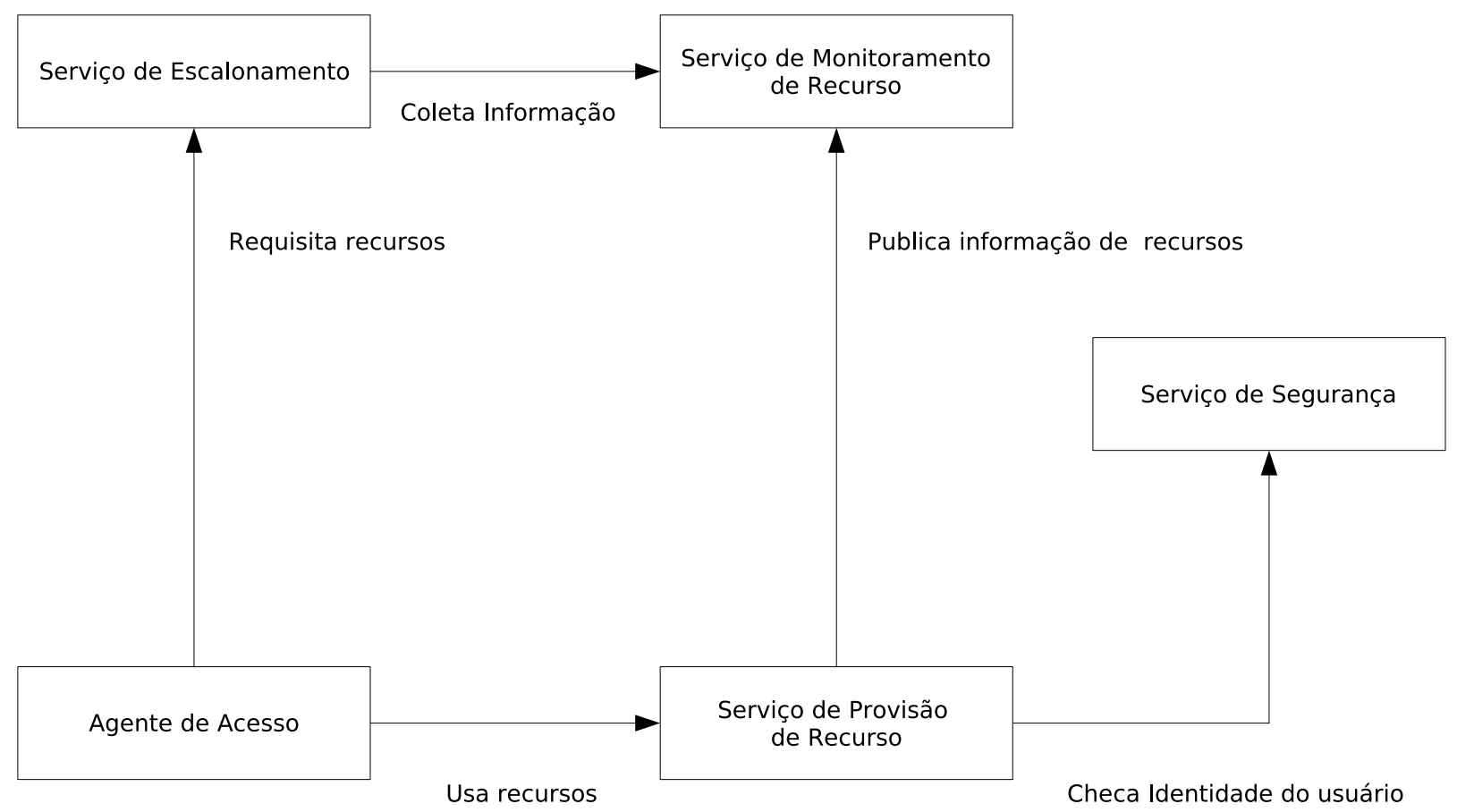

Figura 2.6: Arquitetura de uma Grade computacional.

O serviço de segurança é responsável por três tarefas principais:

1. Proteger os recursos compartilhados, de forma que os usuários que compartilham seus recursos 
com a Grade não sofram os efeitos de aplicações maliciosas.

2. Gerenciar as identidades dos usuários, permitindo relações de confiança e responsabilidade.

3. Proteger as trocas de informações entre os participante da Grade, provendo confidencialidade e integridade.

\subsubsection{Requisitos de segurança}

Sistemas de Grades Computacionais são inerentemente mais vulneráveis a ameaças de segurança do que sistemas tradicionais. Em uma grade existe, potencialmente, uma quantidade grande de usuários, recursos e aplicações sendo administrados por diferentes domínios administrativos. Neste ambiente, as regras de segurança definidas em cada sítio podem ser significantemente diferentes. As políticas definidas para um usuário local podem ser ineficientes em um ambiente de Grade, seja porque são permissivas em excesso ou porque são proibitivas demais, forçando aos participantes um isolamento pouco produtivo.

As organizações que participam de uma grade computacional geralmente possuem investimentos em sistemas de segurança já existentes [26]. Em uma grade pode existir a necessidade da convivência de vários protocolos de segurança. Os mecanismos diferentes podem exigir interoperabilidade segura entre máquinas e ambientes heterogêneos.

A forma de autenticação e autorização em uma Grade é um requisito importante na definição de um sistema de segurança para a Grade. De acordo como foi definido anteriormente, a autenticação na Grade deve permitir a interoperabilidade entre diversos mecanismos de segurança. Da mesma forma, a autorização deve ter suporte a diversos mecanismos de controle de acesso. Ao contrário dos sistemas convencionais, os mecanismos de autenticação e de autorização podem ser implementados por mecanismos de segurança distintos. O sistema de segurança para grade deve possibilitar a interação entre estes mecanismos.

A possibilidade de delegação de direitos de acesso aos elementos de uma Grade é um requisito importante a ser definido. A delegação ameniza o trabalho do administrador em ter que ceder direitos a membros da Grade. Sempre que um dono de recurso confiar em alguém para usar este recurso, este poderá delegar este direito, por um tempo determinado, a um terceiro desde que o sistema assim permita. A delegação de direitos, no entanto, deve ser usada de uma forma restrita. Uma corrente de redelegação muito grande pode fazer com que o recurso acabe sendo usado indevidamente por 
usuários maliciosos. Os sistemas de segurança de grades devem conter dispositivos para minimizar este problema.

No ambiente de grades surge um problema que não é comum em ambiente tradicionais: devemos garantir que um recurso não seja provido por um atacante. Um usuário mal intencionado, por exemplo, poderia disponibilizar recursos na Grade com a intuito de obter informações privilegiadas. Uma boa política de autorização diminui o risco deste problema acontecer. Em geral o "princípio do menor privilégio" é uma boa opção para a definição de políticas de segurança na Grade. Ou seja, não convém dar ao usuário mais direitos do que ele necessita, mesmo que isso gere um aumento no custo da administração do sistema.

A diversidade de usuários e de recursos em uma Grade Computacional aumenta a probabilidade de surgirem ameaças. Por outro lado, sabemos que eliminar as vulnerabilidades de um sistema nem sempre é possível, sobretudo em um ambiente tão dinâmico quanto o de Grade. Os administradores da Grade devem dispor de mecanismos de rastreamento que permitam verificar ameaças ou erros. A auditoria nestes casos se torna imprescindível.

A confidencialidade e a integridade são requisitos para as grades computacionais. Possuir mecanismos que impeçam, ou pelo menos dificultem muito, a modificação ou a obtenção de dados é muito importante. Por questão de desempenho, estas possibilidades podem ser opcionais para os membros da Grade.

Apresentamos neste capítulo os principais conceitos sobre segurança de sistemas computacionais. A seguir mostraremos trabalhos relacionados com segurança em grades computacionais. Sistemas existentes são discutidos e suas deficiências serão apontadas. 


\section{Capítulo 3}

\section{Trabalhos Relacionados}

Neste capítulo, apresentamos estudos de caso de algumas grades computacionais existentes. Inicialmente, mostramos uma breve descrição da suas arquiteturas de segurança. A seguir, descrevemos a implementação de segurança de cada uma delas. Finalmente, teceremos comentários sobre algumas limitações nas implementações de segurança destas arquiteturas.

\subsection{Globus}

O Globus [25,33] é atualmente o projeto de maior impacto na área de Computação em Grade. O Projeto Globus envolve muitas instituições de pesquisa da Europa, da Ásia e principalmente dos Estados Unidos, dentre elas podemos citar: Argonne National Laboratory (ANL), University of Chicago, University of Southern California (USC) e o High-Performance Computing Laboratory of Northern Illinois University e o Imperial College na Inglaterra. Grandes empresas também apóiam o projeto tais como: IBM, Microsoft e Cisco.

O projeto Globus inclui o desenvolvimento de um sistema de Computação em Grade denominado Globus Toolkit. O Globus Toolkit (GT) é um pacote que permite a construção de sistemas de grade de modo incremental. O termo toolkit é utilizado pelo fato dele permitir a configuração e personalização de grades e aplicações especializadas. O Globus Toolkit está atualmente na versão 4.0, que apresentamos nesta subseção.

A versão atual do Globus Toolkit é uma implementação do OGSA (Open Grid Services Architecture), uma arquitetura padrão que visa a construção de uma infra-estrutura para grades baseada em serviços [23]. Serviços são entidades que disponibilizam suas funcionalidades a usuários e aplicações através da rede. No modelo OGSA, qualquer objeto é representado por um serviço, tais como: 
dispositivos de armazenamento, redes, programas, entre outras entidades.

A base da definição de serviços para o OGSA é denominada Grid Service. O Grid Service é uma extensão de um Web Service que mantém informações de estado de serviço. A definição de estados permite a distinção entre a instância de um serviço de outras que provêm uma mesma interface.

As interfaces básicas e o comportamento de um Grid Service é definido através do WSRF (Web Service Resource Framework) [24]. O WSRF é uma evolução do OGSI (Open Grid Service Infrasctructure) que é um padrão utilizado nas versões anteriores do GT. O WSRF separa as funcionalidades do OGSI em diversas especificações e inclui algumas novas especificações que surgiram. O WSRF define uma família de especificações para acessar recursos usando serviços Web.

A seguir apresentamos o GSI, uma implementação de arquitetura de segurança baseada no OGSA.

\subsubsection{Segurança}

O Globus disponibiliza um serviço de segurança denominado GSI (Globus Security Infrastructure) [27], uma implementação da arquitetura de segurança definida no OGSA. Assim como outros serviços do Globus, o GSI é uma especificação abstrata que pode ser implementada sobre diferentes mecanismos de segurança.

A Figura 3.1 mostra o resumo da arquitetura do GSI [40]. O GSI utiliza diversos padrões para implementar funcionalidades como autenticação, delegação, proteção de mensagens e autorização.

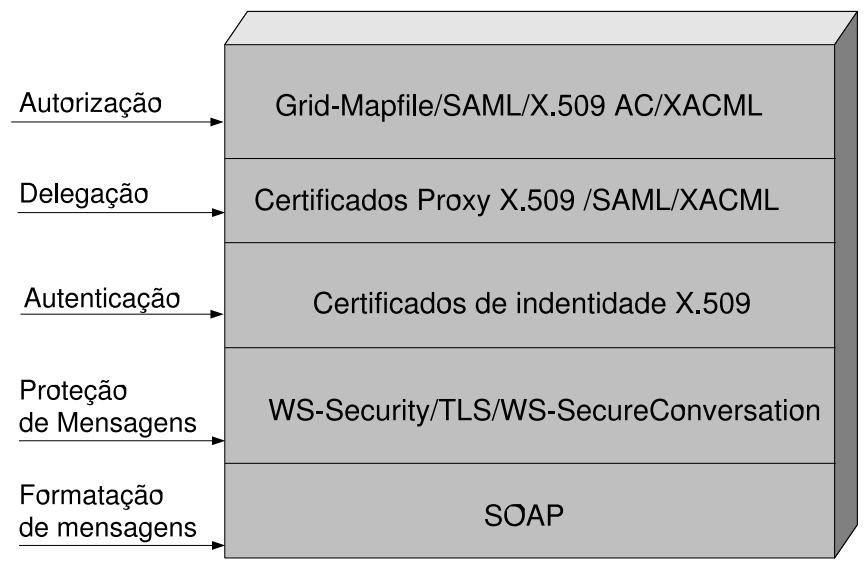

Figura 3.1: Arquitetura do GSI. 
A autenticação do GSI é feita através de certificados X.509 [2] permitindo o estabelecimento de confiança entre domínios de segurança diferentes. Além da autenticação X.509, presente também nas versões anteriores do Globus Toolkit, a versão 4 permite a autenticação de usuários utilizando identificador de usuário e senha. Porém, quando este método é usado, não é possível usar mecanismos de segurança que incluem confidencialidade e integridade de dados.

Para permitir a delegação dinâmica, o GSI estende o conceito de proxy do X.509 que permite ao usuário atribuir uma nova identidade X.509 ao usuário e então delegar alguns de seus atributos de segurança a esta nova identidade [71]. Este mecanismo permite a criação de novas identidades e credenciais sem a intervenção do administrador da rede. A vantagem de se estender o padrão X.509 é a possibilidade de utilização de bibliotecas já existentes com uma modificação bem pequena.

A Tabela 3.1.1 resume as diferenças entre o certificado X.509 e o certificado x.509 com proxy [71]. No campo Issuer o Certificado Proxy é identificado pela chave pública do certificado ou por outro Certificado X.509 Proxy. Esta opção permite que o certificado seja criado dinamicamente pelo possuidor do certificado, sem a intervenção das autoridades certificadoras (CAs - certificate authorities) . Ao contrário do padrão X.509, onde o sujeito de um certificado é definido pela CA, o campo Subject Name do certificado permite a definição de sujeitos dentro do escopo de nomes do emissor do certificado. A restrição do escopo deve ser feita para que os certificados sejam únicos. A chave pública do Certificado X.509 Proxy é distinta da chave pública do seu emissor.

\begin{tabular}{lcc}
\hline \hline Atributo do Certificado & $\mathbf{X . 5 0 9}$ & $\mathbf{X . 5 0 9}$ Proxy \\
\hline \multicolumn{1}{c}{ Issuer/Signer } & Autoridade Certificadora & Certificado de chave pública ou Certificado de outro Proxy \\
\hline Subject Name & Definido pela Autoridade certificadora & Definido no espaço de nomes do dono do certificado \\
Delegação do Emissor & - & Define as condições dos direitos delegados \\
Key pairs & Par de Chave única & Par de chave única \\
\hline \hline
\end{tabular}

Tabela 3.1: Comparação entre X.509 padrão e X.509 proxy estendido pelo Globus Toolkit.

O Certificado Proxy acrescenta duas características adicionais ao Certificado X.509 padrão: $a u$ tenticação única e delegação. A autenticação única dispensa a digitação freqüente de uma senha para provar a autenticidade de um usuário. A delegação, como já definido anteriormente, permite que o servidor se conecte a qualquer recurso em nome do cliente.

A autenticação única permite o conceito de autenticação na Grade para reduzir o número de vezes 
em que o usuário precisa acessar sua chave privada ${ }^{1}$. Com o Certificado Proxy, o usuário autentica uma vez para criar o Certificado Proxy (que possui um par de chaves diferente do seu criador) e o usa inúmeras vezes sem precisa usar a chave privada do seu criador. Para aumentar a segurança, o Certificado Proxy possui um tempo de vida curto e o comprometimento de sua chave não chega a ser um problema grave de segurança.

A autenticação única no Globus Toolkit é ilustrada na Figura 3.2. Inicialmente um novo par de chave pública e privada é criado e associado a uma requisição de certificado ${ }^{2}$. A seguir, o usuário usa sua chave privada para assinar o Certificado Proxy recém criado. Finalmente, o Certificado Proxy é armazenado de forma protegida em disco.

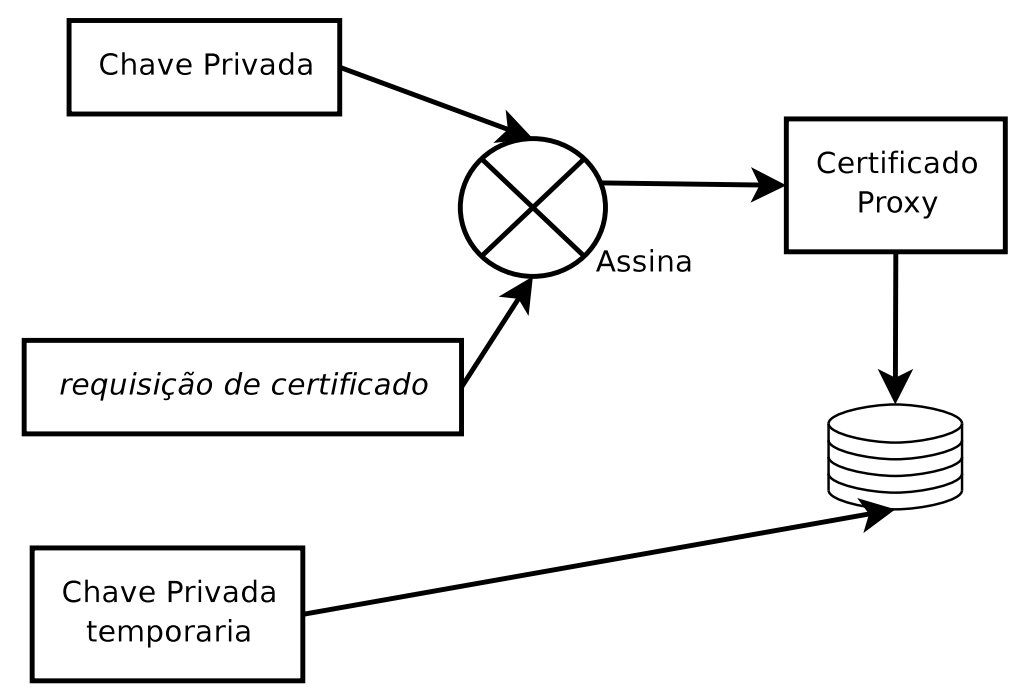

Figura 3.2: Protocolo de Autenticação Única.

A delegação de direitos no Globus Toolkit também pode ser feita sobre um canal de comunicação [71] como pode ser visto na Figura 3.3. Inicialmente, os dois envolvidos na delegação negociam um canal seguro de comunicação. O delegado, aquele que recebe a delegação, cria um par de chaves e uma requisição de certificado. O delegado então envia a requisição de certificado sobre o canal seguro. Ao receber a requisição de certificado, o delegador define as restrições nos direitos doados e usa a chave privada associada ao seu Certificado Proxy para gerar o novo Certificado Proxy. O delegador

\footnotetext{
${ }^{1} \mathrm{O}$ acesso a chave privada é uma ação de risco por isso; ela é geralmente protegida por senha e em um ambiente de grade isso pode não ser viável.

${ }^{2}$ Especificação padrão para codificar requisições de certificados, incluindo o nome da pessoa que requisita o certificado e sua chave pública.
} 
envia o Certificado sobre o canal seguro de rede. Ao receber o certificado, o delegado coloca em um lugar seguro, junto à chave privada criada no início do processo.

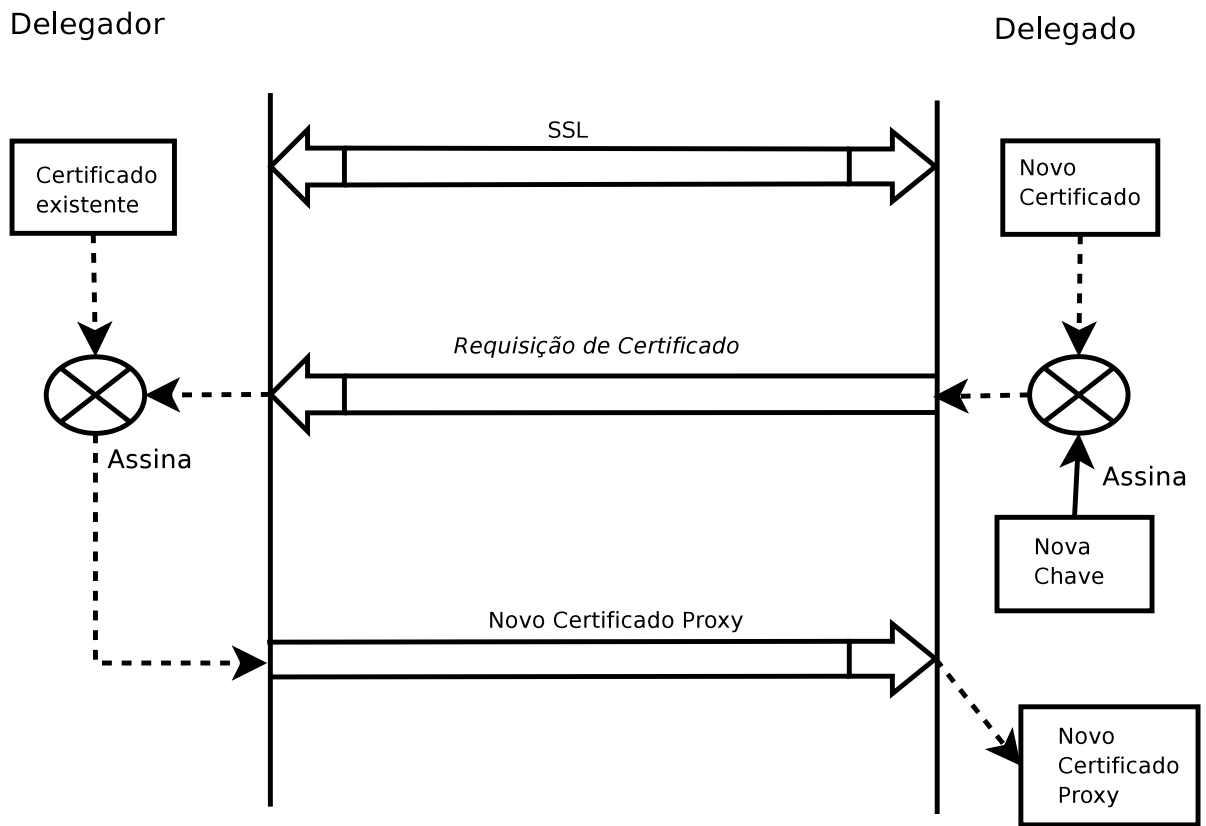

Figura 3.3: Delegação de Certificado Proxy

Para permitir a comunicação entre grades com mecanismos diferentes, o GSI usa gateways que fazem tradução entre credenciais X.509. O KCA ((Kerberos Certificate Authority)) ${ }^{3}$, desenvolvido na University of Michigan, é um sistema baseado no Kerberos que permite que usuários adquiram certificados X.509 usando tickets Kerberos. O usuário se autentica normalmente no Kerberos e solicita uma credencial para acessar o serviço do KCA. O KCA recebe o ticket, determina a identidade do usuário, gera um certificado efêmero (short-lived X.509) e envia de volta ao usuário que solicitou.

O GSI implementa troca segura de mensagens na rede de duas formas: no níveis do transporte e da mensagem. A comunicação no nível do transporte usa o TLS (Transport Layer Security) [18] para a criação de comunicação segura fim a fim. A comunicação no nível da mensagem usa padrões de segurança baseado em Web Services [9] e SOAP (Simple Object Access Protocol) [69].

O TLS é baseado no protocolo SSL (Secure Socket Layer) desenvolvido pela empresa Netscape Corporation. O TLS é um protolo de transporte seguro que provê privacidade e integridade. O

\footnotetext{
${ }^{3}$ http://www.citi.umich.edu/projects/kerb_pki
} 
TLS permite que as partes envolvidas realizem autenticação mútua e negociação de algoritmos de criptografia, criando um canal seguro de comunicação. Ele foi projetado de forma a ser um protocolo eficiente quanto ao uso de CPU e da rede, o que faz com que ele seja uma boa opção de uso em grades computacionais.

O Globus Toolkit implementa as especificações WS-Security e WS-SecureConversation para permitir comunicação segura no nível de mensagem. O padrão WS-Security é um arcabouço que permite a criptografia e assinatura de mensagens sobre SOAP. Ele especifica um mecanismo que associa um token de segurança às mensagens. Para o padrão WS-Security, o token é uma estrutura de dados extensível, codificado em binário, usado para representar de forma transparente os vários mecanismos de segurança. A integridade das mensagens é garantida através de XML Signature e a confidencialidade usando XML Encryption [26]. O WS-SecureConversation gerencia a criação de contextos de segurança e cria chaves que podem ser usadas neste contexto. Este contexto pode então ser usado para proteger mensagens subseqüentes sem que o processo de autenticação seja repetido a cada momento.

A autorização no Globus Toolkit é feita através do uso de SAML (Security Assertions Markup Language) e de Grid mapfiles. O SAML define a sintaxe e semântica de afirmações feitas sobre um sujeito por uma entidade. O GSI usa essa linguagem para permitir a comunicação com autoridades certificadoras e receber as informações a respeito das autorizações que um cliente tem sobre um determinado serviço. O uso do Grid-mapfile é mantido por compatibilidade com a versão 2 do GT e associa um determinado usuário a nomes qualificados que aparecem em certificados X.509. Por exemplo, a entrada " $/ 0=$ Grid /OU=Ime /OU=simpleCA-ime.usp.br /OU=localdomain /CN=Jose Braga', jrbraga associaria o usuário jrbraga ao correspondente identificador X.509.

O Globus Toolkit define o XMKS (XML Key Management Specification) [38] como uma interface para infraestruras de chaves públicas (ICP). O XKMS especifica um protocolo com o objetivo de diminuir a complexidade das ICP o qual descreve a distribuição, localização e o registro de chaves públicas. O XKMS é dividido em duas partes: XKISS (XML Key Information Service Specification) que provê mecanismos para o serviço de informação e XKRSS (XML Key Registration Service Specification) que provê mecanismos de registro e gerenciamento de chaves públicas. Originalmente, o XKMS foi focado para o X.509, Wangham et al. [70] propõe um modelo para permitir o uso de XKMS para o gerenciamento de federações de SPKI/SDSI [62].

O Globus Toolkit disponibiliza o servidor CAS (Comunity Authorization Server) que é responsável 
pelo gerenciamento de políticas de acesso para os recursos da comunidade [58]. Dependendo da política da comunidade, o CAS pode ser controlado por um ou mais administradores, permitindo que as tarefas de administração sejam distribuídas. Um administrador pode, por exemplo, ser responsável pelo registro de usuários e recursos em um servidor CAS, mas não ter o direito de associá-los a grupos que possuem direitos específicos, podendo essa autorização ser feita por um outro administrador.

A Figura 3.4 representa um usuário solicitando ao servidor CAS uma requisição de capacidade (capability). Essa capacidade permite a ele executar um conjunto de ações específicas. O servidor CAS, caso a política de acesso definida para esse usuário permita, devolve ao usuário a capacidade solicitada. De posse dessa autorização, o usuário pode usar a capacidade de acordo com os direitos permitidos ou delegá-la a um terceiro.

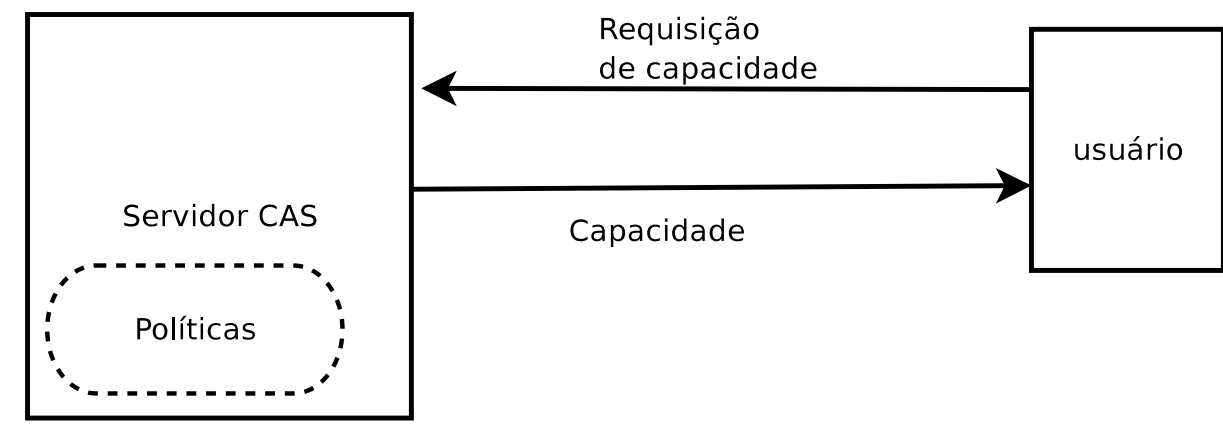

Figura 3.4: Usuário faz uma requisição de capacidade ao servidor CAS.

A Figura 3.5 mostra um usuário submetendo uma capacidade a um provedor do recurso. O usuário faz uma requisição ao dono do recurso provando que possui direitos de acesso. A seguir, o provedor verifica se a capacidade apresentada pelo usuário e se as políticas definidas localmente permitem o uso do recurso. Caso isso seja possível, o usuário finalmente recebe o direito de utilizar o recurso.

O GSI é um sistema de segura flexível e bastante maduro. Ele permite que diversas teconologias sejam usadas de forma tranparente que é um dos resquisitos primordias da segurança para Grades computacionais. No entanto, a arquitetura de segurança do Globus é baseada no uso de ferramentas para sistemas distribuídos convencionais, onde a dinâmica de uma Grade Computacional exige requisitos próprios conforme descritos na Seção 2.2.

O GSI não considera o histórico entre os participantes para implementar o controle de acessos de recursos na grade. As soluções baseadas em ferramentas tradicionais não se fundamentam nas 


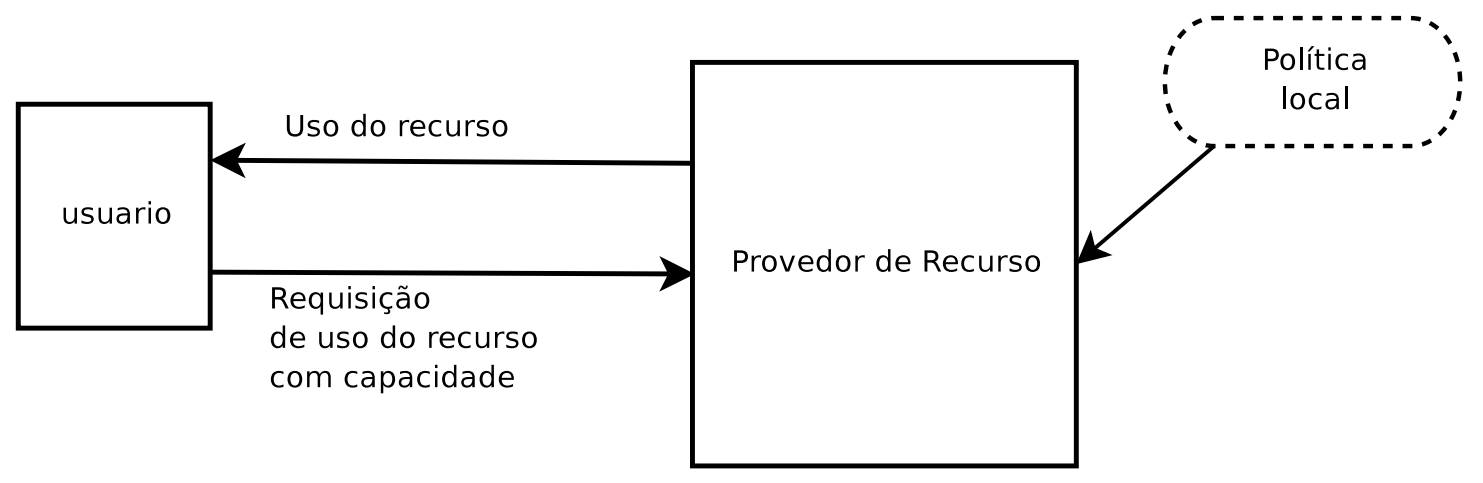

Figura 3.5: Cliente requisitando uso de recurso.

interações entre os participantes para definir se um determinado recurso pode ser acessado ou não. Um usuário pode, ao longo do tempo, ter suas relações de confiança alteradas e as soluções de segurança definidas no contexto do GSI não supre esta necessidade.

\subsection{Legion/Avaki}

O Projeto Legion [52] foi desenvolvido na Universidade da Virginia a partir de 1993 com o objetivo de prover abstrações que permitissem uma visão única para milhares de computadores interligados em um sistema distribuído. Desde o início do projeto, o Legion foi criado com o intuito de permitir a transferência de sua tecnologia para a indústria; isto ocorreu em 2001 através da empresa AVAKI fundada pelos seus idealizadores. A companhia detém os direitos sobre o Legion que passou a ser chamado de Avaki.

No Legion, todas as entidades da grade são representadas por objetos (no sentido de Orientação a Objetos), tais como: computadores, usuários, equipamentos, dispositivos de armazenamento e aplicações. Estes objetos comunicam-se entre si através de chamadas a métodos assíncronas. Cada método possui uma assinatura própria que descreve os seus parâmetros e valores devolvidos. Um objeto é descrito por um conjunto de interfaces que define suas classes. O Legion utiliza uma IDL (Interface Definition Language) para descrever seus objetos e é um sistema reflexivo onde as próprias classes são objetos.

Os objetos Legion são persistentes e podem estar associados a dois estados: ativo ou inativo. Os objetos ativos ficam presentes na memória, possuem um processo associado e podem responder a chamadas a seus métodos. Os objeto inativos são armazenados em algum dispositivo de armazena- 
mento através de sua representação seriada (OPR - Object Persistent Representation). Cada OPR é endereçado por um endereço de representação persistente (OPA - Object Persistent Address).

Cada objeto Legion possui um identificador LOID (Logical Object Identifier) e um endereço de objeto (LOA - Legion Object Address). O LOID é um endereço único, atribuído pela classe do objeto no momento de sua criação. O LOA provê um ou mais protocolos de rede utilizados para a comunicação concreta com um objeto. Por exemplo, o LOA poderia utilizar o protocolo TCP indicando o endereço IP e a porta onde o objeto está localizado.

O Legion define as interfaces e funcionalidade para um conjunto de classes bases denominadas objetos do núcleo. Essas classes básicas oferecem serviços básicos para os objetos que as herdam. Os objetos do núcleo são:

- Legion Object e Legion Class - definem um conjunto de métodos que todos os objetos e classes devem implementar. O Legion Object define o método mayI() usado para controle de segurança das chamadas aos métodos.

- Legion Hosts - Quando um objeto Legion Host é ativado ele cria um processo para contê-lo. Cada recurso computacional pode estar associado a mais de um objeto Host. O Legion Host tem como responsabilidade criar e gerenciar processos para objetos Legion ativos.

- Legion Vaults - representam o armazenamento persistente dos demais objetos Legion. Quando um objeto é seriado, sua representação OPR é armazenada em disco por objetos Legion Vaults.

- Implementation Objects - encapsulam aplicações a serem executadas na grade. O Legion utiliza metadados para apresentar as características importantes de uma aplicação, tais como: formato da aplicação (por exemplo, binário ou byte-code), plataforma e requisitos de hardware.

\subsubsection{Segurança}

O identificador de objetos LOID possui um campo que armazena uma chave pública, que é a base para a autenticação e da autorização do Legion. Através do LOID é possível comunicar-se de forma segura com um objeto obtendo a chave pública armazenada. Como a chave pública no Legion é associada ao nome do objeto, um atacante não pode substituir uma nova chave em um identificador de objeto conhecido, por que se uma parte do LOID é alterada, incluindo a chave, um novo LOID é criado e não será conhecido. 
O Legion usa o paradigma de usuário e senha para permitir a autenticação do usuário. Para se autenticar, o usuário fornece um identificador de conta (login) e uma senha. O nome do usuário é associado ao que o Legion chama de objeto de autenticação que age como o procurador do usuário na grade. O objeto de autenticação possui a chave privada, a senha criptografada e o perfil do usuário no seu estado persistente. A senha oferecida pelo usuário é comparada à senha armazenada no estado persistente do procurador para negar ou permitir o acesso à grade. O estado de autenticação do objeto é armazenado de forma persistente no disco na máquina.

Uma outra forma de autenticação no Legion é através do DAP (Data Access Point). O DAP cria um mapeamento entre o identificador do usuário no Unix e o LOID de um objeto de autenticação para acessar dados da grade usando o protocolo NFS. Quando um cliente NFS monta um DAP, ele mapeia o espaço de nomes no sistema de arquivo local de sua máquina permitindo um acesso aos dados da grade de forma transparente. O DAP fornece suporte ao mecanismos de segurança do Legion, o controle de acesso é feito através de credenciais assinadas e as interações com a grade podem ser assinadas.

O Legion usa credenciais para permitir a delegação de direitos e define uma forma de transferência de direitos através de credenciais para objetos. A credencial é uma lista de direitos assinada pelo usuário ou pelo seu procurador. O recurso verifica a credencial e segue a cadeia de confiança até conferir a assinatura, decidindo se garantirá o direito de acesso ao recurso.

A autorização do usuário no Legion é feita através de listas de controle de acesso. Para cada função ou ação associada a um objeto, existe uma lista de permitidos e negados (allow e deny). Cada lista contém o nome de outros objetos ou um diretório que contém uma lista de objetos. Caso um diretório contenha objetos de autenticação (um objeto de autenticação é o representante do usuário na grade) então ele atua como grupo de usuários. Se um objeto estiver presente simultaneamente nas duas listas (permitidos e negados), o objeto não poderá efetuar a ação.

O protocolo SSL é usado para permitir a comunicação segura no Legion. Os dados são protegidos no Legion de três formas: privada, protegida e nenhuma. Na primeira, mais restritiva, todas as mensagens são completamente criptografadas, garantindo confidencialidade e autenticidade. No modo protegido, as mensagens são protegidas de modificação através de resumos criptográficos. (hashing). E finalmente, o Legion permite que as mensagens possam ser transmitidas sem criptografia, com exceção das credenciais.

O Legion provê um mecanismo de sandboxing para a proteção das máquinas hospedeiras. O 
sandbox faz um isolamento do identificador do usuário e do sistema de grade na máquina hospederia. O sandboxing do Legion permite a definição de identificadores genéricos, portanto que não estão associados a nenhuma conta na máquina.

O uso intensivo do paradigma de orientação a objetos no Avaki deixou um legado importante para o estudo das Grades Computacionais. A identificação dos objetos Avaki através de chaves públicas, como apresentado na seção anterior, demonstra a preocupação dos seus projetistas com a segurança. A sua implementação de segurança, no entanto, possui restrições devido a falta de flexibilidade, uma vez que usa uma quantidade limitada de ferramentas de segurança e soluções próprias. O Avaki não considera também o histórico de relacionamentos entre os participantes da grade para decidir sobre o uso dos seus recursos. Sua característica de orientação a objetos, no entanto, indica que uma adaptação a outras soluções de segurança pode ser realizada com algum esforço.

\subsection{Condor}

O sistema Condor ${ }^{4}$ foi criado no início dos anos 80 na Universidade de Wisconsin como um sistema para computação distribuída caracterizado por deixar o controle das máquinas sob a responsabilidade dos seus proprietários. O Condor (Condor high-througput computing system) é um sistema de computação batch distribuído para computação intensiva, com mecanismos para gerenciamento de tarefas, políticas de escalonamento, gerenciamento e monitoramento de recursos, etc.

A disponibilidade de grande montante de recursos tolerante a falhas por prolongados períodos de tempo (high throughput) associada a computação oportunista (aproveitamento de recursos ociosos) são características fundamentais do Condor. Essas características são implementadas através dos mecanismos de ClassAds, migração, checkpoint de tarefas e chamadas de sistema remotas.

A linguagem ClassAd provê meios eficientes para comparar os recursos oferecidos com as solicitações de recursos recebidas na submissão de tarefas. O Checkpointing periódico de tarefas provê tolerância a falhas e permite migração de tarefas entre máquinas para escalonamento preemptivo de baixo custo [49]. Condor implementa chamadas de sistema remotas, um mecanismo de sandbox móvel, para redirecionar, quando executando tarefas em máquinas remotas, chamadas de callback relacionadas a tarefas de $\mathrm{E} / \mathrm{S}$ para a máquina que submeteu a tarefa. Com esse mecanismo, os usuários não precisam disponibilizar arquivos de dados em estações de trabalho remotas antes da execução do Condor nessas máquinas.

\footnotetext{
${ }^{4}$ http://www.cs.wisc.edu/condor
} 
Condor-G [30] é um encontro das tecnologias Condor e Globus. Protocolos para comunicação inter-domínio e acesso padronizado a diversos sistemas batch remotos são contribuições do Globus. O Condor-G incorpora do Condor os conceitos de submissão e alocação de tarefas, recuperação de erros e criação de um ambiente de execução amigável. No relacionamento com o Globus Toolkit, o Condor-G pode ser usado como um serviço confiável para gerenciamento e submissão de tarefas para um ou mais sites enquanto o sistema Condor high-throughput pode ser usado como um serviço de gerenciamento da estrutura subjacente para um ou mais domínios, com o Globus Toolkit como elo entre eles.

\subsubsection{Segurança}

O Condor possui uma biblioteca chamada CEDAR que permite a clientes e servidores negociarem e usarem diferentes protocolos de autenticação tais como Kerberos, GSI, chaves públicas, autenticação via redes ou nós confiáveis e sistema de arquivos. Essa biblioteca implementa um conjunto de interfaces de autenticação simples e extensível. A biblioteca CEDAR possui a capacidade de negociar a integridade de dados e algoritmos de privacidade separado do protocolo de autenticação. A Figura 3.6 mostra a arquitetura de segurança do Condor.

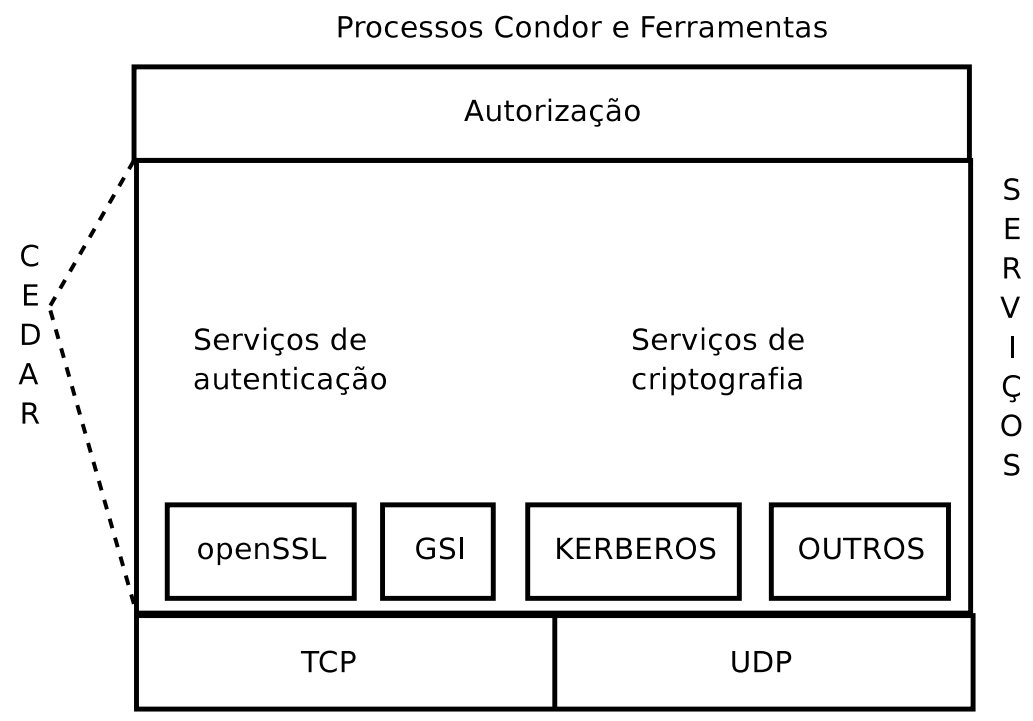

Figura 3.6: Arquitetura de Segurança do Condor.

A autenticação no Condor baseada em sistema de arquivos é implementada da seguinte forma. Um 
processo daemon utiliza a propriedade do arquivo para decidir a identidade. Quando um usuário deseja entrar na grade, o processo solicita a escrita de um arquivo em um diretório de escrita temporária. Comparando o dono do arquivo e o nome que o usuário indicou, ele decide sobre a autorização.

A execução de uma tarefa no Condor é necessariamente cooperativa. Certas informações são conhecidas unicamente pela máquina de execução, tais como quais sistemas de arquivos, redes e bases de dados podem ser acessados, enquanto somente a máquina de submissão conhece em tempo de execução os recursos necessários para a tarefa. Essa cooperação conhecida como split execution é realizada no Condor pelos componentes shadow e sandbox.

O Shadow provê os parâmetros necessários para especificação da tarefa em tempo de execução: o executável, os argumentos, o ambiente, arquivos de entrada, etc. As operações de E/S realizadas no site de execução são realizadas por uma biblioteca que captura as chamadas de sistemas e as repassa para um proxy. Este proxy se comunica com o Shadow através de um canal de comunicação seguro de forma que estes parâmetros estão disponíveis somente no momento real da execução.

O sandbox no site de execução deve proteger os proprietários de máquinas, impedindo acesso indevido aos recursos. O sandbox é formado por dois componentes distintos: sand, responsável por criar o ambiente apropriado à execução da tarefa e box, responsável pela proteção dos recursos de possíveis danos que uma tarefa maliciosa possa causar.

Em versões iniciais, Condor restringia a execução de tarefas a uma parte limitada do sistema de arquivos através do comando chroot do Unix. Atualmente, as tarefas são executadas sem restrições no sistema de arquivos, mas com restrições no login. Essa abordagem possibilita contudo, em uma máquina multiprocessada executando várias tarefas simultaneamente, o seqüestro de uma tarefa de usuário por outro usuário malicioso, porque compartilham um mesmo ID de usuário, ainda que de uma conta nobody padrão com poucos privilégios. Condor evita esse problema alocando dinamicamente IDs de usuário para cada tarefa em execução. O Condor também usa o conceito de domínio de ID de usuário para um conjunto de máquinas compartilhando uma mesma base de dados de usuário.

O Condor é um sistema maduro e a primeira tentativa consistente de implementar uma grade computacional. O Condor é um sistema flexível que permite o uso de diferentes protocolos de autenticação e a execução das tarfeas em um ambiente cooperativo e restrito permite a segurança na execução de processos. O Condor, assim como as soluções de segurança para os sistemas de grades vistos, fundamenta sua segurança em tecnologias tradicionais e estas carecem da dinâmica necessária para lidar com os relacionamentos voláteis ocorridos numa grade computacional. Numa grade, as 
opiniões que os usuários possuem sobre outros podem mudar com o tempo (vide os requisitos de segurança na Seção 2.2).

\subsection{OurGrid}

O OurGrid [4] foi criado em 2003 na Universidade Federal de Campina Grande. Ele utiliza o MyGrid [10] para implementar um sistema de Grade baseado numa rede peer to peer. O MyGrid é um sistema que teve como premissa de projeto construir um sistema simplificado para executar aplicações sobre recursos computacionais distribuídos. No MyGrid, o próprio usuário pode instalar um grade computacional com os recursos de que dispõe. A instalação do MyGrid não requer nenhum privilégio especial de administrador.

O MyGrid define duas categorias de máquinas. A máquina base é ponto de acesso à grade. Através desta máquina, o usuário pode adicionar, submeter e monitorar aplicações e ainda adicionar outras máquinas à grade. As máquinas de grid, por sua vez, são as máquinas responsáveis pela execução de aplicação na Grade. As máquinas de grid e as máquinas base não necessitam compartilhar nenhum sistema de arquivos, bastando que sejam acessíveis pela máquina dos usuários.

O MyGrid define a Grid Machine Interface, um conjunto mínimo de serviços que precisam estar disponíveis para que uma dada máquina possa ser adicionada à grade do usuário [63]. Os serviços são transferências de arquivo, execução remota e interrupção de execução múltipla. O Mygrid provê as seguintes implementações para estes serviços:

1. Grid Script - usa comandos básicos do sistema operacional;

2. User Agent - pequena aplicação desenvolvida em Java;

3. Globus Proxy - direciona as operações necessárias para serviços implementados no Globus (GSI, GRAM e GridFTP).

A Figura 3.7 apresenta os três componentes básicos do OurGrid: MyGrid Broker, OurGrid Peer e Swan. O MyGrid Broker provê um alto nível de abstração da grade. O OurGrid Peer é responsável por gerenciar as máquinas que pertencem a um determinado domínio administrativo e obter acesso a máquinas em outros domínios [56]. E finalmente, o SWAN é uma solução de sandboxing baseado na máquina virtual Xen [6]. 


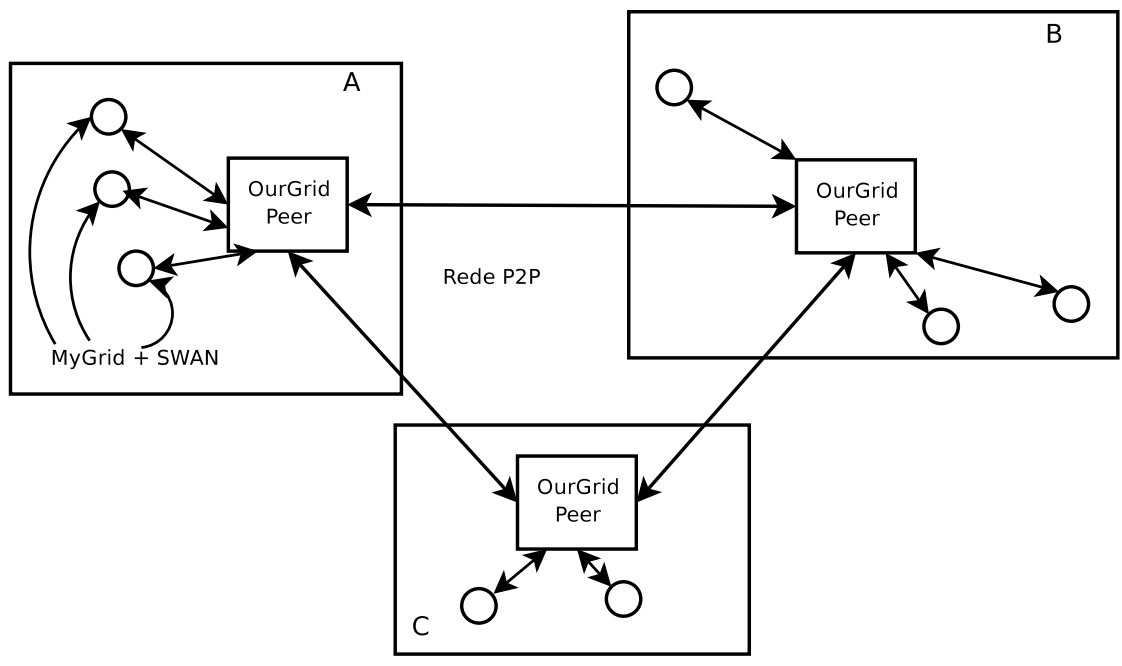

Figura 3.7: Arquitetura do OurGrid.

\subsubsection{Segurança}

O OurGrid possui duas formas de autenticação: acesso direto e via OurGrid Peer. No acesso direto os usuários obtém os recursos pela máquina grid através de autenticação no sistema operacional via login e senha. A outra forma de autenticação é via certificados digitais no formato X.509. Nesse modo de autenticação, somente módulos confiáveis podem comunicar entre si.

A autenticação do OurGrid é feita em duas fases [63]. A primeira garante que o usuário tem permissão para solicitar serviços às maquinas grid. A segunda parte garante que o usuário não está solicitando serviços a uma falsa maquina grid. Dessa forma os usuários (através do broker), os OurGrid Peers gerenciam uma lista de certificados usadas para validar a tentativa de acesso.

O OurGrid utiliza os certificados para permitir comunicação segura entre o MyGrid Broker e o Ourgrid Broker. A segurança na comunicação é fornecida através do uso de RMI baseado em SSL, que garante comunicação criptografada.

Detsch $[17,32]$ propõe um arcabouço de segurança para redes P2P chamado P2PSLF (Peer-toPeer Security Layer Framework) que foi implementado no OurGrid. Este arcabouço define serviços de autenticação e confidencialidade para sistemas P2P. O P2PLSF foi implementado para ser completamente independente da aplicação do usuário. O arcabouço tem características como modularidade, definição de requisitos de segurança por peer e redefinição dos requisitos dinamicamente. 




Figura 3.8: Arquitetura do P2PSL

A Figura 3.8 apresenta o resumo da arquitetura do P2PLSF. O arcabouço permite a definição de grupos de peers que compartilham requisitos de segurança. Cada peer possui perfis associados que representam os sentidos das mensagens entre os peers e os requisitos definidos. No exemplo da Figura 3.8, o Peer 1 exige autenticação quando houver troca de mensagens com os Peers 2 e 4 . O Peer 1 também define que as mensagens com o Peer 3 serão autenticadas quando o sentido for de 1 para 3 e autenticadas e confidenciais no sentido inverso. O Peer 3, por sua vez, envia mensagens autenticadas com confidencialidade para os Peers 1 e 4 e mensagens somente autenticadas no sentido contrário. E finalmente, o Peer 3 envia mensagens com autenticação para o Peer 2 e o mesmo Peer autentica e registra eventos ocorridos quando recebe mensagens do Peer 2.

Em cada um dos peers presentes na arquitetura há um módulo de configuração que é responsável pela descoberta de peers que formam o grupo. Assim que ingressa na rede, o módulo faz uma requisição especial de busca para descobrir as configurações de segurança dos peers remotos. Baseado nas informações obtidas, o administrador pode reconfigurar os requisitos de segurança definidos para aquele nó.

O OurGrid é uma promissora tentativa brasileira de criar uma Grade Computacional baseada em P2P. O OurGrid permite autenticação utilizando certificados X509, o que o faz alinhado as tecnologias atuais de segurança. O P2PSLF é um arcabouço do OurGrid que permite que os recursos 
sejam controlados de uma forma simples e escalável, tornado-o adequado à dinâmica de uma grade computacional. Porém as configurações de segurança do OurGrid são feitas manualmente e dependem da interação do dono do recurso e do conhecimento que este tem a respeito dos seus clientes para definir o controle de acesso. Entendemos que em uma grade computacional é necessário que o sistema de segurança seja dinâmico a ponto de decidir por si mesmo sobre as relações de confiança entre os participantes.

\subsection{InteGrade}

O InteGrade ${ }^{5}$ é um sistema de Grade motivado principalmente pela necessidade de aproveitamento de recursos computacionais compartilhados (computadores pessoais, estações de trabalho), em geral subutilizados, com predomínio de períodos ociosos, para execução de aplicações com grande demanda por tais recursos. As características do InteGrade incluem suporte para uma gama de aplicações paralelas e mecanismos que buscam minimizar a percepção, pelos proprietários dos recursos compartilhados, de qualquer possível perda de qualidade de serviço [34,35].

Uma grade do InteGrade é constituída de aglomerados (clusters) de computadores organizados de forma hierárquica. A Figura 3.9 mostra a arquitetura do InteGrade com seus principais componentes. Uma descrição resumida destes componentes é dada a seguir.

- Gerenciador do aglomerado: responsável por gerenciar o aglomerado e pela comunicação com gerenciadores de outros aglomerados. Este nó pode ser distribuído para balanceamento de carga ou replicado para tolerância a falhas.

- Nó dedicado: reservado para as aplicações da grade.

- Nó compartilhado (fornecedor de recursos): tipicamente uma estação de trabalho, disponibiliza parte de seus recursos para execução de aplicações dos usuários da grade.

- Nó de usuário: pertence ao usuário que submete aplicações à grade.

O LRM (Local Resource Manager) e o GRM (Global Resource Manager) cooperam no gerenciamento dos recursos de um aglomerado. O LRM é executado nos nós do aglomerado, coletando informações sobre o estado do nó (uso de CPU, disco, memória, recursos de rede, etc.) e as envia

\footnotetext{
${ }^{5}$ http://www. integrade.org.br
} 


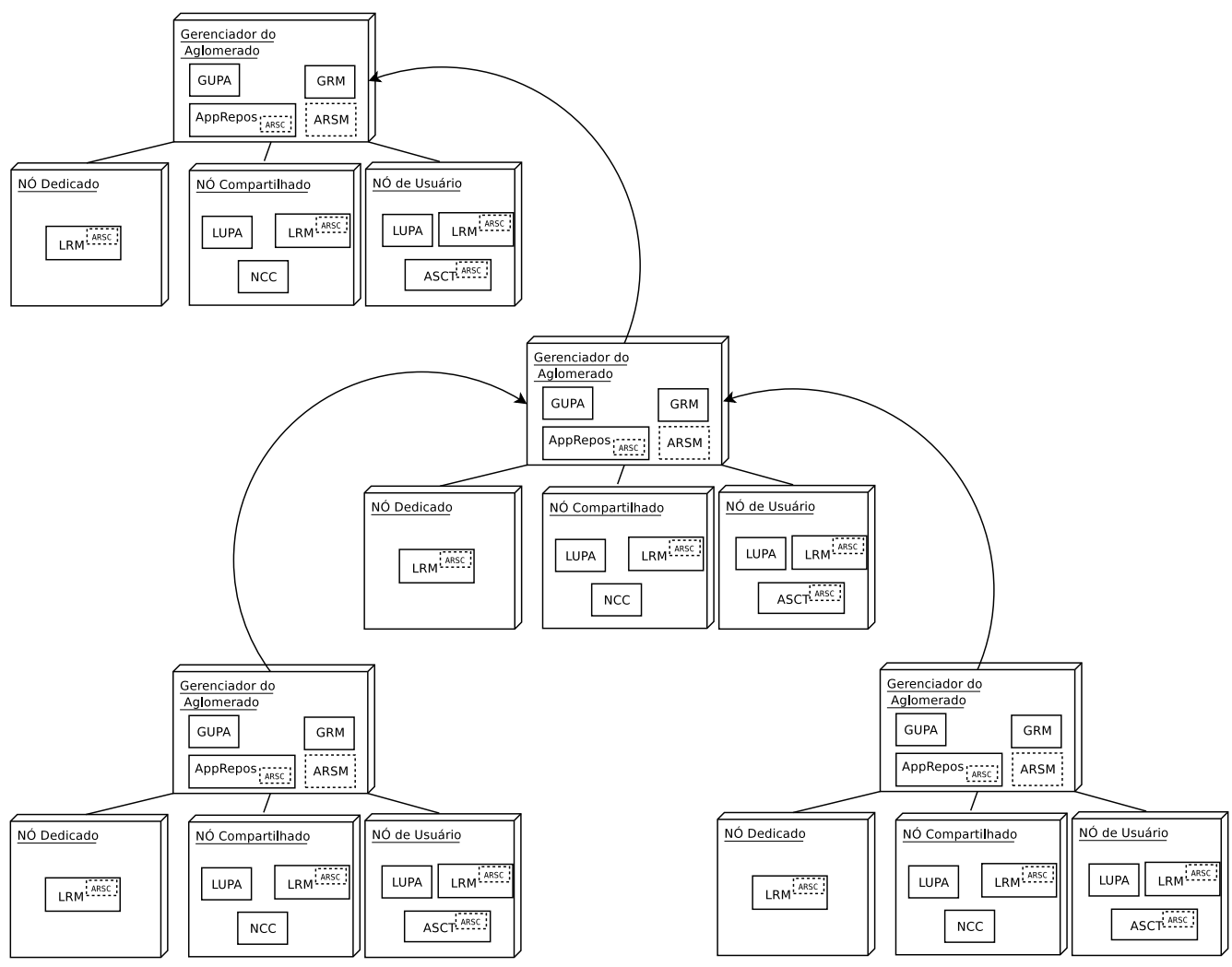

Figura 3.9: Arquitetura do InteGrade com os módulos de segurança.

periodicamente ao GRM. Este último executa no nó gerenciador do aglomerado e usa as informações enviadas pelos LRMs para escalonamento das aplicações submetidas à grade.

LRM e GRM também colaboram no protocolo de alocação de recursos e execução de aplicações. O GRM seleciona nós candidatos para executar uma aplicação submetida pelo usuário da grade, com base nos requisitos da aplicação e na disponibilidade de recursos. Estas últimas informações são coletadas pelos LRMs nos nós fornecedores de recursos.

De modo semelhante à cooperação LRM/GRM, os módulos LUPA (Local Usage Pattern Analyzer) e GUPA (Global Usage Pattern Analyzer), ainda em desenvolvimento, também trabalham cooperativamente na análise de padrões de uso das máquinas para contribuir para um escalonamento eficiente na grade [34]. 
O ASCT (Application Submission and Control Tool) permite que o usuário submeta aplicações para serem executadas na grade. Através desta ferramenta, ele estabelece requisitos para a execução, tais como hardware, software ou recursos necessários, e controla o andamento da execução das aplicações na grade.

O módulo AR (Application Repository) permite o armazenamento e recuperação de aplicações.

\subsubsection{O Repositório de Aplicações}

O repositório de aplicações do InteGrade provê a persistência e a recuperação de aplicações. A implementação da persistência consiste no armazenamento das aplicações em disco permitindo que sejam identificadas univocamente na grade. Além de persistência, ele oferece outras facilidades para uso e controle das aplicações da grade por usuários e administradores. Essas facilidades envolvem, por exemplo, aspectos relacionados a segurança e a gerenciamento de versões. O gerenciamento de versões pelo repositório de aplicações provê suporte para tratamento de variantes das aplicações em diferentes plataformas.

O repositório define interfaces que permitem a navegação pelo espaço de nomes, de forma similar a diretórios em um sistema de arquivos, cujo conteúdo abrange as aplicações registradas e suas informações associadas. As principais funcionalidades dessas interfaces incluem registrar uma aplicação, suas versões em diferentes plataformas e recuperar arquivos binários para execução e escalonamento na grade.

Um esquema simples de metadados é utilizado para manter informações descritivas sobre as aplicações e sobre as versões de código binário dessas aplicações. Ao registrar uma aplicação, o sistema cria no repositório de aplicações, um diretório com o nome da aplicação e dentro desse diretório um arquivo de descrições. Esse arquivo contém metadados sobre a aplicação, incluindo quantidade e nome das versões de códigos binários existentes para essa aplicação. Ao armazenar uma nova versão de código binário para uma aplicação, o sistema atualiza o arquivo de meta-dados. Esse arquivo também é atualizado se uma versão de código binário for excluída.

As informações armazenadas no arquivo de metadados são utilizadas no escalonamento de aplicações. Ao submeter uma aplicação, o usuário pode escolher se deseja executar uma versão específica do código binário ou se a aplicação pode ser executada por qualquer das versões armazenadas no repositório. No primeiro caso o escalonador deverá selecionar apenas as máquinas disponíveis que atendam a essa restrição sobre a plataforma. No segundo caso, o escalonador seleciona máquinas e 
versões compatíveis ao distribuir a tarefa entre os nós da grade.

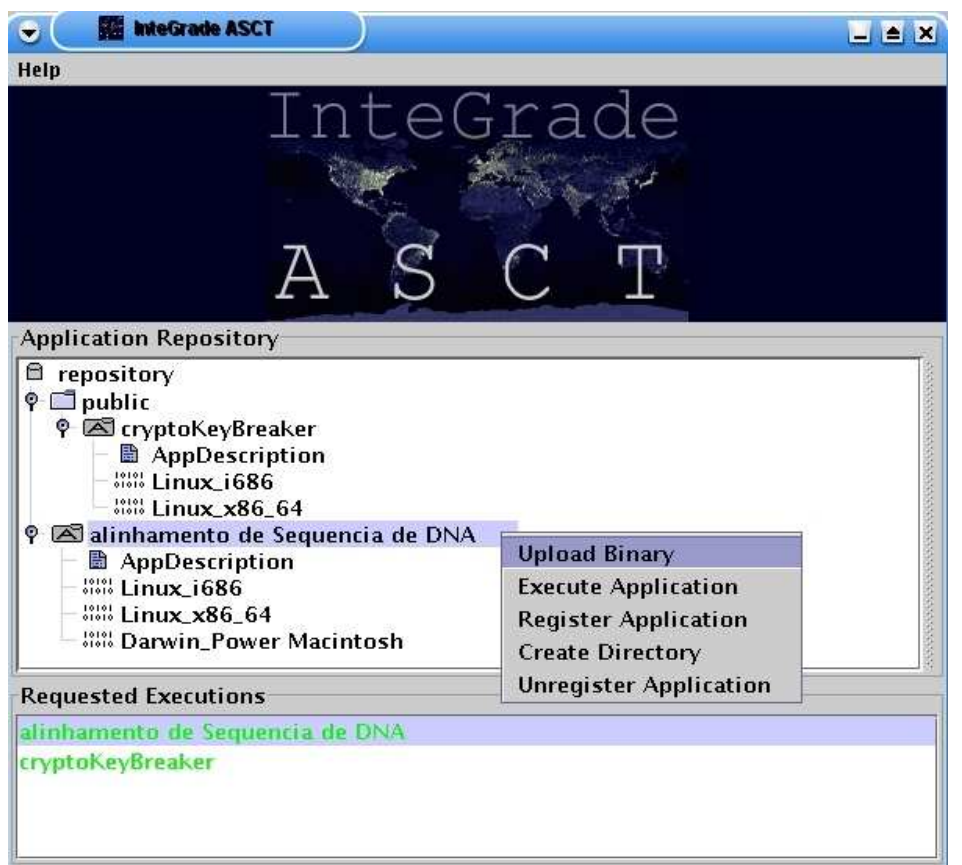

Figura 3.10: Visão do Repositório de Aplicações via ASCTGui.

A Figura 3.10 mostra a interface gráfica do módulo ASCT navegando sobre o espaço de nomes do repositório de aplicações. Cada usuário autenticado tem acesso a uma árvore de diretórios pessoal (home directory) e ao diretório public (ver figura), o qual também é compartilhado pelos demais usuários. Nesse exemplo, a aplicação "Alinhamento de Seqüência de DNA" foi registrada com 3 tipos de executáveis correspondentes a plataformas de hardware diferentes: Linux/86, Linux/AMD64 e MacOSX/PowerPC Macintosh. O menu de contexto apresentado na figura pode ser utilizado para submeter aplicações à grade.

\subsubsection{Segurança}

O InteGrade necessita, como os demais sistemas de grade, de uma atenção adicional quanto à segurança dos recursos cedidos. A implementação de segurança do InteGrade [44] tem como enfoque a proteção do repositório de aplicações contra usuários maliciosos que desejem alterar as aplicações executadas no InteGrade. Sua principal motivação foi servir como abordagem inicial para a implementação de um sistema de segurança mais abragente. 
Os módulos que implementam os serviços de segurança do InteGrade são o ARSC (Application Repository Security Client) e o ARSM (Application Repository Security Manager) [44]. Ambos utilizam a API GSS [54] para obter os contextos de segurança entre o repositório de aplicações e os módulos que com ele interagem. O GSS, por sua vez, tem seus serviços implementados através do Kerberos [48]. A implementação atual do repositório seguro utiliza a versão 5 do Kerberos desenvolvida pelo MIT $^{6}$ para a linguagem C. Para a linguagem Java, essa implementação utiliza a API GSS Java [47].

O ARSM é responsável por iniciar e gerenciar os contextos. Cada cliente, através do ARSC, possui um contexto de segurança com o ARSM. Todas as trocas de mensagens entres os módulos são feitas utilizando esses contextos. O ARSC pode efetuar quatro operações básicas: assinar e verificar uma mensagem enviada com o contexto que ela possui, ou ainda, assinar e verificar uma mensagem enviada sob um outro contexto. Mais especificamente, o repositório usa o ARSM (via o ARSC) para verificar e assinar os arquivos executáveis das aplicações dos seus clientes, enquanto estes clientes usam o ARSC para assinar e verificar arquivos durante o armazenamento e recuperação do repositório.

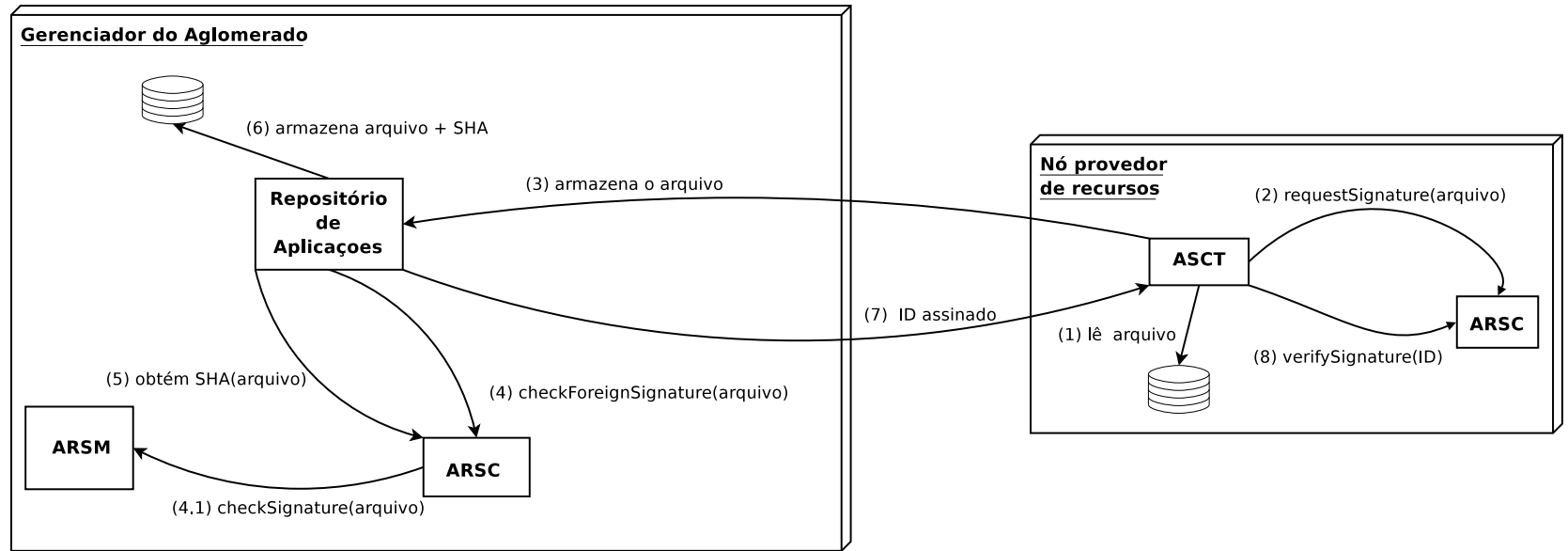

Figura 3.11: Protocolo de armazenamento do executável de uma aplicação no repositório.

O protocolo de armazenamento de uma aplicação do InteGrade é apresentado na Figura 3.11. O ASCT utiliza o ARSC para assinar o arquivo e solicitar ao repositório de aplicações o seu armaze-

\footnotetext{
${ }^{6}$ http://web.mit.edu/kerberos/www
} 
namento $(1,2,3)$. O repositório de aplicações verifica a assinatura deste binário através do ARSC (4), que o faz através do ARSM (4.1). Após o arquivo ser verificado com sucesso, o repositório de aplicações calcula um resumo do binário através de uma função hash conhecida ${ }^{7}$, por exemplo, MD5, (5) e o armazena a seguir no sistema de arquivos (6). Ao final do processo de armazenamento em disco, o repositório de aplicações envia a identificação (ID) assinada da aplicação (7), que por sua vez também é verificada (8). Caso qualquer uma das operações falhar é gerada uma exceção que é devidamente tratada e registrada em um arquivo de log.

A Figura 3.12 apresenta o protocolo de recuperação de um arquivo. Assim que um determinado LRM recebe a solicitação de execução de uma aplicação [34], ele obtém o executável compatível com a sua plataforma. De posse do ID da aplicação, o LRM o assina e indica ao repositório de aplicações o arquivo executável desejado $(1,2)$. O Repositório obtém o arquivo desejado e verifica sua integridade através da função de hash $(3,4)$. Antes de enviar o arquivo executável ao LRM, o repositório assina o binário através do ARSC (5), que repassa essa função para o ARSM (5.1), pois a assinatura deve ser feita através do contexto criado para o LRM que fez a requisição. Ao receber o arquivo, o LRM verifica sua assinatura $(6,7)$ e o armazena em disco para execução $(8)$.

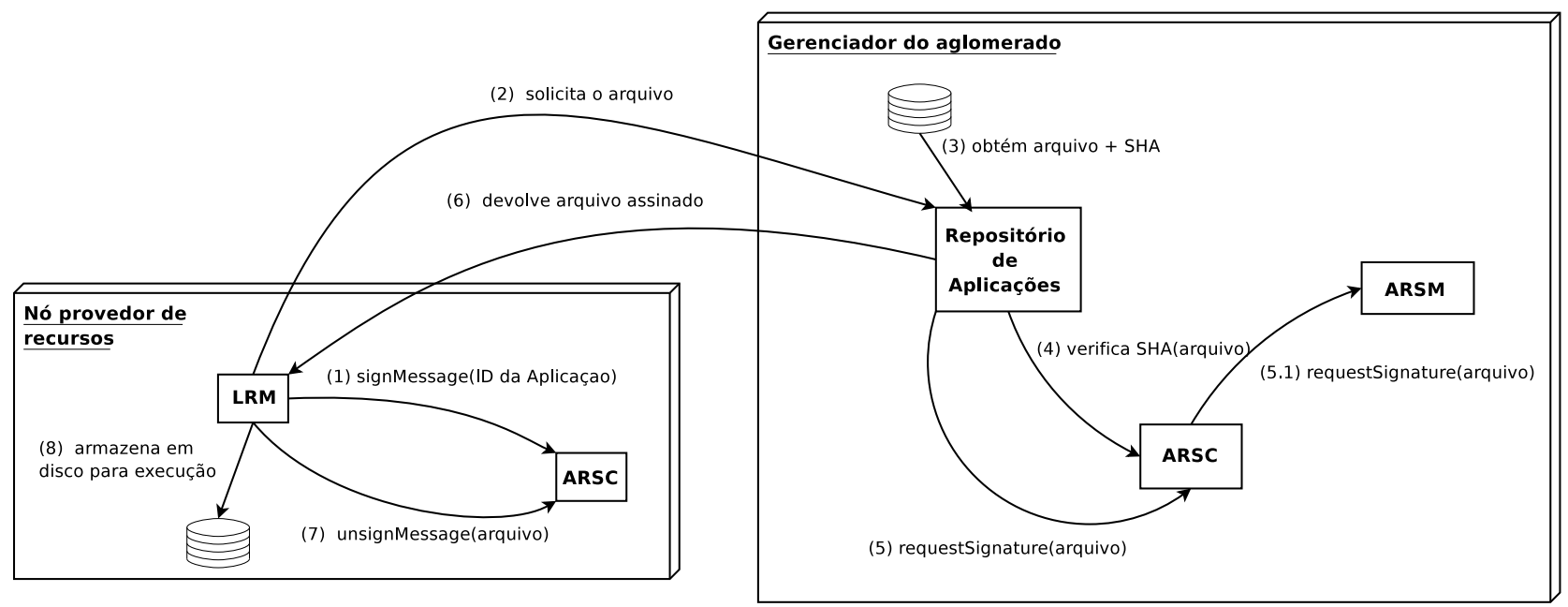

Figura 3.12: Protocolo de recuperação do executável de uma aplicação.

\footnotetext{
${ }^{7}$ Para garantir que essa chave não possa ser gerada pelo atacante, o ARSM adiciona ao arquivo uma chave que é obtida pela API GSS. Essa é uma técnica bastante utilizada em sistemas de segurança [67].
} 
Os protocolos anteriormente descritos garantem a autenticidade e a integridade dos arquivos executáveis submetidos à grade. Todas as mensagens trocadas entre o repositório de aplicações e seus clientes são devidamente assinadas e criptografadas. Pessoas mal intencionadas terão mais dificuldade ao utilizar técnicas de ataque conhecidas para modificar, interceptar ou fabricar dados, prejudicando assim o uso da grade. O uso de função de hash no sistema de arquivos é útil para tentar impedir a modificação das aplicações através de falhas de segurança no sistema de arquivos do gerenciador do aglomerado.

A implementação do repositório seguro de aplicações disponibiliza aos seus usuários três dos quatro fundamentos básicos na implementação de sistemas de segurança: confidencialidade, integridade e uso legítimo. A confidencialidade e a integridade são oferecidas através do uso de serviços disponíveis na API GSS. O fato de todas as mensagens entre clientes e o repositório de aplicações serem protegidas por assinatura e criptografia, reforça estes dois fundamentos. A sessão estabelecida, com autenticação prévia dentro de um contexto de segurança, acrescida da visão limitada de cada usuário às aplicações registradas, possibilita o uso legítimo dos recursos. No entanto, a solução atual de segurança do InteGrade é uma limitada ao repositório e não trata dos requisitos gerais de segurança para grades computacionais, conforme definido na Seção 2.2

\subsection{Conclusão}

Os sistemas de computação em grades aqui apresentados utilizam-se de variados mecanismos de segurança, cujas características são resumidas na Tabela 3.6. Os mais maduros, como o Globus Toolkit e o Condor, são flexíveis na escolha destes mecanismos, um dos principais requisitos de segurança de um sistema de grades. O Legion, o InteGrade e o OurGrid se utilizam de mecanismos já amplamente conhecidos e usados de forma a facilitar a integração entre sítios diferentes. Algumas questões no entanto precisam ser discutidas de forma a delinear suas principais limitações e propor soluções.

\begin{tabular}{cccccc}
\hline \hline Sistema & Autenticação & Autorização & Delegação & Distribuição & Histórico de relacionamentos \\
\hline Globus & Sim & Sim & Sim & Não & Não \\
\hline Avaki & Sim & Sim & Não & Não & Não \\
\hline Condor & Sim & Sim & Não & Não & Não \\
\hline Ourgrid & Sim & Sim & Não & Não & Não \\
\hline InteGrade & Sim & Sim & Não & Não & Não \\
\hline \hline
\end{tabular}

Tabela 3.2: Características dos mecanismos de segurança dos sistemas de grade. 
Os mecanismos de segurança usados pela maioria dos sistemas de grade apresentados são centralizados e baseados em sistemas convencionais para redes de computadores. Um sistema centralizado é mais vulnerável, pois se o servidor for subjugado, todo sistema está comprometido. Dessa forma a melhor opção para as grades computacionais é que o sistema de segurança seja distribuído. A distribuição permitiria que características como escalabilidade, alta disponibilidade e tolerância a falhas sejam estendidas para a segurança do sistema. Nós propomos o uso de cadeias de confiança como mecanismo de segurança e a infra-estrutura da própria grade para implementar a distribuição deste serviço.

Os sistemas apresentados não consideram a experiência individual dos participantes da grade para implementar o controle de acessos de recursos da grade. Como são baseados em sistemas tradicionais, cabe somente ao administrador do sítio, em última instância, a decisão sobre o uso dos seus recursos. Os sistemas de grades, particularmente aqueles de grande escala, são compostos por diversos domínios administrativos onde nem sempre é possível ter uma medida inicial sobre a relação de confiança entre as partes. O uso de modelos matemáticos que representem a subjetividade nas opiniões entre pares dos elementos da grade pode ser uma opção para a representação de confiança. Introduziremos no próximo capítulo as cadeias de confiança baseadas em SPKI/SDSI e de que forma, através de uma extensão proposta, ela pode ser usada para minimizar os problemas aqui discutidos. 


\section{Capítulo 4}

\section{Opiniões em Cadeias de Confiança SPKI/SDSI}

Este capítulo apresenta a nossa proposta de extensão das cadeias de confiança baseada em SPKI/SDSI (Simple Distributed Security Infrastructure e Simple Distributed Security Infrastructure). Nele apresentamos um modelo matemático que representa opiniões e a forma de aplicá-lo no SPKI/SDSI para que este seja usado em grades computacionais. Através de simulações da proposta, verificamos o seu uso em um sistema de grande escala.

\subsection{Introdução}

Prover segurança no acesso às informações é uma tarefa árdua e envolve questões que podem ou não ser técnicas. Se por um lado as tecnologias de segurança surgiram para dificultar a tentativa de acesso não autorizado a informações, por outro, pessoas ou agentes de um sistema computacional dotados de privilégios podem acabar utilizando suas prerrogativas para executar ações indevidas. Considere, por exemplo, um sistema dito seguro que proteja informações privilegiadas de uma empresa. Neste caso, basta apenas que um funcionário, possivelmente novo na empresa, para o qual foi delegado o direito de acessar um software corporativo, utilize este sistema de forma indevida para que as informações estejam comprometidas. Acontece que o referido usuário poderia necessitar destes direitos concedidos para executar suas funções dentro da corporação, de outra forma seu trabalho estaria prejudicado.

A questão por trás dos fatos acima descritos é que, em geral, sistemas de segurança não estão preparados para considerar os históricos de relacionamentos entre os sujeitos participantes. Nestes casos, um sujeito recebe direitos de uso de recursos de uma forma binária (booleana) e sobre ele não é tomado qualquer valor que considere o fato dele não possuir um histórico que permita estabelecer seu 
grau de confiança. É importante ressaltar que um usuário, mesmo legítimo, pode, em determinado momento, executar ações indevidas e então passar a ser não confiável. No mundo real, é bastante comum afirmações do tipo: "depois que eu emprestei dinheiro para fulano, ele não me parece o mesmo", o que indica que as opiniões podem mudar com o tempo.

Em ambientes de rede centralizados, este problema é resolvido pelos administradores. Cabe a eles e não aos verdadeiros donos dos recursos decidir sobre quem é ou não confiável. Em geral, nestes casos, existe uma ou mais base de dados que é responsável pela identificação e controle de acesso aos recursos. Cabe ao dono de um recurso confiar totalmente nestes administradores e assim delegar a eles o direito de uso. O administrador tem que "conhecer" todos os sujeitos (ou grupos deles) e decidir por eles se alguém é confiável ou não.

Em ambientes mais particulares, como o de grades computacionais, estas tarefas se fazem mais difíceis de tratar. Nestes casos é comum, e bem provável, que as grades sejam formadas por domínios administrativos diferentes. Dessa forma, usando a mesma solução anterior, caberia aos administradores decidir sobre o uso dos recursos da grade. Esta estratégia facilita a administração, porém dificulta o uso em ambientes de maior escala em que milhares de recursos podem ser adicionados ou retirados com facilidade todos os dias. O verdadeiro dono do recurso não poderia intervir sobre o uso de seus recursos devendo submeter-se às políticas de segurança definidas pelo administrador do domínio ao qual pertence, com mais, ou menos, direitos cedidos do que desejado.

As grades oportunistas são um caso particular de grades computacionais [13]. Nestas grades, usuários cedem seus recursos ociosos à grade e estes podem ser utilizados por aplicações da grade de acordo com sua disponibilidade. Sistemas como estes devem ser bastantes escaláveis e necessitam de um cuidado maior quanto à segurança, pois o custo administrativo de incluir ou retirar centenas de recursos sob demanda seria muito alto.

Uma solução a ser considerada quanto ao controle de acesso aos recursos de forma descentralizada são as cadeias de confiança (Trust Chains) [42]. As cadeias de confiança são baseadas nas relações de confiança mútua entre sujeitos. Através destas relações, os sujeitos podem transmitir o direito de acesso aos seus recursos de forma direta ou indireta. No primeiro caso, o dono do recurso cede o recurso a um terceiro em que confia. Eventualmente, este mesmo sujeito pode redelegar os recursos que lhes foram delegados, o que pode acontecer subseqüentemente formando uma cadeia de confiança.

O SPKI/SDSI [20] é uma opção de implementação dos conceitos de cadeias de confiança. No SPKI/SDSI, cada sujeito gerencia seu próprio espaço de nomes localmente. O sujeito, representado 
por sua chave pública, decide sobre o uso de seus recursos de acordo com políticas sobre as quais tem total controle. O SPKI/SDSI no entanto, reflete a confiança entre sujeitos de uma forma binária; assim, quando decide se um usuário é confiável, parte do princípio que possui total certeza dessa afirmação. Além disso, ele considera que o usuário é ou confiável ou não-confiável, i.e., não tem meio termo. O que nos faz retornar à questão colocada anteriormente, de que não se considera as interações entre os sujeitos para se tomar decisões relativas à segurança dos recursos. Neste capítulo, apresentamos uma extensão ao modelo do SPKI/SDSI utilizando os conceitos de lógica subjetiva para representar as relações de confiança entre sujeitos de uma grade computacional.

\subsection{Modelo de cadeias de confiança SPKI/SDSI}

O SDSI [60] foi projetado no MIT por Ronald Rivest e Butler Lampson. A complexidade das infra-estruturas de chave públicas, em especial sua dependência de espaços de nomes globais, foi a principal motivação do seu desenvolvimento. O SDSI é uma infra-estrutura de chaves públicas com espaço de nomes locais, o que concede a ele características de descentralização. Dessa forma, os usuários que utilizam o SDSI são responsáveis por identificar todos os sujeitos que interagem, sem a necessidade de um elemento central, como, por exemplo, uma autoridade certificadora no X509. O SPKI foi desenvolvido por Carl Ellison e outros [20] e é um sistema simples e flexível de autorização. A união dos dois projetos constituiu o SPKI/SDSI um sistema de autenticação e autorização que combina os espaços de nomes locais do SDSI com o sistema de autorização do SPKI.

No SPKI/SDSI, a identificação é feita através de chaves públicas de algoritmos assimétricos de criptografia. Ele relaciona uma chave pública a um nome no espaço de nomes local do usuário. Esta relação é conhecida somente localmente, ou seja, o nome associado não necessita ser globalmente único. O esquema permite a definição de grupos, onde cada grupo possui um nome e um conjunto de membros, podendo referenciar também outros grupos.

Como uma solução totalmente distribuída, o SPKI/SDSI permite flexibilidade nas definições de certificados. Cada usuário é responsável por gerenciar seus próprios certificados, ou seja, é uma autoridade certificadora. Existem dois tipos de certificados no SPKI/SDSI: o Certificado de Nome (Name Certificate) e o Certificado de Autorização (Auth Certificate). O Certificado de Nome provê autenticidade a um nome local, ou seja, ele certifica que o nome criado dentro do espaço de nomes do emissor é válido. O Certificado de Autorização concede uma autorização de acesso a um recurso ao sujeito do certificado. 
Um Certificado de Nome é composto por quatro campos: issuer, identifier, subject e validity specification [11]. O issuer é a chave pública que assina o certificado. O identifier identifica o nome local que se está definindo. O subject é representado por uma chave pública ou por um nome. Caso o subject não seja iniciado por uma chave pública, considera-se que o nome pode ser encontrado dentro do espaço de nomes local. O validity specification descreve as condições de validade do certificado, podendo indicar um intervalo de tempo ou até mesmo uma lista de revogação.

Um Certificado de Autorização consiste de cinco campos: issuer, subject, delegation, tag e validity specification. Os dois primeiros têm função análoga ao Certificado de Nome explanado anteriormente, sendo que o subject pode também indicar um grupo. O campo delegation indica se o certificado pode ser delegado ou não. O tag especifica que tipo de autorização (ou autorizações) o sujeito do certificado receberá. O validity specification tem função análoga ao Certificado de Nome.

Através da indicação do campo delegation, um Certificado de Autorização pode permitir que o sujeito do certificado delegue seus direitos a outros sujeitos. A Figura 4.1 mostra um exemplo típico de delegação que poderia ocorrer no SPKI/SDSI. O detentor do recurso sistema de arquivos (ou um sistema de gerenciamento que o represente) emite um certificado com delegação para $D_{1}$ permitindo o direito de escrever ou ler (RW), negando porém a possibilidade que este direito possa ser redelegado (ND). Para o delegado $D_{2}$, no entanto, é permitido somente a leitura (R), sendo que este direito pode ser repassado a terceiros (D). Na mesma figura, o delegado $D_{2}$ repassa o direito de leitura para o $D_{3}$ indicando que este não pode ser redelegado. Ao acessar um determinado arquivo, $D_{3}$ prova que tem este direito apresentando toda a cadeia de delegação $\left(D_{2} R: D \longrightarrow D_{3} R: N D\right)$. Uma cadeia de autorização pode ser reduzida para uma delegação entre o dono do recurso e aquele que o recebeu [39].

\subsection{Exprimindo opiniões em uma rede SPKI/SDSI}

Em alguns ambientes específicos, como os de grades computacionais, podem haver relacionamentos de confiança entre sujeitos de uma forma bem dinâmica. O modelo de cadeias de confiança implementado pelo SPKI/SDSI, por outro lado, não valoriza este tipo de interação. Para exemplificar, considere a cadeia de confiança na Figura 4.2; ela representa a relação de confiança entre os sujeitos de $\mathrm{A}$ até $\mathrm{D}$. Caso $\mathrm{C}$ não seja muito confiável, porque age de forma indevida ou até mesmo por ser novo na grade, toda a cadeia poderia estar comprometida.

Nesta tese, propomos a utilização do conceito de lógica subjetiva na relação de confiança entre 


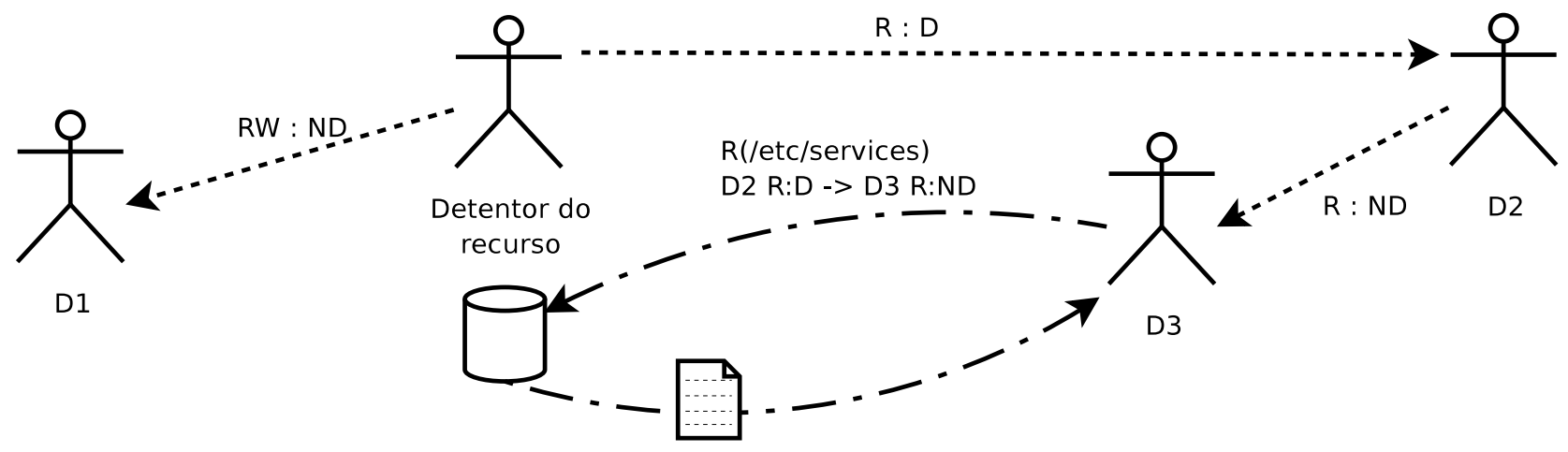

Figura 4.1: Delegação de um Certificado

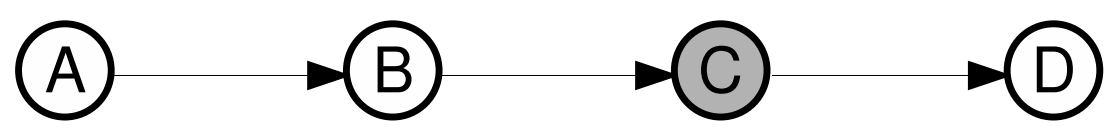

Figura 4.2: Cadeia de certificação com o nó C não muito confiável

os usuários. A lógica subjetiva é definida como uma lógica que opera em nossas crenças subjetivas a respeito do mundo [41]. Assim, a confiança em um sujeito, ou em uma chave criptográfica que o representa, poderia ser medida através de opiniões geradas por outros sujeitos. Esta quantificação poderia ser utilizada pelo provedor do recurso para decidir, utilizando suas políticas de segurança, sobre o uso de seus recursos.

\subsubsection{Modelo de Jøsang}

Para representar a opinião, utilizamos o modelo definido por Audun Jøsang [41,42]. Este modelo foi escolhido, pois é possível através dele expressar a ignorância no início da vida do sistema, conforme será apresentado a seguir. A opinião é definida como a crença que um determinado sujeito tem sobre uma sentença que pode ser verdadeira ou falsa. Assim, por exemplo, pode-se utilizar este modelo para representar a seguinte opinião: "a chave de um determinado sujeito é autêntica". A opinião $\omega$ é expressa matematicamente como:

$$
\omega=\{b, d, u\} \quad \text { tal que } \quad b+d+u=1, \quad\{b, d, u\} \in[0,1]^{3}
$$


onde $b, d$ e $u$ são números reais que representam, respectivamente, crença (belief), descrença (disbelief) e incerteza (uncertainty). A opinião é representada através da letra $\omega$ e de letras sobrescritas e subscritas de tal forma que

$$
\omega_{p}^{A}=\left\{b_{p}^{A}, d_{p}^{A}, u_{p}^{A}\right\}
$$

representa a opinião que um sujeito A possui sobre uma sentença $p$, com a crença, a descrença e a incerteza definida por $b_{p}^{A}, d_{p}^{A}, u_{p}^{A}$, respectivamente.

Jøsang descreve vários operadores lógicos para combinar opiniões [42]. Os operadores definidos podem ser equivalentes aos tradicionais como $O R, A N D, N O T$ ou não tradicionais como CONJUNÇÃO, RECOMENDAÇÃO e CONSENSO. A CONJUNÇÃO é usada quando um sujeito necessita compor opiniões a respeito de duas sentenças independentes. A RECOMENDAÇÃO acontece quando um sujeito $\mathrm{B}$ recomenda ao sujeito $\mathrm{A}$ a sua opinião sobre uma sentença $p$. A opinião resultante pode ser interpretada como a opinião A a partir da opinião que B possui. O CONSENSO é relativo à opinião formada sobre uma sentença a partir de duas outras opiniões. A seguir a definição mais formal de cada um destes operadores.

\section{Definição 1: CONJUNÇÃO}

Seja $\omega_{p}^{A}=\left\{b_{p}^{A}, d_{p}^{A}, u_{p}^{A}\right\}$ e $\omega_{q}^{A}=\left\{b_{q}^{A}, d_{q}^{A}, u_{q}^{A}\right\}$, opiniões sobre as sentenças $p$ e $q$, respectivamente. A conjunção de $\omega_{p}^{A}$ e $\omega_{q}^{A}$ sobre as sentenças binárias $p$ e $q$ é definida por

$$
\omega_{p \Lambda q}^{A}=\omega_{p}^{A} \Lambda \omega_{q}^{A}=\left\{b_{p \Lambda q}^{A}, d_{p \Lambda q}^{A}, u_{p \Lambda q}^{A}\right\} \quad \text { onde } \quad\left\{\begin{array}{l}
b_{p \Lambda q}^{A}=b_{p}^{A} b_{q}^{A} \\
d_{p \Lambda q}^{A}=d_{p}^{A}+d_{q}^{A}-d_{p}^{A} d_{q}^{A} \\
u_{p \Lambda q}^{A}=b_{p}^{A} u_{q}^{A}+u_{p}^{A} b_{q}^{A}+u_{p}^{A} u_{q}^{A}
\end{array}\right.
$$

\section{Definição 2: RECOMENDAÇÃO}

Sejam A e B dois sujeitos onde $\omega_{B}^{A}=\left\{b_{B}^{A}, d_{B}^{A}, u_{B}^{A}\right\}$ é a opinião de A sobre a recomendação de B e seja $p$ uma sentença binária onde $\omega_{p}^{B}=\left\{b_{p}^{B}, d_{p}^{B}, u_{p}^{B}\right\}$ é a opinião de B sobre $p$ em recomendação a A. Então a opinião de A sobre $p$ como resultado da recomendação de B é definida por

$$
\omega_{p}^{A B}=\omega_{B}^{A} \otimes \omega_{p}^{B}=\left\{b_{p}^{A B}, d_{p}^{A B}, u_{p}^{A B}\right\} \quad \text { onde } \quad\left\{\begin{array}{l}
b_{p}^{A B}=b_{B}^{A} b_{p}^{B} \\
d_{p}^{A B}=b_{B}^{A} d_{p}^{B} \\
u_{p}^{A B}=d_{B}^{A}+u_{B}^{A}+b_{B}^{A} u_{p}^{B}
\end{array}\right.
$$




\section{Definição 3: CONSENSO}

Sejam $\omega_{p}^{A}=\left\{b_{p}^{A}, d_{p}^{A}, u_{p}^{A}\right\}$ e $\omega_{p}^{B}=\left\{b_{p}^{B}, d_{p}^{B}, u_{p}^{B}\right\}$, respectivamente as opiniões tomadas pelos sujeitos A e B sobre uma afirmação. A opinião do CONSENSO tomada por um sujeito imaginário [A,B] representando A e B é definida por

$$
\omega_{p}^{A, B}=\omega_{p}^{A} \oplus \omega_{p}^{B}=\left\{b_{p}^{A, B}, d_{p}^{A, B}, u_{p}^{A, B}\right\} \quad \text { onde } \quad\left\{\begin{array}{l}
b_{p}^{A, B}=\left(b_{p}^{A} u_{p}^{B}+b_{p}^{B} u_{p}^{A}\right) /\left(u_{p}^{A}+u_{p}^{B}-u_{p}^{A} u_{p}^{B}\right) \\
d_{p}^{A, B}=\left(d_{p}^{A} u_{p}^{B}+d_{p}^{B} u_{p}^{A}\right) /\left(u_{p}^{A}+u_{p}^{B}-u_{p}^{A} u_{p}^{B}\right) \\
u_{p}^{A, B}=\left(u_{p}^{A} u_{p}^{B}\right) /\left(u_{p}^{A}+u_{p}^{B}-u_{p}^{A} u_{p}^{B}\right)
\end{array}\right.
$$

\subsubsection{Aplicando o modelo de Jøsang no SPKI/SDSI}

Neste trabalho propomos a aplicação do modelo de Jøsang no SPKI/SDSI. Estendemos os conceitos de opinião para representar a confiança entre sujeitos de uma cadeia SPKI/SDSI, destacando quais operações que poderiam ser usadas para compor uma opinião sobre esta cadeia. Ademais, definimos um gerador de opiniões que trata eventos de segurança para gerar opiniões sobre sujeitos através de um sistema de créditos.

Os conceitos de lógica subjetiva associados ao modelo de Jøsang podem ser tomados para tentar minimizar o problema apresentado na Figura 4.2. Opiniões sobre os componentes de uma determinada cadeia de confiança poderiam nortear as decisões sobre o uso de recursos. As operações definidas por Jøsang, apresentadas anteriormente, podem ser aplicadas sobre a cadeia para compor uma opinião.

\section{Definição 4: Opinião entre sujeitos}

Seja A um sujeito e b a sentença que afirma "O sujeito B é confiável", então

$$
\omega_{b}^{A}=\left\{b_{b}^{A}, d_{b}^{A}, u_{b}^{A}\right\}
$$

é a opinião de A sobre B ser confiável ou não.

A Figura 4.3 apresenta uma cadeia de confiança utilizando os conceitos de opinião aqui apresentados. Neste exemplo, o sujeito A deseja verificar uma cadeia de confiança através de delegações feitas a partir dele até o sujeito final D. Ele possui opiniões bem formadas sobre a credibilidade de cada um dos participantes da cadeia, com exceção do sujeito C. Na falta dessa informação, ele usa a sua opinião sobre a recomendação dada por E para compor a opinião sobre C. A opinião final sobre 


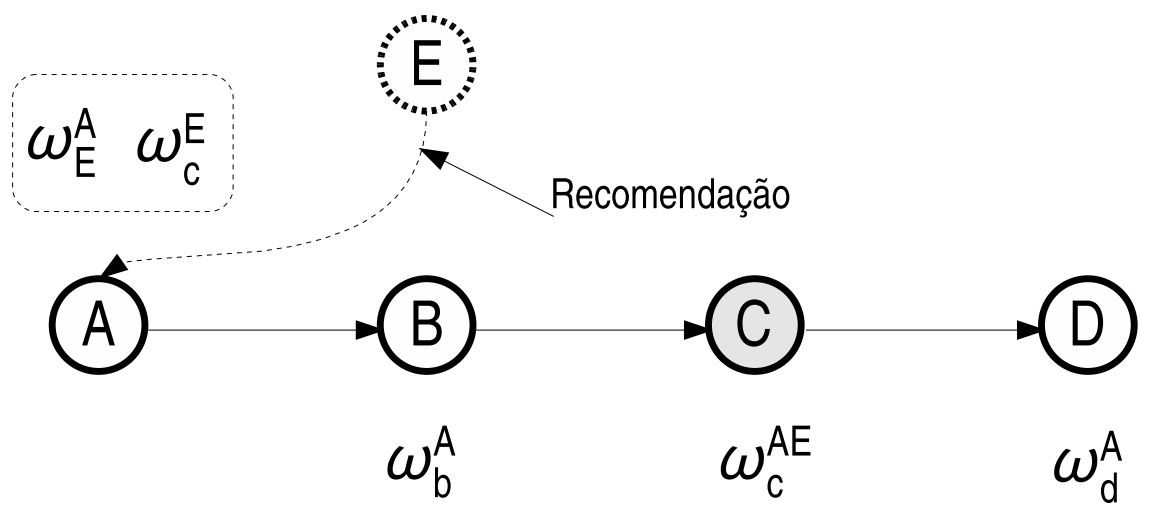

Figura 4.3: Cadeia de certificação com o nó C não muito confiável

a cadeia é conseguida através do consenso de todas as opiniões tomadas pelo provedor do recurso A sobre cada um dos sujeitos, incluindo a recomendação dada por E sobre C.

A Figura 4.4 mostra duas situações que representam a mudança de opinião de um sujeito a partir de seu comportamento. Inicialmente elas partem de uma opinião $\omega_{0}$, totalmente imprecisa, que é representada no modelo como a tupla $\{0,0,1\}$. Na primeira situação, o sujeito possui um comportamento hostil e a opinião sobre ele mudaria ao longo do tempo com uma tendência crescente da descrença. No caso extremo, a opinião poderia alcançar a situação de alta descrença perto do ponto $\omega_{I}=\{0,1,0\}$. Na outra situação, um comportamento amistoso faria a opinião mudar até um ponto que indicaria uma crença maior. Note, na figura apresentada, que uma vez que a opinião poderia representar se um determinado usuário é confiável ou não, as áreas hachureadas simbolizariam regiões onde se classificariam os amigos, inimigos ou desconhecidos, sendo eles muito confiáveis, pouco confiáveis ou sem muita certeza disso, respectivamente.

Para gerar uma opinião é necessário ter mecanismos que obtenham informações que sejam usadas para decidir se um sujeito é confiável ou não. A Figura 4.5 mostra os tipos de dados de entrada que poderiam ser usados para compor um julgamento. O histórico de relacionamentos entre pares, indicando uso correto de recursos cedidos, poderia influenciar positivamente a crença em um sujeito. Os registros (logs) de eventos de segurança relevantes, por outro lado, poderiam ser usado para aumentar a descrença em um sujeito. Um usuário poderia intervir manualmente sobre a apreciação da credibilidade de um sujeito de acordo com suas próprias conviç̧ões. O padrão de uso de um usuário, por sua vez, poderia ser usado para apontar ações indevidas que fogem daquilo que é esperado para 


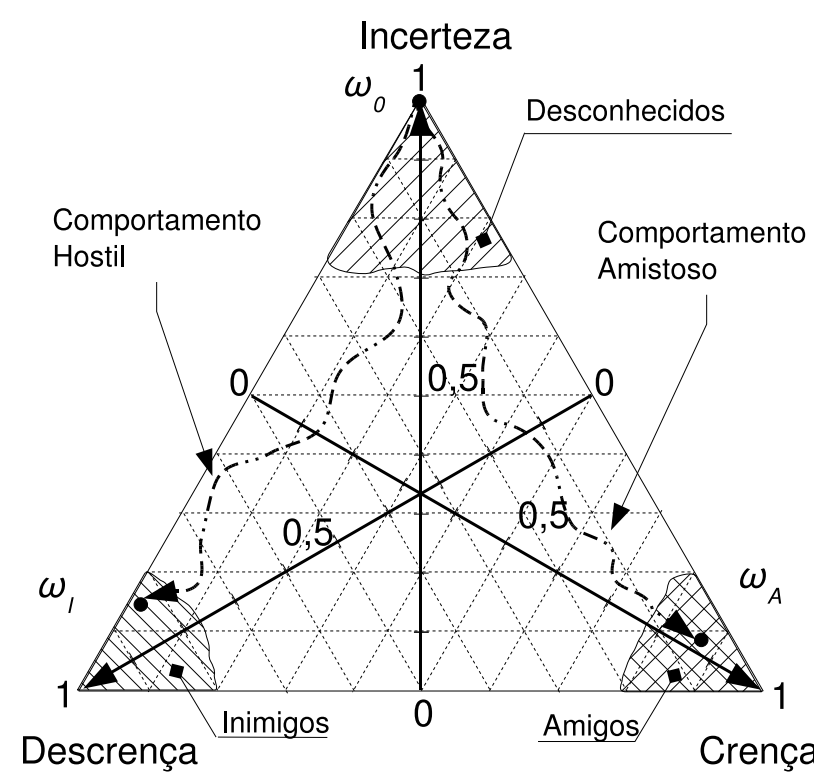

Figura 4.4: Mudança de opinião

um determinado sujeito ou tipo de usuário. Finalmente, outras informações poderiam ser utilizadas da mesma maneira a contribuir na definição de um ponto que represente a opinião sobre um sujeito.

A Tabela 4.3.2 mostra uma possível maneira de incrementar a opinião através de um sistema de crédito. Neste sistema, as operações de crédito de crença e descrença ocorreriam de acordo com pesos $w$ definidos para cada operação. Estes pesos poderiam ser associados a valores ponderados de acordo com valores padrão ou definidos através de intervenção do usuário. Assim, de acordo com a mesma tabela, uma operação de crédito de crença corresponderia a um débito do mesmo valor de descrença para manter a relação definida na equação (4.1). Um aumento da incerteza, por sua vez, corresponderia a uma diminuição de crédito na crença e descrença. Dessa maneira, a opinião poderia mudar de acordo com as várias interações entre sujeitos.

\subsubsection{Extensão do Modelo SPKI/SDSI}

Para estender o SPKI/SDSI propomos a criação de um Certificado de Opinião, ilustrado na Figura 4.6, contendo quatro campos: issuer, subject, opinion e validity specification. O issuer é o emissor da opinião, o sujeito, representado pela sua chave pública como todo objeto SDSI, que dará seu juízo 


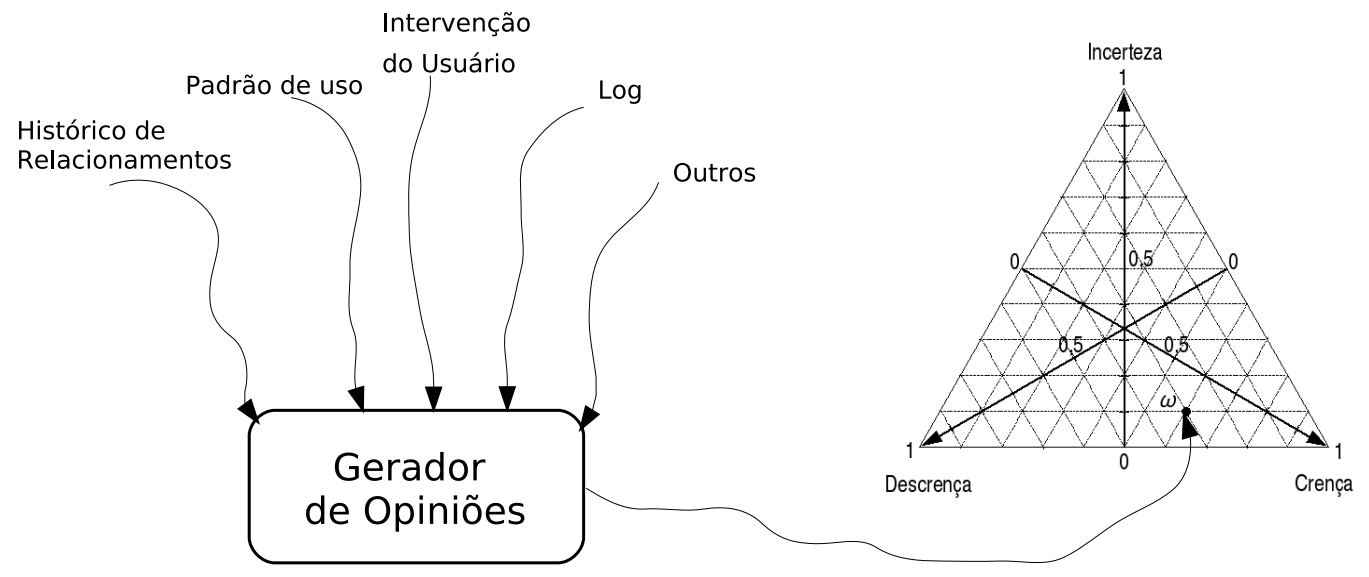

Figura 4.5: Gerador de opiniões

\begin{tabular}{lccc}
\hline \hline Operação de credito & $\mathbf{b}$ & $\mathbf{d}$ & $\mathbf{u}$ \\
\hline Crença & $+\mathrm{w}$ & $-\mathrm{w}$ & 0 \\
Descrença & $-\mathrm{w}$ & $+\mathrm{w}$ & 0 \\
Incerteza & $-\frac{w}{2}$ & $-\frac{w}{2}$ & $+\mathrm{w}$ \\
\hline
\end{tabular}

Tabela 4.1: Sistemas de créditos para o modelo de opinião.

sobre um outro. O subject é o sujeito a ser julgado, aquele sobre o qual foi formada uma opinião. O campo opinion é a opinião propriamente dita; ela é composta de três subcampos: crença, descrença e incerteza, de acordo com o definido por (4.1) e (4.2). Esta opinião é construída sobre a seguinte sentença "emissor confia no sujeito", ou seja, ela representa a opnião gerada pelo emissor que diz o quanto ele confia no sujeito alvo do certificado. Finalmente, validity specification, representa a condição de validade do certificado, um intervalo de tempo, como pode ser percebido na figura.

A extensão proposta agrega ao modelo SPKI/SDSI a possibilidade de pares de sujeitos ajuizarem opiniões entre si, o que traz vantagens claras. Primeiro, a composição de opiniões resulta numa verificação de cadeia que considera as opiniões não binárias tomadas para todos os sujeitos envolvidos. Através desta extensão, é possível provar matematicamente que uma cadeia longa resulta numa opinião composta (conjunção) que tende a aumentar a incerteza. Segundo, caso haja o conceito 


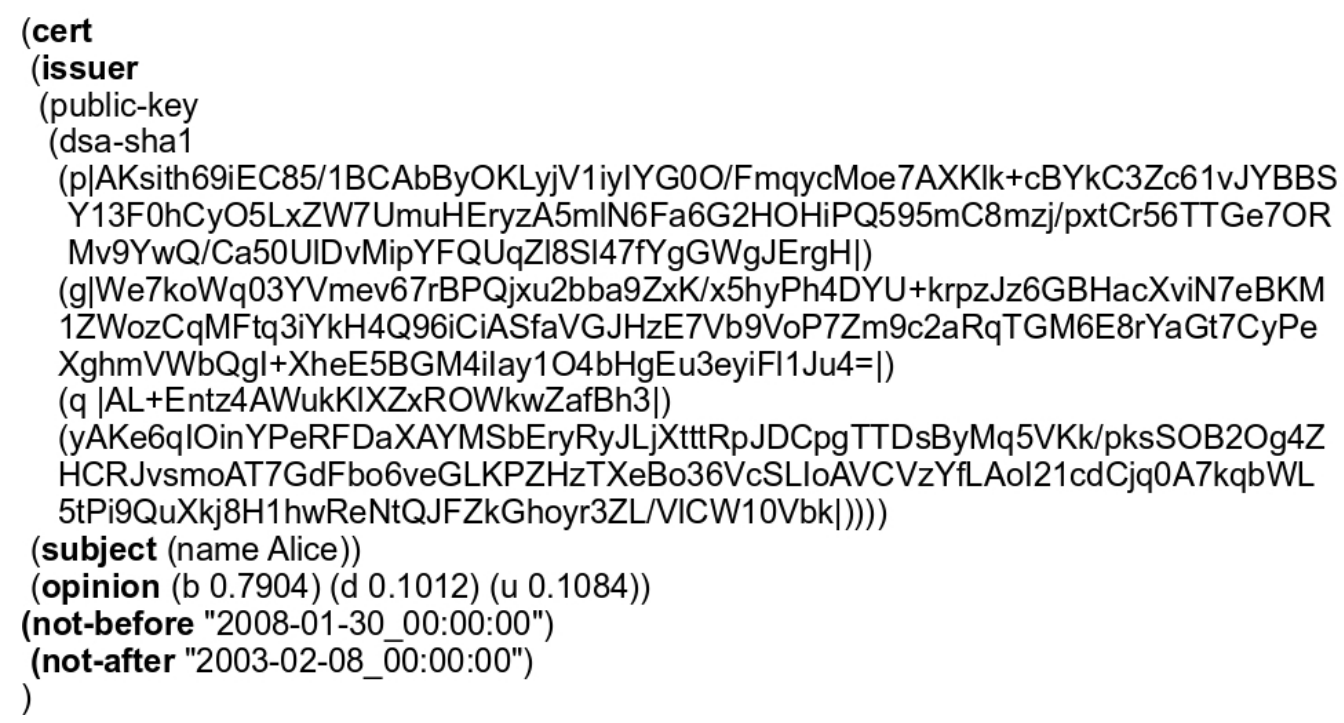

Figura 4.6: Um certificado de opinião SPKI/SDSI

de federação em uma grade computacional, uma confiança maior entre os membros, reforçará as relações entre eles permitindo que o uso de seus recursos possam ser priorizados. Finalmente, o teor não binário para a confiança entre sujeitos permite que o acesso aos recursos possa ser efetuado com restrições (menos disco do que o desejado, por exemplo), de acordo com políticas de segurança apropriadas. Por exemplo, um sujeito cuja a opinião tende a ser confiável poderia obter o acesso a leitura e escrita em um sistema de arquivos; um outro sujeito, não confiável, teria o acesso ao recurso negado. No mesmo exemplo, um sujeito medianamente confiável poderia obter o acesso ao sistema de arquivos somente para leitura. A seguir apresentar-se-á a implementação de uma Arquitetura de Seguarança para Grades computacionais baseada na extensão do SPKI/SDSI propota nesta seção. 


\section{Capítulo 5}

\section{Xenia: Uma Arquitetura de Segurança Baseada em Opiniões}

Xenia ( $\xi \varepsilon v i ́ \alpha)$ é um conceito grego de hospitalidade, generosidade e cortesia. O ritual de Xenia é expressado como um relacionamento recíproco entre o hóspede e o anfitrião [7]. O conceito de Xenia consiste em três regras básicas: o respeito do hóspede com o anfitrião, o respeito do anfitrião com o hóspede e um presente do anfitrião para o hóspede. Xenia é caracterizado como uma amizade ritualizada, um relacionamento formal entre dois membros de grupos sociais diferentes e manifestada pela troca de bens e serviços. De maneira análoga, num ambiente de Grade Computacional, a confiança entre os usuários que compartilham seus recursos, dirigida por regras de uso, deve ser um ponto a ser considerado no desenvolvimento de sistemas de segurança. Este capítulo apresenta implementação de uma arquitetura de segurança para uso em grades computacionais baseada nos conceitos de cadeias de confiança com opinião, denominada Xenia. Apresenta-se também um caso de uso desta arquitetura no sistema de grades oportunistas InteGrade.

\subsection{Introdução}

A arquitetura de um sistema de segurança para grades deve ser sobretudo flexível [26]. Esta arquitetura precisa proporcionar uma implementação facilmente extensível que se adeque às possíveis tecnologias de segurança utilizadas nos diferentes sítios computacionais. Ela deve possibilitar o gerenciamento independente de cada domínio administrativo e, mesmo assim, permitir um controle de acesso que abranja toda a grade. Finalmente, ela deve ser escalável permitindo a adequação às várias configurações possíveis. A arquitetura apresentada neste trabalho cobre os principais requisitos de segurança de um sistema em grades [46], como mostrado a seguir.

As cadeias de confiança possuem características úteis para a definição de uma arquitetura de 
segurança para grades, a saber:

- Descentralização - pela sua característica inerentemente descentralizada, as cadeias de confiança se adequam às necessidades distribuídas das Grades;

- Escalabilidade - com as cadeias de confiança a entrada de sujeitos pode ser feita sem a necessidade de intervenção direta de administradores.O modelo não exige que conhecimento global seja armazenado por completo em nenhum ponto da grade.

- Delegação flexível - as cadeias de confiança permitem que direitos sejam delegados entre sujeitos, mesmo que estes não estejam sob um mesmo domínio administrativo;

- Adaptabilidade - as cadeias de confiança não definem protocolos complexos e, em princípio, qualquer tecnologia que utilize chaves assimétricas podem ser facilmente adaptadas.

A arquitetura que propomos é baseada nas cadeias de confiança. Através da importação de chaves criptográficas obtém-se suporte às várias tecnologias de segurança, possibilitando ao usuário utilização de chaves de aplicativos já existentes. A delegação maleável permitida pelas cadeias de confiança possibilita uma administração distribuída dos recursos, sem a interferência obrigatória de um administrador de sistema.

A confidencialidade e a integridade são providas nessa arquitetura através da comunicação segura, assinatura e criptografia explícita entre objetos. A comunicação segura será provida através da utilização de uma implementação do protocolo SSL baseada em cadeias de confiança. A assinatura e a criptografia de objetos, por sua vez, impede a modificação de um objeto qualquer por sujeitos não autorizados. Finalmente, um sistema de SandBoxing completa a arquitetura criando um ambiente protegido para execução de aplicações em grade. A arquitetura contempla um sistema de auditoria tolerante a falhas que utiliza dados distribuídos sobre um sistema em grade. A seguir, descrevemos a arquitetura e cada um dos seus componentes.

\subsection{Biblioteca SPKI/SDSI}

A arquitetura do Xenia foi baseada na versão 2 da biblioteca SPKI/SDSI [29,61] desenvolvida pelo Massachusetts Institute of Technology, MIT. A biblioteca foi desenvolvida utilizando as linguagens C e Perl, sua distribuição, incluindo o código de criptografia, é disponível de forma aberta. A biblioteca fornece uma coleção de funções que permitem às aplicações utilizar o SPKI/SDSI e ferramentas para 
gerenciamento de certificados. A biblioteca foi alterada para correção de defeitos e para refletir a extensão do SPKI/SDSI proposta neste trabalho.

A referida biblioteca possui uma interface, no modo gráfico (Web) e texto, para manipulação de certificados SPKI/SDSI. Através desta interface é possível gerenciar nomes SDSI, definir grupos e permissões. Juntamente com a biblioteca, a interface foi modificada para permitir ao usuário o gerenciamento de opiniões sobre objetos SPKI/SDSI. Toda chave pública nomeada através da biblioteca pode, a partir daí, obter uma opinião gerada pelo usuário.

\section{Give an SDSI Opinion}

This page allows you to give opinions about individuals and groups. Answer the questions below and click on Go!, or read the help about this section.

You may want to reset this form first to get rid of any old values in it.

- What opinion do you want to give?

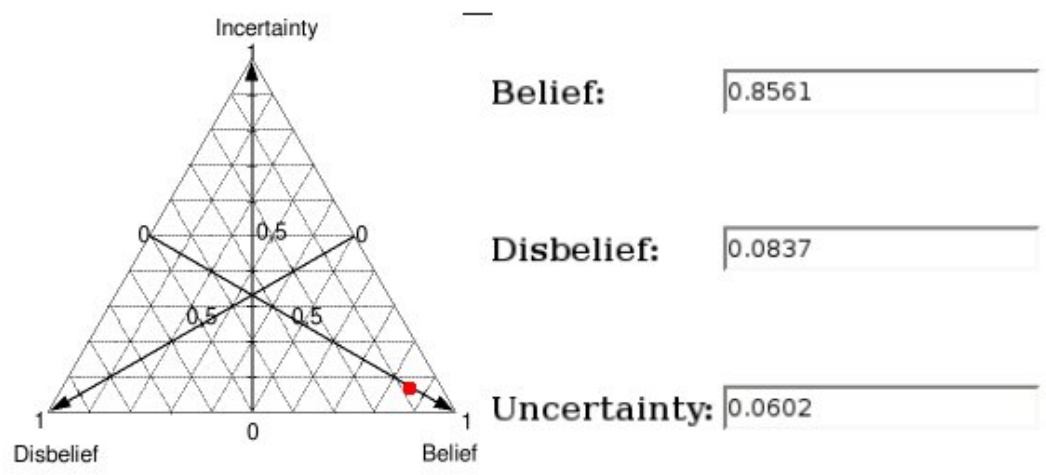

- Who do you want to give that opinion about?

The individuals: Alice

Bob

Figura 5.1: Usuário Alice recebe uma opinião.

A Figura 5.2 exemplifica o usuário Alice fornecendo uma opinião. Através de uma página Web gerada pela biblioteca, o usuário seleciona o nome Alice para compor a opinião e escolhe no triângulo as coordenadas baricêntricas que representam sua opinião a respeito de Alice. No exemplo, o valor selecionado $0.8561,0.0837$ e 0.0602 representam, respectivamente, a crença $(b)$, a descrença $(d)$ e a 
incerteza $(u)$ que ele possui quanto ao fato de Alice ser confiável.

\subsection{Módulos de Segurança}

A arquitetura de segurança está baseada sobre dois módulos: o LSM (Local Security Manager) e o GSM (Global Security Manager), vistos na Figura 5.2. O LSM é responsável pelas políticas locais de segurança em cada nó do aglomerado, permitindo o controle de acesso aos recursos por terceiros. Sendo o representante do nó na grade, o LSM identifica cada nó unicamente podendo se submeter às políticas definidas para o aglomerado ao qual pertence. O GSM prima pelo gerenciamento das políticas de um determinado domínio administrativo na grade. Além disso, o GSM é o representante de todos os nós daquele aglomerado. Em conjunto, os GSMs dos vários aglomerados que compõem a grade são responsáveis pelo gerenciamento global da segurança, mas individualmente, nenhum deles possui o conhecimento de todo o sistema.

A arquitetura proposta define dois tipos de nó na grade: os gerenciadores e os provedores de recursos, respectivamente representados pelos módulos GSM e LSM. Um nó é identificado por um par formado pelo seu identificador $(n I d)$ e pelo domínio administrativo a qual pertence $(d I d)$.

Os nós gerenciadores conhecem a identidade de todos os nós do seu aglomerado, define serviços para resolver nomes de qualquer sujeito na grade e certifica, com suas chaves criptográficas, as identidades dos nós provedores de recursos do seu aglomerado. Um administrador do aglomerado adequa as políticas da grade àquelas definidas para o domínio administrativo do seu sítio. Um nó gerenciador possui os mesmos valores para o $n I d$ e o $d I d$, como representado na Figura 5.2.

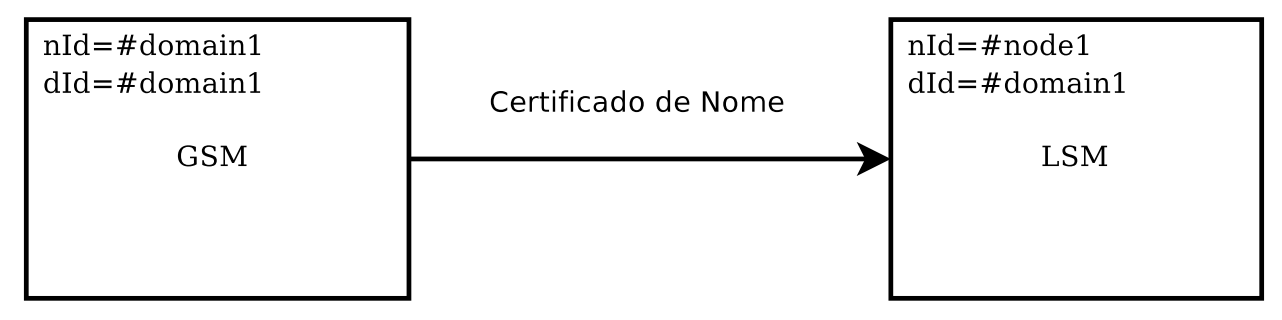

Figura 5.2: Módulos de Segurança do InteGrade

Os provedores de recursos possuem nomes devidamente atribuídos pelo seu gerenciador, como mostrado na Figura 5.2. Um nome completo de um provedor de recurso será composto pela sua chave pública e pela chave pública do seu gerenciador que indica o aglomerado ao qual pertence. Um provedor de recurso pode, através de delegação, permitir que os seus recursos sejam utilizados 
por qualquer nó da grade, de maneira flexível. Quando porém um nó opta por delegar um recurso a um nó previamente nomeado por um gerenciador, terá certificada a sua origem. Caberá ao usuário gerenciador do nó, de acordo com as políticas locais, decidir a maneira mais adequada de delegação dos seus recursos.

A Figura 5.3 mostra um caso de uso da arquitetura de segurança no InteGrade. Em cada módulo da arquitetura original do InteGrade, é incluído o módulo LSM, a partir do qual será feito o controle de acesso aos seus serviços. O AR (Application Repository), por exemplo, controlará o acesso às suas aplicações, o GRM influenciará suas políticas de escalonamento, o LRM decidirá sobre a execução de aplicações, GUPA e LUPA disponibilizarão suas informações, todos levando em consideração as políticas de segurança definidas localmente, em cada nó, ou no aglomerado ao qual pertencem. Além dos módulos apresentados anteriormente, outros módulos fazem parte da arquitetura, são eles: ImportPublicKey, LOG, XeniaBox e SecurityAPI.
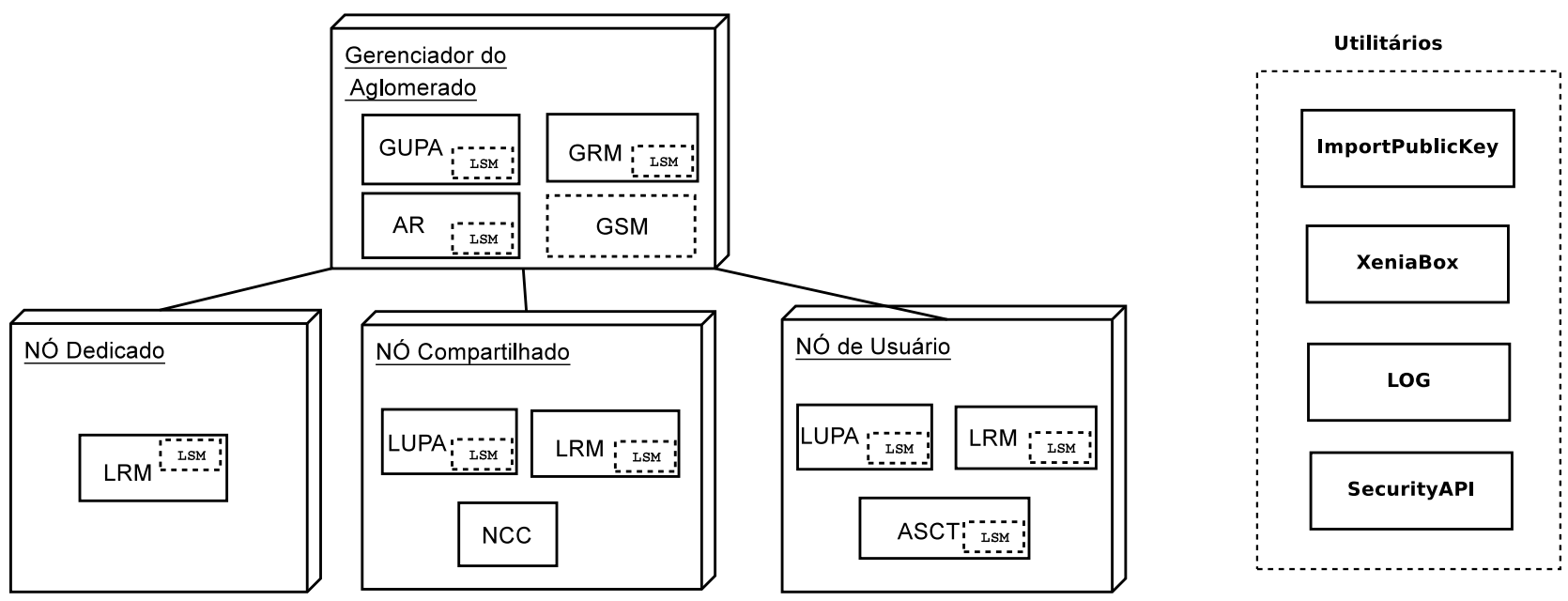

Figura 5.3: Arquitetura do InteGrade incluindo os módulos de segurança

O módulo ImportPublicKey é responsável pela importação de chaves públicas de sistemas já existentes. Através deste módulo pode-se, por exemplo, importar chaves privadas e públicas de uma infra-estrutura de chaves públicas ou até mesmo de programas que geram pares de chaves criptográficas como o ssh-keygen (www.openssh.com) ou o keytool (java.sun.com).

O módulo ImportPublicKey foi baseado na ferramenta de importação já existente contida na biblioteca original do SPKI/SDSI do MIT. A versão original, permite a conversão de chaves PGP e 
SSH da versão 1 para chaves públicas SPKI/SDSI. Com a nossa alteração, incluimos o suporte aos certificados X.509 e chaves SSH versão 2, o que inclui chaves públicas RSA e DSA e um formato de arquivo de leitura diferente. A partir daí, a biblioteca permite que usuários que mais chaves públicas e privadas em domínios administrativos diferentes, com suas respectivas tecnologias, possam utilizá-las, mantendo assim sua identificação original.

No módulo ImportPublicKey, o processamento do X.509 foi realizado através do uso da biblioteca OpenSSL [21]. Ela é uma biblioteca de código livre, escrita em $\mathrm{C} / \mathrm{C}++$, baseada no projeto SSLeay, desenvolvido pela Columbia University. O OpenSSL implementa os portocolos SSL e o TLS e possui uma biblioteca de criptografia de propósito geral. Essa biblioteca é formada por um conjunto de funções que implementam os algoritmos de criptografia simétrica e assimétrica mais comuns, algoritimos de hash e suporte à leitura e escrita de certificados digitais. O código que analisa a chave SSH versão 2 foi implementado utilizando o OpenSSH [1]. O OpenSSH é um projeto de software livre que implementa ferramentas de conectividade SSH.

O módulo $L O G$ é responsável pelo registro de eventos de segurança relevantes no sistema. Uma suspeita de ataque pode ser auditada através dos dados gerados por este módulo. Todos os dados gerados por este módulo são assinados e os eventos registrados pelo módulo LOG são utilizados para modificar negativamente as opiniões sobre os sujeitos. Para minimizar a vulnerabilidade ocasionada pela modificação ou destruição dos registros gerados pelo módulo, os dados gerados podem ser distribuídos pela grade utilizando o subsistema OppStore $[9,14]$ do InteGrade.e [14,15].

O XeniaBox permite a execução protegida de programas na grade. O ambiente por ele controlado limita os acessos aos recursos, negando ou restringindo o acesso de acordo com as políticas definidas pelo nó provedor. A política poderia, por exemplo, impedir o acesso ao sistema de arquivos, bloquear o acesso à rede ou até mesmo permitir que um aplicativo seja executado sem nenhum tipo de restrição.

O módulo SecurityApi disponibiliza um conjunto de interfaces aos programadores das aplicações da grade. Através destas interfaces, as aplicações poderão usufruir de todas as facilidades de segurança de que a arquitetura dispõe. Assinatura, criptografia, delegação de recursos e controle de acesso são exemplos de funcionalidades disponíveis às aplicações do sistema a partir deste módulo. A seguir, apresentaremos a autenticação, a autorização e o controle de acesso na arquitetura de segurança proposta. 


\subsection{Autenticação na grade}

A autenticação na grade é feita através da definição de um certificado de entrada na grade. Este processo é uma variação do protocolo definido no Globus Toolkit [68]. Na implementação do protocolo estendeu-se o certificado X.509 para permitir que o usuário obtenha uma nova identidade a ser usada na grade por um período determinado. Dessa forma a chave privada do usuário estaria protegida, evitando que seja tomada por atacantes. No protocolo proposto nesta tese, utilizamos certificados SPKI/SDSI no lugar de certificados X.509.

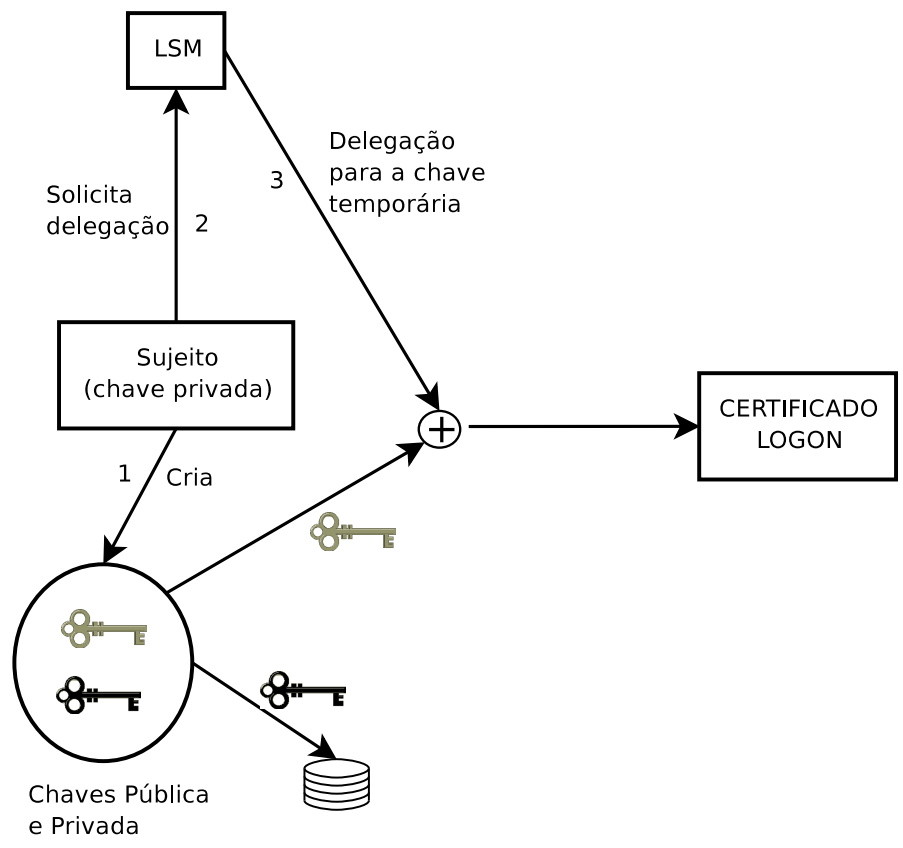

Figura 5.4: Logon na Grade

A Figura 5.4 mostra o processo de autenticação. Inicialmente, o sujeito que deseja se autenticar na grade cria um par de chaves temporárias. Em seguida, ele solicita a delegação de todos os seus direitos, ou parte deles se for o caso, para este par de chaves, por um período de validade relativamente curto, uma semana, por exemplo. Finalmente, este certificado representará o sujeito na grade com as prerrogativas para ele delegadas. Até o término do período de validade, a autenticação na grade deve ser revalidada, podendo ser realizada de forma automática. 


\subsection{Autorização e Controle de Acesso}

O processo de autorização definido para a arquitetura pode ser visto na Figura 5.5. Sempre que uma autorização ou acesso a um recurso for necessário, a política definida para o aglomerado pode ser verificada. Uma vez que o detentor de recursos também pode possuir localmente suas próprias políticas, estas também são verificadas sempre que necessário. Pode-se ver que o Aglomerado $B$, por exemplo, possui um conjunto de políticas de segurança que são locais ( $L O C A L P O L I C Y$ ) a cada nó provedor de recurso e um conjunto de políticas para o aglomerado (CLUSTER POLICY). Sempre cabe ao detentor de recursos decidir se deverá se adequar ou não às políticas definadas para o Aglomerado.

A transmissão de direito de acesso a um recurso pode ser realizado de duas formas: delegação para o aglomerado ou delegação direta. No primeiro caso, o detentor do recurso delega o direito de uso para o aglomerado que pode redelegar este direito para um grupo, provavelmente aquele formado por todos os outros provedores de recursos do aglomerado, ou de acordo com a política definida pelo administrador do aglomerado. Ainda na Figura 5.5, pode-se ver que o $\mathrm{LSM}_{B}$ delega diretamente os direitos de uso de seus recursos para o $\mathrm{GSM}_{B}$.

Na segunda forma de transmissão de direito, a delegação direta, o detentor do recurso delega para qualquer outro nó da grade os direitos de uso do recurso. Este último caso pode ser visto como uma possibilidade de vulnerabilidade na arquitetura, assim, para que um certificado de delegação seja considerado mais confiável, ele poderá ser verificado simultaneamente pelo gerenciador do aglomerado e pelo detentor do recurso. No exemplo visto na Figura 5.5, podemos ver que para o $\mathrm{LSM}_{C}$ delegar o direito de uso de seu recurso para o $\mathrm{LSM}_{B}$, ele o faz conjuntamente com o seu gerenciador GSM .

Eventualmente, dois ou mais aglomerados podem criar uma relação de confiança entre si e formar o que chamamos de federação. Numa federação, os aglomerados compartilham todos os seus recursos. Tipicamente, uma federação pode ser definida quando um conjunto de aglomerados fazem parte de um mesmo domínio administrativo. A idéia de federação aqui definida, facilitaria a administração evitando a repetição de tarefas de delegação entre aglomerados. A federação é um conceito lógico e não está necessariamente associado a proximidade física entre os aglomerados. Na Figura 5.5, o aglomerado $B$ forma uma federação com o aglomerado $A$. 


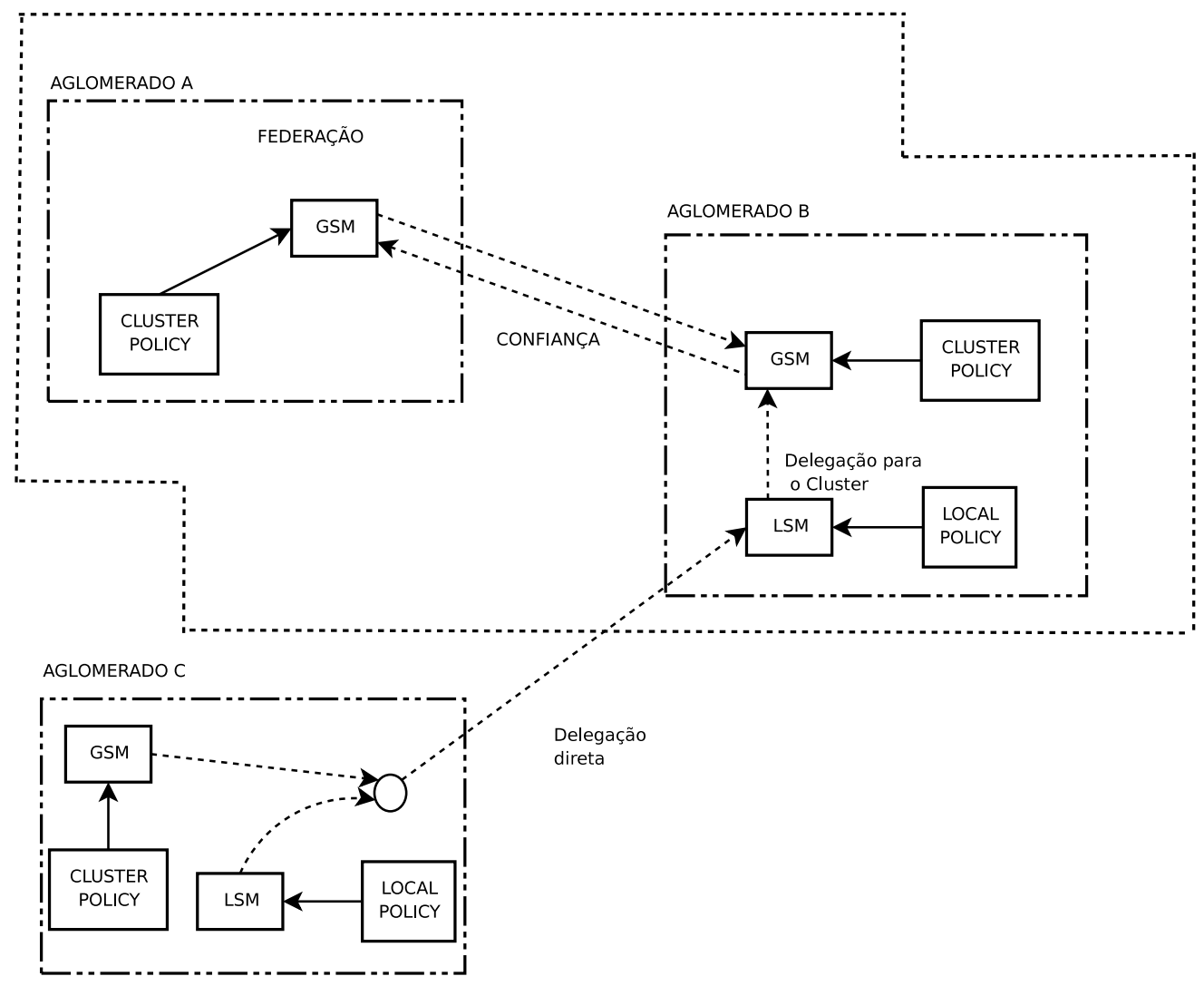

Figura 5.5: Autorizações e delegações no Xenia.

O controle de acesso aos recursos é ilustrado no diagrama de seqüencia da Figura 5.6 e segue o padrão de projeto Reference Monitor [64]. Este padrão define um processo que intercepta todas as requisições aos recursos e as avalia com suas autorizações. Como pode ser visto na figura, uma requisição é feita pelo sujeito que repassa uma cadeia de certificados de autorização e a indicação do recurso a ser acessado. O monitor de referência, SecurityMonitor, intercepta a requisição de acesso ao recurso efetuada pelo sujeito. De posse da cadeia que autoriza o acesso, o objeto Authorizations verifica se ela é válida e se a lista de controle de acesso (ACL - Access Control List) autoriza aquele acesso. A cadeia é valida se o requisitor possui uma opinião, ou uma composição de opiniões através do uso do operador CONJUNÇÃO definido na subseção 4.3.1, que permita que o acesso seja feito. 


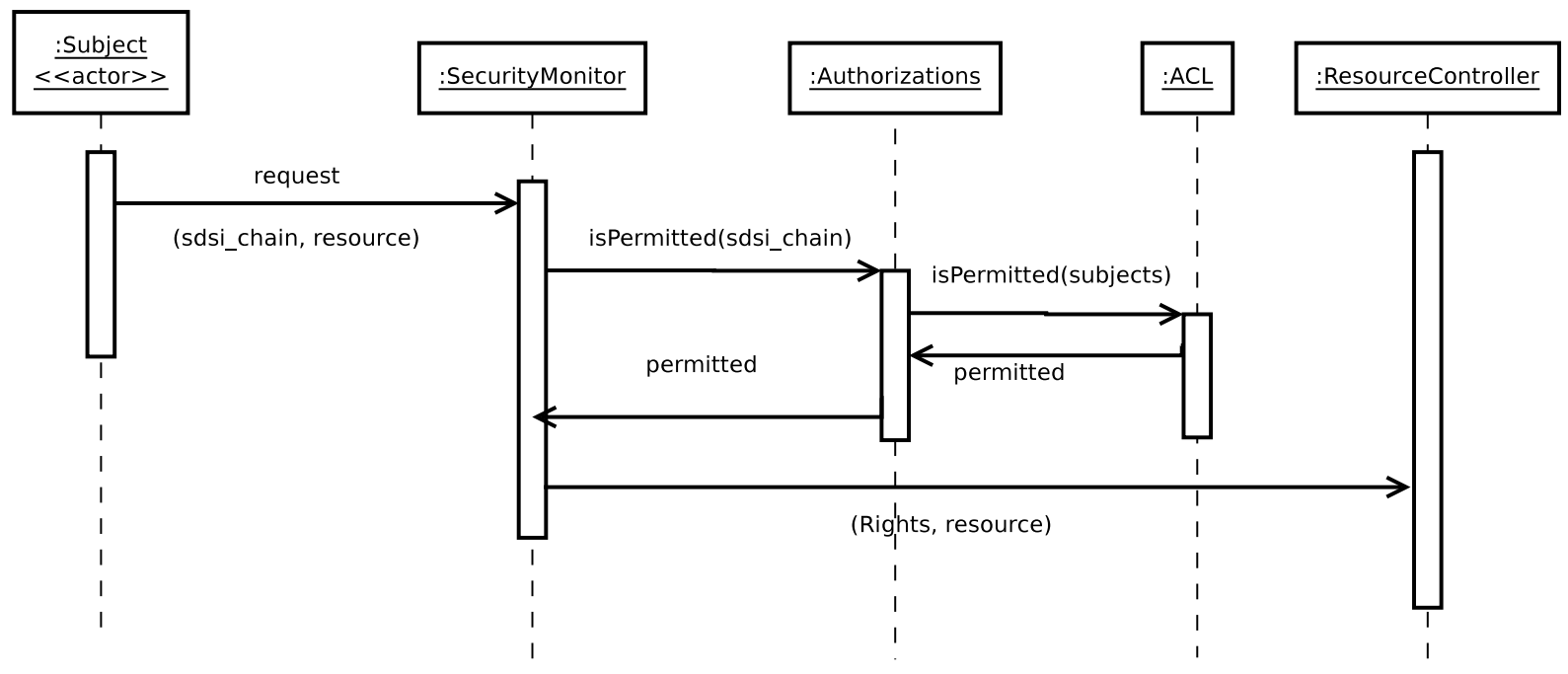

Figura 5.6: Dinâmica do controle de acesso do Xenia

Como pôde ser visto anteriormente, o controle de acesso aos recursos é reforçado através de uma lista de controle de acesso. Uma ACL tradicional, associa um usuário ou um grupo às permissões de acesso ao recurso que este possui. No caso da arquitetura do Xenia, um acesso ao recurso é associado às opiniões a respeito do usuário que acessa o recurso. A ACL do Xenia utiliza um polígono que define a faixa de opiniões às quais o acesso ao recurso está associado. A Figura 5.7 mostra uma área destacada na qual uma regra da ACL poderia ser definida, opiniões contidas neste polígono poderiam acessar um determinado recurso. O ponto $\omega_{1}$, que se encontra dentro do polígono, representa a opinião sobre um determinado usuário e este poderia ter o acesso ao recurso permitido, por outro lado, a opinião sobre um segundo usuário, definida pelo ponto $\omega_{2}$ no mesmo exemplo, poderia indicar que este não teria acesso ao recurso.

No Xenia, as opiniões entre sujeitos dispersos na grade são compostas através de caminhos de confiança entre os nós que formam uma teia de confiança. Pode-se visualizar uma teia de confiança como um grafo onde os nós da grade representam os vértices e as relações de confiança entre eles simbolizam os arcos. Um caminho de confiança é definido como uma seqüência de vértices não repetidos em que cada vértice é adjacente ao anterior. A solução usada no Xenia para compor um caminho de confiança como uma única opinião é a utilização dos operadores de Jøsang conforme apresentado nas definições 1, 2 e 3 da Seção 4.3.1. Por exemplo se A confia em B com a opinião $\omega_{C}^{A}$ e B confia em $\mathrm{C}$ com a opinião $\omega_{C}^{B}$, poderemos compor a opinião de $\mathrm{A}$ sobre $\mathrm{C}$ da seguinte maneira 
$\omega_{c}^{A}=\omega_{b}^{A} \Lambda \omega_{c}^{B}$ e assim sucessivamente.

Um problema a ser resolvido é como encontrar pelo menos um caminho de confiança em um ambiente distribuído como o de grade computacional. Mello [16] avaliou positivamente, através de simulações, que essa busca poderia ser realizada através de algoritmos de rede Par-a-Par (em inglês P2P - Peer to Peer). Ele considerou que as buscas seriam efetuadas utilizando algoritmos baseado em inundação (flooding). As buscas seriam repassadas aos vizinhos e terminaria quando o caminho fosse encontrado ou um número máximo de saltos fosse alcançado.

O Xenia resolve este problema utilizando o algoritmo de busca de recursos do InteGrade, pois encontrar uma opinião sobre um sujeito na grade tem o mesmo custo computacional de encontrar um determinado recurso. Uma busca no Xenia termina quando o caminho de confiança é encontrado ou quando a opinião resultante do caminho corrente não for suficiente para a utilização do recurso solicitado pelo sujeito. Para saber se a opinião resultante é suficiente, os nós da grade recebem uma dica do seu vizinho. Essa dica é a opinião resultante do comprimento do caminho já percorrido e a opinião necessária para utilização do recurso. Dessa forma, um nó só repassa a busca para um vizinho se este for capaz de gerar uma opinião que possa ser utilizada para uso do recurso.

\subsection{Sandboxing}

O Sandboxing é um mecanismo que permite a execução segura de programas, confinando-os a um ambiente controlado. Sua principal função é proteger um sistema computacional da execução de código malicioso e de usuários não confiáveis. Implementações deste ambiente de execução permitem o controle do uso de recursos, tais como memória, espaço em disco e uso da rede, com uma granuralidade mais fina, cedendo apenas a quantidade necessária para a execução de um determinado processo. Dentro de um ambiente como este, os aplicativos podem ser executados de forma protegida sobre a grade, minimizando os riscos de uso indevido dos recursos.

A Figura 5.8 ilustra a execução de um programa em um ambiente confinado pelo XeniaBox, o SandBox do Xenia. O RC (Resource Controller) é o elemento responsável por controlar o nível de uso que uma aplicação tem direito para cada recurso, de acordo com as suas prerrogativas. A quantidade de recursos utilizados será definida de acordo com o nível de confiabilidade do certificado SPKI apresentado. No exemplo mostrado na mesma figura, o programa A obtém a capacidade máxima de processamento disponível, o direito de ler e escrever (RW) no disco, e o acesso à rede como cliente e servidor (CS) de máquinas externas. As políticas padrão ou do usuário definirão o controle de acesso 


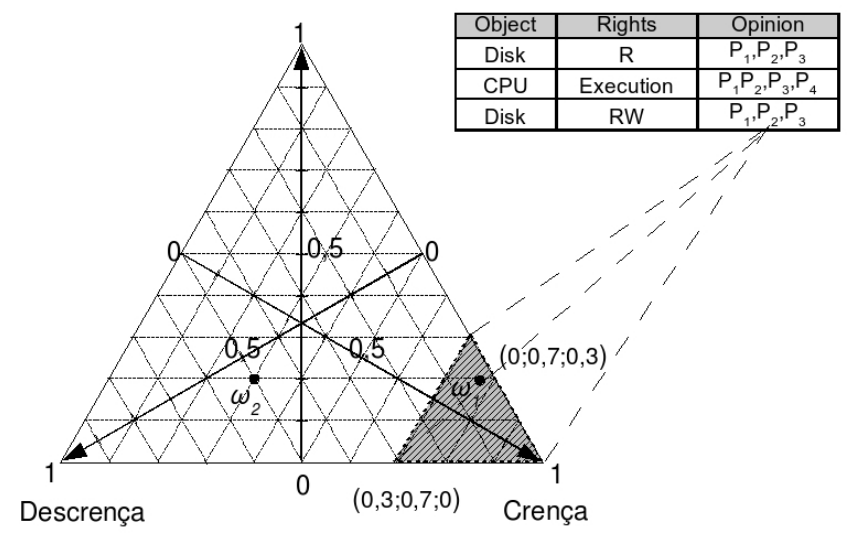

Figura 5.7: Exemplo de lista de controle de acesso no Xenia.

que deverá ser cumprido.

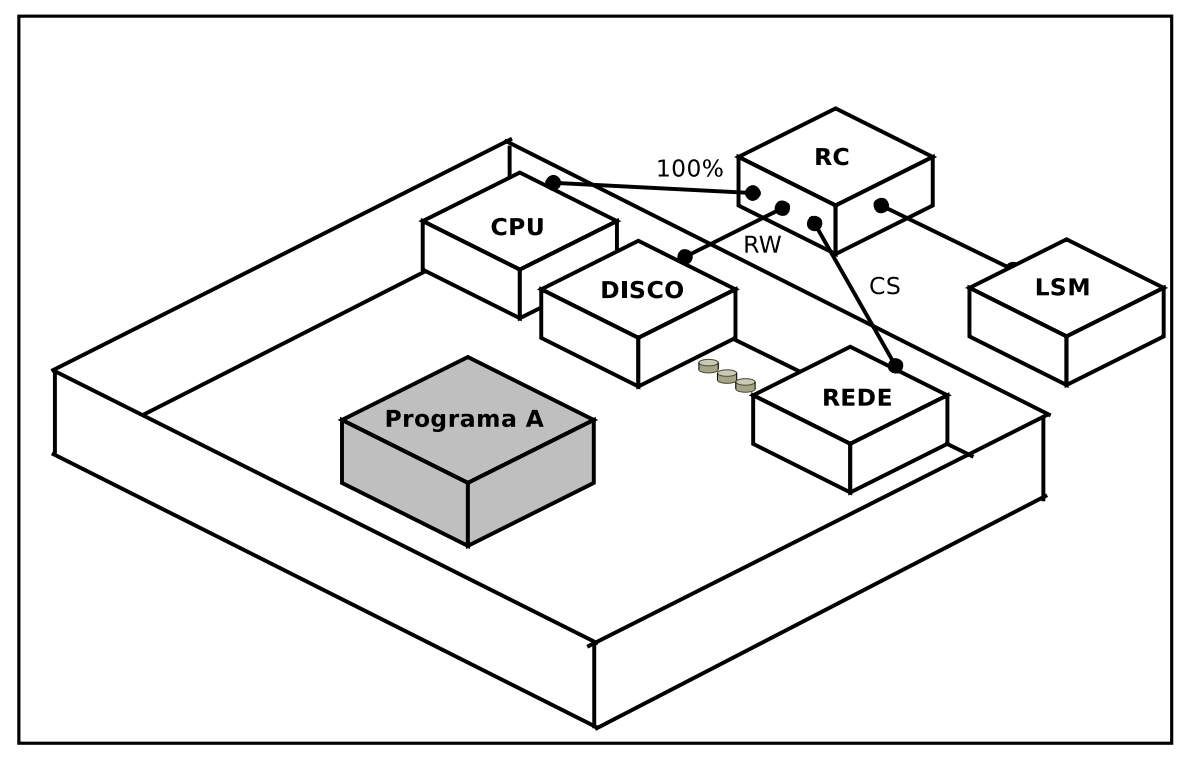

Figura 5.8: XeniaBox

O XeniaBox foi implementado utilizando-se a máquina virtual Xen [6]. O Xen é uma máquina virtual para a arquitetura Intel x86 que permite a execução de múltiplos sistemas operacionais concorrentes com bom desempenho [6] e isolamento de recursos. O Xen usa o conceito de paravirtualização, 
o que indica, entre outras coisas, que a máquina virtual repassa as instruções a serem executadas ao sistema operacional sem a necessidade de interpretação como ocorre em emuladores. O Xeniabox, no entanto é flexível e permite que outras máquina virtuais possam ser utilizadas.

O RC, de acordo com os direitos obtidos para execução de um processo, cria configurações para a execução da máquina virtual de forma dinâmica. O RC é responsável por criar e gerenciar a execução do processo, garantindo que este seja executado no ambiente confinado de uma XeniaBox. O diagrama de seqüencia mostrado na Figura 5.9 apresenta o controle da execução de processos no Xenia. O RC inicialmente, a partir dos direitos de execução recebidos, solicita uma configuração válida para ser executada na máquina virtual. O MakeConfiguration, recebe os direitos de acesso aos recursos e gera, a partir destes direitos, uma configuração válida para a máquina virtual. Com a configuração aplicada na máquina virtual, o processo é executado de forma protegida. É importante ressaltar que as classes que implementam os objetos MakeConfiguration e VirtualMachine seguem o padrão de projeto Abstract Factory, o que permite que diversas máquinas virtuais possam ser utilizadas, tais como: VMware e QEMU.

A arquitetura do Xenia, provê aos sistemas de grades computacionais um sistema de segurança flexível e extensível. Sua característica descentralizada, herdada do SPKI/SDSI, permite o gerenciamento independente dos domínios administrativos sem a necessidade que o conhecimento global da segurança seja armazenado por completo em algum ponto da grade. No próximo capítulo apresentaremos a avaliação da implementação da arquitetura do Xenia. 
68CAPÍTULO 5. XENIA: UMA ARQUITETURA DE SEGURANÇA BASEADA EM OPINIÕES

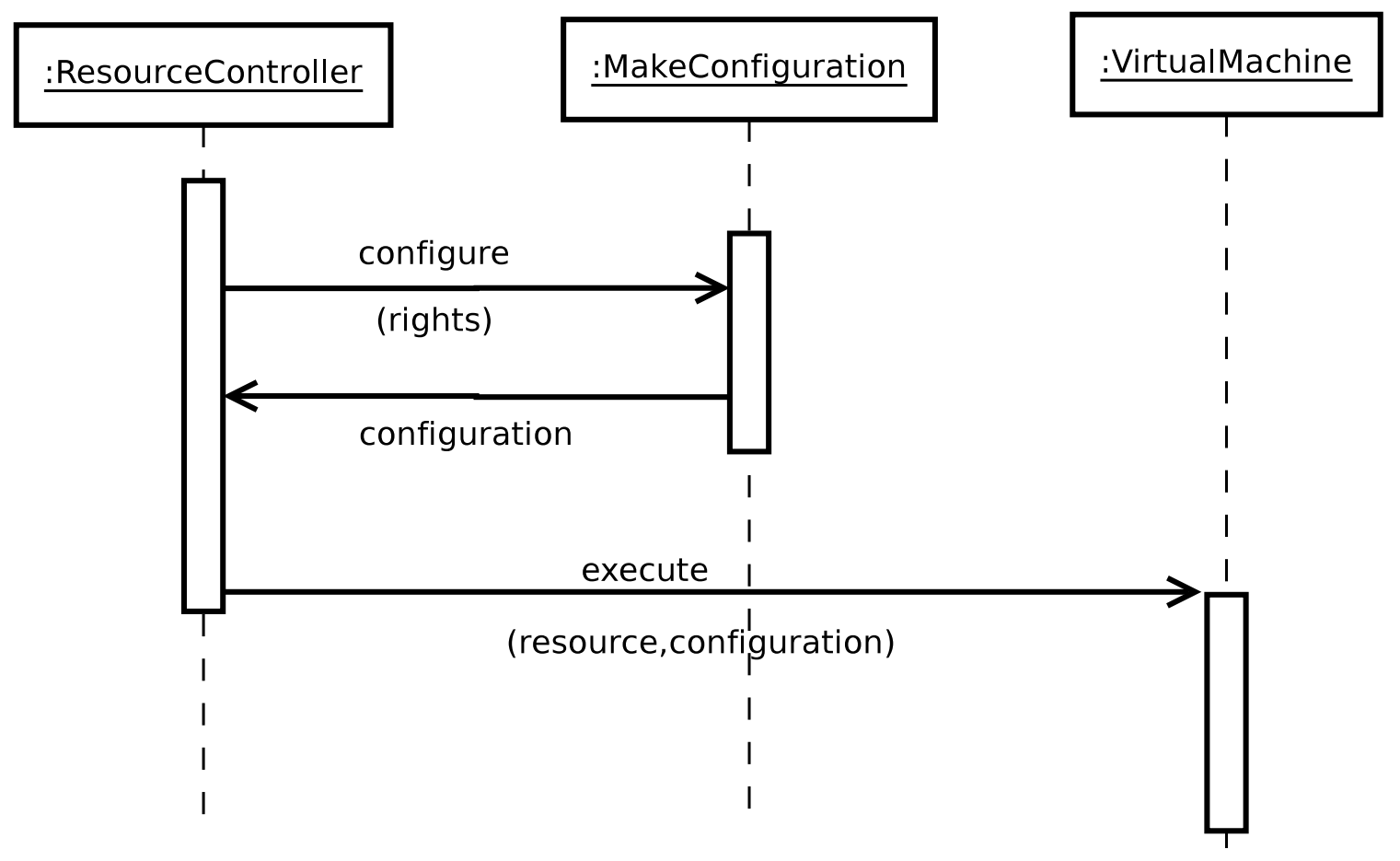

Figura 5.9: Controle de execução do XeniaBox 


\section{Capítulo 6}

\section{Avaliação do Modelo do Xenia}

Este capítulo apresenta a avaliação do modelo de segurança proposto pelo Xenia. Para executar esta avaliação utilizamos duas metodologias. A primeira metodologia é a simulação de um ambiente de grade computacional que utiliza a principal característica do Xenia, o gerenciamento de opiniões $[43,45]$. A segunda metodologia é o experimento com uma grade computacional que utiliza a arquitetura do Xenia para prover segurança. O objetivo desta avaliação é verificar o comportamento de uma rede de confiança com opiniões em um ambiente hostil e medir o desempenho para avaliar o impacto da solução proposta num ambiente de grade existente.

\subsection{Simulações}

Apresentaremos a seguir as simulações da arquitetura Xenia. Esta simulação tem como objetivo avaliar o comportamento do Xenia em um ambiente de grade computacional dinâmico e composto por centenas de nós.

\subsubsection{Inicialização}

A grade utilizada foi definida de acordo com a arquitetura do InteGrade apresentada na subseção 3.5. Para realizar a simulação, utilizou-se Java e o simulador do projeto Bamboo ${ }^{1}$ que permite comunicação usando mensagens assíncronas. O ambiente de grade simulado foi composto por 100 sujeitos que representam os gerenciadores LRM (vide Seção 3.5). Por questão de simplificação, considerou-se que cada sujeito controla apenas um recurso que pode ser acessado com ou sem restrições. O GRM ${ }^{2}$

\footnotetext{
${ }^{1}$ http: //www . bamboo-dht.org

${ }^{2} \mathrm{O}$ GRM já possui um serviço de busca de informação sobre recursos ( Trader) na sua implementação original. Este serviço foi representado na simulação.
} 
(vide Seção 3.5), por sua vez, provê o serviço usado para resolver as cadeias de delegação, ou seja, como buscar opiniões relativas aos sujeitos desconhecidos pertencentes a uma determinada cadeia. Finalmente, o módulo LUPA (vide Seção 3.5) disponibiliza informações sobre os perfis de uso dos sujeitos na grade.

A inicialização do ambiente ocorre da seguinte forma. Inicialmente, as opiniões entre os sujeitos da grade é incerta, para o modelo de opinião usado). Em seguida, os sujeitos aleatoriamente delegam seus recursos para outros sujeitos da grade. Depois disso, todos os sujeitos da grade tentam acessar recursos e, de acordo com as ações tomadas, as opiniões entre os pares de sujeitos são geradas. Estas ações são executadas considerando que alguns sujeitos presentes na grade podem ter atitudes hostis, ou seja tentam acessar recursos sobre os quais não tem direito. As opiniões foram atualizadas utilizando as operações de crédito mostradas na Tabela 6.1.1, com o peso $w$ fixado em 0.1. Finalmente, as cadeias de confiança são criadas através da redelegação dos recursos de forma aleatória, porém, em eventos independentes dos anteriores.

\begin{tabular}{lcc}
\hline \hline Ações executadas & Operação de crédito & $\mathbf{w}$ \\
\hline \hline Acesso legítimo ao recurso & Crença & 0.1 \\
Acesso legítimo ao recurso, porém fora do padrão de uso & Descrença & 0.1 \\
Acesso ilegítimo ao recurso & Descrença & 0.1 \\
\hline
\end{tabular}

Tabela 6.1: Sistemas de créditos para o modelo de opinião.

\subsubsection{Ambiente de Simulação}

No ambiente simulado, cada sujeito da grade apresenta uma cadeia de confiança, obtida no passo anterior, sempre que necessita acessar um recurso. Três níveis de opinião foram definidos para permitir o controle de acesso aos recursos. Os recursos podem ser acessados sem nenhuma restrição se o resultado da conjunção (vide Seção 4.3.2) entre as opiniões sobre cada elemento da cadeia atingir um nível de confiança considerado aceitável $\left(W_{r}(b, d, u)\right.$ onde $\left.b \geq 0.6, d \leq 0.2, u \leq 0.2\right)$. Caso a opinião sobre a cadeia esteja entre os valores $W_{b}(b, d, u)$ onde $\left.b>0.2, d \leq 0.2,0.2<u<0.6\right)$, uma restrição é feita no acesso ao recurso. Em ambos os casos anteriores, se o dono do recurso não possuir opinião sobre um outro sujeito que pertence à cadeia apresentada a ele, este poderá fazer uma busca na rede e compor uma recomendação (vide Seção 4.3.2). Finalmente, se a opinião tomada para a 
cadeia estiver fora das faixas definidas, o acesso ao recurso é negado, apesar da cadeia ser considerada válida.

O experimento foi dividido em duas partes, sendo que que em ambas existem sujeitos hostis e normais. Os sujeitos hostis executam ações impróprias e recebem opiniões negativas. Sua presença em uma cadeia pode resultar em acesso negado. Por outro lado, sujeitos normais somente executam ações corretas e recebem opinião positiva. Na primeira parte do experimento, as cadeias de confiança formam um grafo aleatório, na segunda parte formam uma topologia denominada Scale-free Network.

A Scale-free network é um tipo de grafo em que alguns vértices (denominados hubs) têm alto grau de conectividade. Em 1999, Albert Lázló Barabási e Réka Albert mapearam a conectividade de páginas $W e b$ e descobriram que ela seguia uma distribuição específica (power-law) [5]. Estas características ocorrem em outras redes como as elétricas, sociais e referências de artigos na literatura científica. Se considerarmos o crescimento potencial da computação em grade, podemos supor que este modelo é adequado para representar relações de confiança em uma grade de grande escala.

Em uma scale-free network a probabilidade que um vértice na rede esteja conectado a $k$ outros vértices segue a distribuição $P(k) \sim k^{-\gamma}$. Uma scale-free network pode ser construída através da adição de nós para uma rede existente. Ligações são introduzidas para nós já existentes com a probabilidade $\prod\left(k_{i}\right)=k_{i} / \sum_{j} k_{j}$, onde $k_{i}$ é a conectividade do vértice $i$. Nós usamos o seguinte algoritmo de Albert e Barabási para gerar uma scale-free network:

1. Inicie com um grafo completo com um pequeno número de nós $\left(m_{0}\right)$.

2. A cada passo adicione um novo nó com grau $m<m_{0}$. A probabilidade de ligação do nó será $\prod\left(k_{i}\right)=k_{i} / \sum_{j} k_{j}$.

A simulação foi repetida 30 vezes. Como cada simulação é independente e dura cerca de 1 hora, ela foi executada em paralelo em uma grade InteGrade. Nossa simulação usou como parâmetros de rede o conjunto de dados gerados pelo modelo King [37] que é largamente usado em simulações e representa um ambiente real de rede. Este conjunto de dados é formado pela matriz que representa a latência entre máquinas de uma rede extraída de medidas reais de 2048 servidores DNS. Nossa simulação colheu aleatoriamente amostras da latências de rede do conjunto de dados do modelo King e as usou como parâmetro.

Nós medimos a relação entre o número de cadeias aceitas e rejeitadas e a porcentagem de elementos 
hostis na grade. O objetivo destas medidas foi verificar se a proposta da extensão do SPKI/SDSI possui o comportamento desejado em um ambiente de grade. Durante a simulação, nós consideramos o comportamento da proposta nas topologias aleatórias e scale-free network.

\subsubsection{Resultados Obtidos}

A Figura 6.1(a) mostra a curva que representa a porcentagem de cadeias aceitas em relação à porcentagem de sujeitos não confiáveis na grade. As barras verticais em cada ponto da figura representam o desvio padrão dos valores obtidos. Como visto na figura, assim como esperado, há decréscimo no número de cadeias com o aumento de sujeitos não confiáveis na grade. Contudo, a topologia scale-free decai com uma taxa menor. Nós verificamos que a presença de hubs confiáveis na topologia scale-free melhora a opinião de todas as cadeias delegadas que os contém.

A Figura 6.1(b) mostra a curva que representa a média aritmética do comprimento válido de uma cadeia. Um comprimento válido de uma cadeia foi definido como o comprimento do maior fragmento da cadeia que possui uma opinião válida. Uma opinião válida é aquela que permite o acesso ao recurso com ou sem restrições como definido anteriormente. Por exemplo, a cadeia $A \rightarrow B \rightarrow C \rightarrow D$ tem o comprimento válido igual a 2 se a conjunção $\omega_{b \wedge c}^{A}\left(b_{b \wedge c}, d_{b \wedge c}, u_{b \wedge c}\right)$ tem $b_{b \wedge c}=0.6, d_{b \wedge c}=0.2, u_{b \wedge c}=0.2$ e $\omega_{d}^{A}\left(b_{d}, d_{d}, u_{d}\right)$ tem $b_{d}<0.6$. Como pode ser visto na mesma figura, o comprimento decai com o acréscimo de sujeitos não confiáveis na grade. Com a diminuição do comprimento válido das cadeias, foi percebido que os nós formaram agrupamentos virtuais de sujeitos mutuamente confiáveis.

Uma outra informação analisada foi a caminhada segura na rede de confiança composta por todas as cadeias de uma grade em um determinado instante. Nós consideramos que uma rede de confiança pode ser representada como um grafo cujos vértices são sujeitos, as arestas orientadas representam delegações e as opiniões, como definido neste trabalho, são os pesos das arestas. Uma caminhada segura pode ser definida como uma caminhada em um grafo que representa uma rede de confiança onde a conjunção dos pesos das arestas resulte numa opinião válida.

A Figura 6.2 mostra caminhadas seguras nas cadeias de confiança de uma grade. Para simplificar a apresentação, a simulação apresentada na figura possui somente 10 nós e representa uma topologia scale-free. Os rótulos das arestas representam as delegações entre os sujeitos. Por exemplo, $10 \rightarrow 3$ significa que o Recurso 10 foi delegado para o Sujeito 3. Uma aresta impressa com linhas pontilhadas indica um caminho inseguro; em outras palavras, a opinião resultante alcançou valores baixos. $\mathrm{Na}$ 


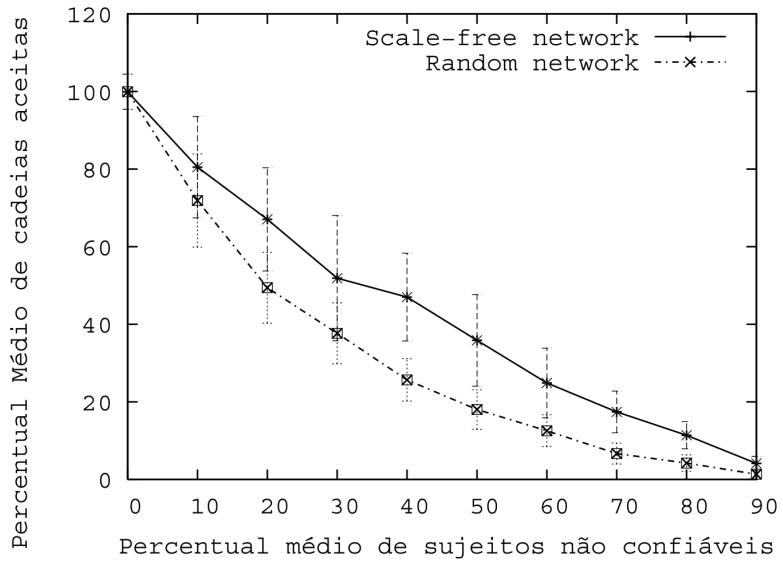

(a) Comprimento da cadeia segura

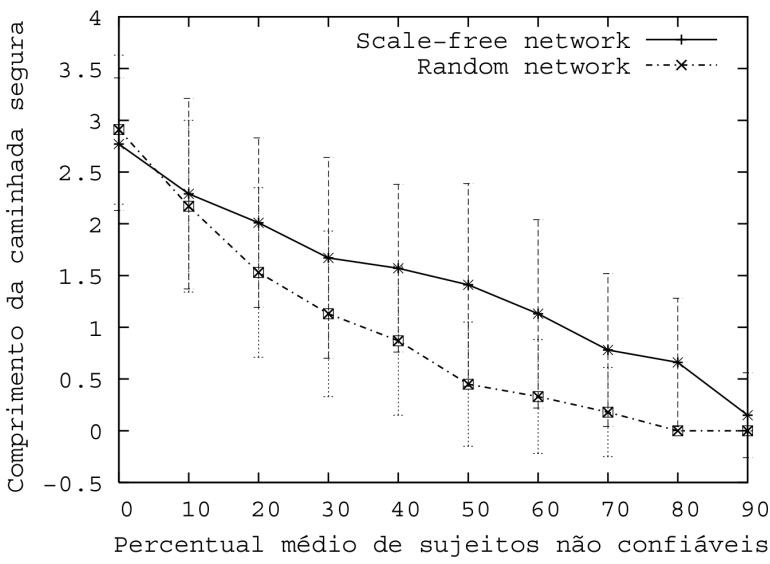

(b) Caminhada segura na rede

Figura 6.1: Resultados das simulações

figura podemos ver que a cadeia de confiança $(3 \rightarrow 2 \rightarrow 5)$, destacada em negrito, indica que o recurso delegado pelo o Sujeito 3 pode ser usado pelo Sujeito 2, mas a conjunção das opiniões que inclui o Sujeito 5 nega o acesso para ele.

Sujeitos não confiáveis na Figura 6.2 estão representados como losango. Nós podemos notar que estes sujeitos ficaram isolados na grade pois não há delegação válida chegando até eles. Isto ocorre por que suas reputações foram propagadas na rede. Em um ambiente de grade computacional esta situação é interessante pois ele conecta sujeitos de diferente domínios administrativos. Se há um sujeito malicioso na grade, o sistema reage e o isola.

A extensão apresentada nesta tese permite que o SPKI/SDSI seja usado em ambientes de grande escala com os benefícios aqui discutidos. A extensão agrega ao mecanismo de segurança características que permitem a definição de ferramentas e arquiteturas de segurança flexíveis.

\subsection{Experimentos}

A avaliação do Xenia foi realizada num ambiente real de uma Grade Oportunista composta por três aglomerados geograficamente dispersos e conectados pela Internet. Estes aglomerados foram distribuídos como segue: três aglomerados em São Paulo (spo1 e spo2) e um em São Luis (slz). A latência das redes que conectam os aglomerados de São Paulo aos de São Luis é de cerca de 60 ms 


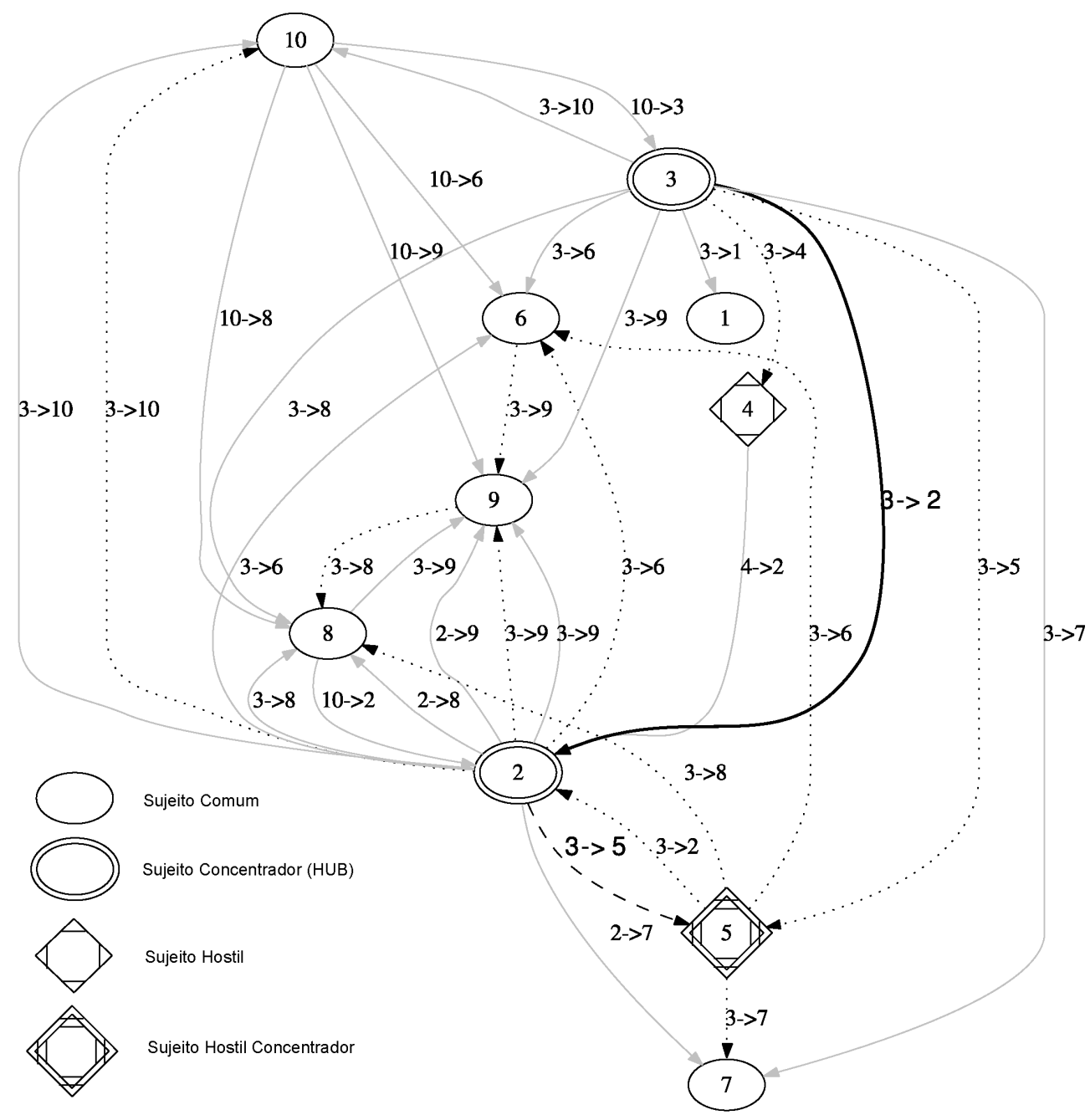

Figura 6.2: Caminhada segura pelas cadeias

em média.

A Figura 6.3 mostra a topologia de conexão entre os aglomerados. Em cada aglomerado existe um conjunto de computadores que compartilham o mesmo domínio de segurança, gerenciado pelo nó GSM (vide Seção 3.5) representado por um octógono na figura. Os nós GSM são interligados entre si através de rede, sendo local para os aglomerados SPO1 e SPO2 e remota para o aglomerado SLZ através de um link de 36 Mbps com a Internet. O aglomerado SPO1 é formado por seis máquinas 
homogêneas não dedicadas com CPUs AMD Atlhon XP 2800+ e memória de 1GB, estes equipamentos são interligados em uma rede local a velocidade de 100Mbps. O aglomerado SPO2 é formado por um cluster dedicado de 8 computadores com 2 CPUs Intel Pentium 4 com frequência de 3 GHZ, memória de $1 \mathrm{~GB}$ cada e rede de interligação dedicada de $1 \mathrm{Gbps}$.

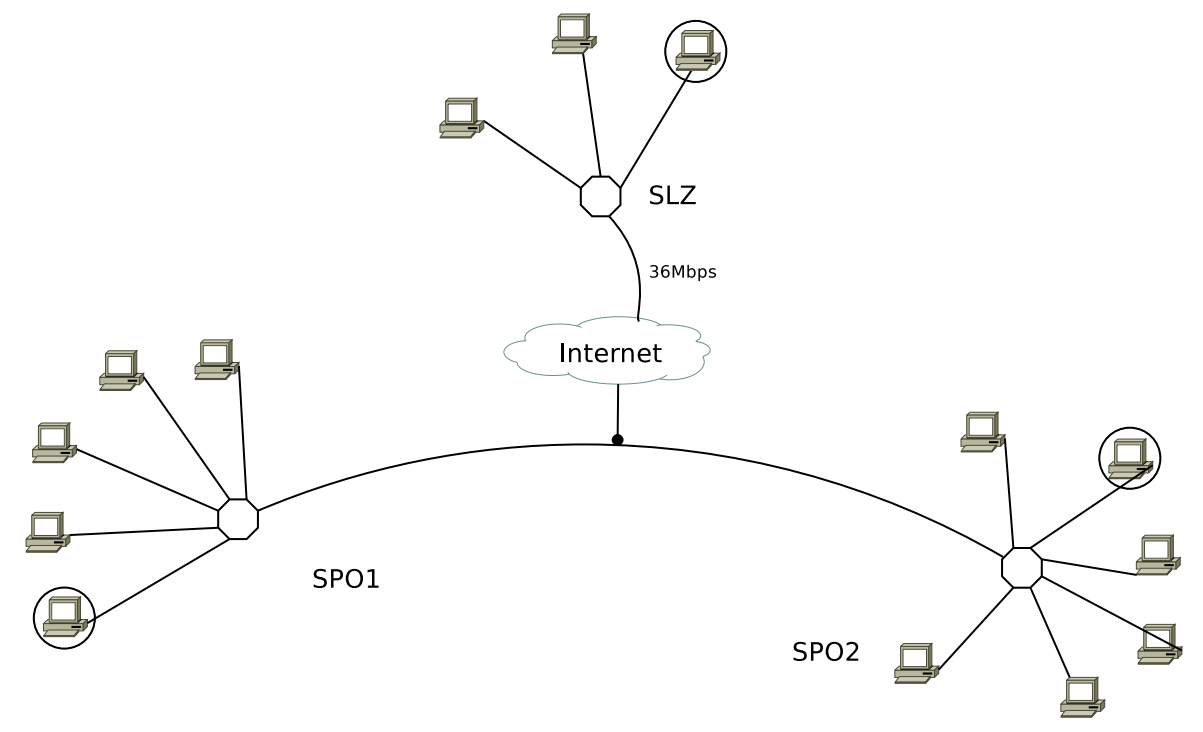

Figura 6.3: Topologia para os experimentos que medem a performance do Xenia

Os experimentos foram executados em dois cenários. No primeiro cenário, tivemos como objetivo verificar se, assim como na simulação, sujeitos maliciosos que tentam obter privilégios indevidos ficam isolados na grade. No segundo cenário, medimos o acréscimo no tempo de execução das tarefas submetidas à grade introduzido pelos protocolos de segurança do Xenia.

\subsubsection{Cenário 1: Usuários Maliciosos na Grade}

Este experimento foi implementado de tal forma que em três nós da grade, um em cada aglomerado, máquinas foram programadas para executar ações indevidas na solicitação de recursos. A Figura 6.3, apresentada anteriormente, ilustra com o destaque de um circulo, os nós maliciosos em cada um dos aglomerados. Na grade Integrade, os recursos são solicitados durante a submissão da execução dos programas através de restrições impostas pelos usuários através de uma linguagem de consulta específica (TCL - Trader Constraint Language) [34]. Uma das ações indevidas dos nós maliciosos era selecionar recursos que não lhes era permitido, aumentando assim a desconfiança dos nós 
sobre a sua credibilidade. De outra forma, estes mesmos nós geravam cadeias inválidas e submetiam aos outros nós da grade que negava o acesso a seus recursos, evidentemente, e ainda imputavam um decréscimo em sua confiança. De acordo com o esperado, o experimento ratificou a simulação apresentada na Seção 6.1 uma vez que os nós maliciosos obtiveram opiniões negativas de todos os nós da grade, negando a tentativa de acesso aos recursos diretamente ou através de cadeias de confiança de que participavam.

\subsubsection{Cenário 2: Medida de Desempenho}

Um sistema de segurança introduz através dos seus protocolos uma sobrecarga no tempo de execução dos programas por eles protegidos. Os algoritmos de criptografia, em geral, demandam algum tempo para serem executados, aumentando o tempo durante a comunicação, os acessos a dados e a recuperação de informações. Este custo, porém, é o preço pago por ter um sistema mais seguro. O experimento aqui descrito tem como objetivo avaliar qual é o custo computacional introduzido nos sistemas de grade quando da utilização do Xenia.

Para medida de performance do Xenia, utilizamos um programa exemplo contido no código fonte do InteGrade. O programa executa uma multiplicação sistólica de duas matrizes [3]. Este programa recebe como parâmetro de entrada $N$, o número de processadores que executarão a tarefa, $O$ a ordem de uma matriz quadrada que seja divisível pelo raiz quadrada do número de processadores e, finalmente, $M$ o número de multiplicações sistólicas consecutivas que serão realizadas. Fixamos os valores dos dois primeiros parâmetros em $N=9$ e $O=9810$ e variamos o número de multiplicações consecutivas de 1 a 6 .

O gráfico apresentado na Figura 6.4 mostra o acréscimo no tempo de execução do programa de multiplicação sistólica em relação ao tamanho da matriz. Cada ponto representa a média aritmética de 8 repetições do experimento. A linha tracejada representa o tempo de execução do programa na grade sem a proteção do Xenia, enquanto a linha contínua representa o tempo de execução considerando o uso do Xenia. Como podemos notar, o tempo de execução aumentou no mínimo $30 \%$ e ocorreu de forma aproximadamente linear com a quantidade de multiplicações. O desvio padrão não foi muito baixo, pois a grade era formada por máquinas heterogêneas e em determinadas situações, o escalonador selecionava máquinas mais lentas.

O Xenia, assim como todo sistema de segurança, insere um custo nos sistemas de Grade Computacional. Este custo possui valores aceitáveis e compatíveis com os sistemas de segurança existentes. 


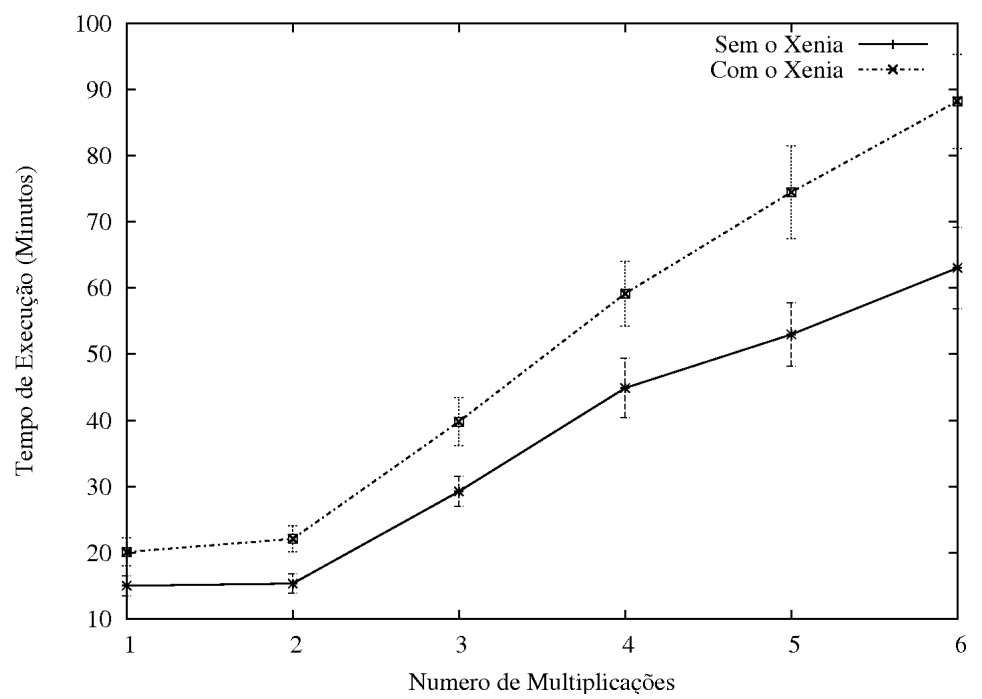

Figura 6.4: Tempo de execução versus Numero de Multiplicações

Os resultados aqui apresentados, de simulações e experimetos realizados indicam que o Xenia é uma arquitetura de segurança adequada para Grades computacionais e adiciona uma sobrecarga moderada nos sistemas que protege. 


\section{Capítulo 7}

\section{Considerações Finais}

O principal objetivo deste trabalho foi investigar o uso de arquiteturas de segurança descentralizadas baseadas em cadeias de confiança em sistemas de grades computacionais.

Nesta tese estendemos o modelo SPKI/SDSI para introduzir um conceito novo ao modelo inicial: a subjetividade. Com este conceito é possível atribuir valores contínuos (não boleanos) para representar a confiança que sujeitos podem ter sobre outros. A partir dessa característica é possível representar mais adequadamente a forma com que humanos se relacionam, valorando suas relações de confiança de acordo com informações históricas. Esta extensão foi usada como base para a implementação de uma arquitetura de segurança para grades computacionais denominada Xenia.

As características da arquitetura do Xenia, flexibilidade e descentralização, permitem que esta seja usada em ambientes heterogêneos e dispersos sobre uma rede de grande abrangência. A utilização das cadeias de confiança, sobretudo com a proposta de extensão ao modelo SPKI/SDSI, permite uma granularidade maior na definição de políticas de segurança em ambientes de grade. O sistema de SandBoxing, que adequa o controle do uso de recursos à flexibilidade permitida por esta granularidade fina, minimiza a vulnerabilidade ocorrida na execução de códigos maliciosos. Todas as características anteriormente descritas permitem que a arquitetura de segurança seja adequada ao uso de Grades Computacionais suprindo assim os seus principais requisitos.

De acordo com os resultados obtidos na simulação e na avaliação da arquitetura, a extensão do modelo SPKI/SDSI se mostrou adequada ao comportamento de um ambiente dinâmico como o de Grades Computacionais. 


\subsection{Publicações durante o doutorado}

No decorrer do nosso trabalho muitos caminhos foram trilhados até que este fosse considerado uma proposta madura e, a cada passo dado, publicações demostraram os resultados que obtivemos com as nossas pesquisas. Inicialmente, levantamos os principais aspectos relativos à segurança em Grades Computacionais e as implementações nos principais sistemas de grade existentes [46]. Uma implementação inicial de um repositório seguro baseado na API GSS foi realizada com o objetivo de avaliar os problemas mais comuns que poderiam surgir na implementação de soluções de segurança para Grades Computacionais [44]. Através de estudos de diversos mecanismos de segurança, apontamos aquele que possuía as características mais atrativas para implementação de uma arquitetura de segurança em ambiente distribuído: cadeias de confiança. Para esse mecanismo, propomos a utilização de lógica subjetiva para representar opiniões não booleanas entres os pares de uma grade e uma extensão ao modelo de cadeias de confiança SPKI/SDSI que contempla esta idéia. Para consolidar a extensão proposta, simulações foram executadas em vários contextos e apontaram resultados satisfatórios [43,45]. Finalmente, uma arquitetura de segurança para Grades Computacionais denominada Xenia foi então implementada e avaliada. Os esforços desprendidos resultaram nas publicações citadas nesse parágrafo.

\subsection{Contribuições do Trabalho}

Com o desenvolvimento desta tese esperamos contribuir para o estudo da segurança em grades computacionais. Neste contexto, a nossa proposta permite que sujeitos em uma grade computacional possam obter, com granularidade mais fina, opiniões a respeito daqueles com os quais interage. Além disso, aplicações para grades computacionais podem usufruir de um ambiente mais seguro para execução. A nossa contribuição para o estudo das grades computacionais pode ser vista sob dois aspectos: tecnológico e científico.

\subsubsection{Sob o ponto de vista tecnológico}

Desenvolvimento de um repositório seguro - Desenvolvemos para o InteGrade um repositório que permite a autenticação, confidencialidade e integridade as aplicações submetidas e armazenadas na grade.

Extensão da biblioteca SPKI/SDSI - Utilizamos os conceitos propostos sobre opiniões em cadeias de confiança para estender, modificar e corrigir a biblioteca desenvolvida pelo MIT. Entre 
as modificações, aumentamos o suporte da biblioteca acrescentando dois formatos de chaves públicas a implementação original: SSHv2 e X509.

Implementação Xenia - O uso do subsistema Xenia não se resume ao InteGrade. O Xenia foi desenvolvido para ser usado em qualquer grade computacional ou sistema que possua características descentralizadas.

\subsubsection{Sob o ponto de vista científico}

Levantamento dos requisitos de segurança - Neste trabalho sintetizamos em uma publicação as principais questões sobre segurança em grades computacionais na nossa língua permitindo que esta fosse uma boa referência sobre o tema.

Extensão do modelo SPKI/SDSI - Propusemos o uso do conceito de lógica subjetiva no modelo de segurança SPKI/SDSI permitindo que as relações de confiança entre sujeitos se dê através de relações não boleanos o que é uma abordagem diferente ao tratar cadeias de confiança.

Definição de uma arquitetura de segurança flexível e distribuída - Propusemos o uso do modelo do SPKI/SDSI estendido em uma arquitetura de grades computacional. Desenvolvemos então uma arquitetura baseada nesta extensão que herda a flexibilidade e a natureza distribuída do modelo SPKI/SDSI.

Análise por Simulação do modelo proposto - Simulamos a dinâmica de um sistema de grades computacionais onde os conceitos propostos nesta tese pudessem ser verificados. O resultado positivo da análise dessa simulação mostrou que o modelo é apropriado para o uso em grades computacionais.

Avaliação experimental do Xenia - Realizamos experimentos com a arquitetura Xenia numa grade oportunista composta por aglomerados distribuídos geograficamente e interligados pela Internet. Mostramos com estes experimentos a viabilidade da arquitetura proposta para o uso em grades computacionais.

\subsection{Trabalhos futuros}

A implementação do Xenia utiliza o SPKI/SDSI 2.0 do MIT que foi desenvolvido para sistemas baseados em UNIX. Seria interessante desenvolver uma versão que permitisse o uso da arquitetura 
para sistemas baseados no sistema operacional Windows ou baseado na linguagem Java. Estas novas implementações permitiriam uma portabilidade maior para a arquitetura.

Poderíamos aprimorar a arquitetura estendendo seu mecanismo de busca para utilizar outros algoritmos, como os de redes P2P. Nesse tipo de topologia, seria possível adequar a solução proposta pelo Xenia em outros sistemas já existentes. Simulações podem ser usadas para analisar o uso destas tecnologias de rede.

O mecanismo do gerador de opinião implementado no Xenia é simples e baseado num sistema de créditos associado a eventos de segurança. Uma melhoria desejável seria prover inteligência a este mecanismo utilizando técnicas avançadas de reconhecimentos de padrão e inteligência artificial. Esse novo motor do gerador de opinião, permitiria, provavelmente, resultados melhores na obtenção de opiniões entre os sujeitos de uma grade computacional que utilize a arquitetura do Xenia.

O limiar quando dois nós tem a sua relação de confiança quebrada também deve ser objeto de estudos futuros. Nesse contexto, devemos investigar modelos que permitam dizer, com alguma precisão, quando dois nós deixam de confiar entre si quando representamos esta relação utlizando o modelo de Jøsang.

Finalmente, consideramos relevante a realização de experimentos de grande escala em uma grade com dezenas de aglomerados e milhares de nósdm. Tal experimento serviria para avaliarmos o comportamento do Xenia neste tipo de ambiente e, se for o caso, aprimorarmos seus mecanismos. 


\section{Referências Bibliográficas}

[1] OpenSSL Project, http://www.openssh.org/, 2008.

[2] C. Adams and S. Farrell, Internet X. 509 Public Key Infrastructure Certificate Management Protocols, Internet RFC \#2510, 1999.

[3] C. E. R. Alves, E. N. Cáceres, F. Dehne, and S. W. Song, A Parallel Wavefront Algorithm for Efficient Biological Sequence Comparison., The 2003 International Conference on Computational Science and its Applications - ICCSA 2003.Lecture Notes in Computer Science (Venice, Italy), September 2003, pp. 126-133.

[4] Nazareno Andrade, Walfredo Cirne, Francisco Brasileiro, and Paulo Roisenberg, OurGrid: An Approach to Easily Assemble Grids with Equitable Resource Sharing, Proceedings of the 9th Workshop on Job Scheduling Strategies for Parallel Processing, Springer Verlag, June 2003, Lect. Notes Comput. Sci. vol. 2862, pp. 61-86.

[5] A. L. Barabasi and R. Albert, Emergence of scaling in random networks, Science 286 (1999), no. 5439, 509-512.

[6] Paul Barham, Boris Dragovic, Keir Fraser, Steven Hand, Tim Harris, Alex Ho, Rolf Neugebauer, Ian Pratt, and Andrew Warfield, Xen and the art of virtualization, SOSP '03: Proceedings of the nineteenth ACM symposium on Operating systems principles (New York, NY, USA), ACM Press, 2003, pp. 164-177.

[7] Elizabeth Belfiore, Xenia in Sophocles' Philoctetes, The Classical Journal 89 (1993), no. 2, $113-119$.

[8] Fran Berman, Geoffrey Fox, Anthony J. G. Hey, and Tony Hey, Grid Computing: Making the Global Infrastructure a Reality, John Wiley \& Sons, Inc., 2003.

[9] David Booth, Hugo Haas, Francis McCabe, Eric Newcomer, Michael Champion, Chris Ferris, and David Orchard, Web Services Architecture, World Wide Web Consortium, February 2004.

[10] Walfredo Cirne, Daniel Paranhos, Lauro Costa, Elizeu Santos-Neto, Francisco Brasileiro, Jacques Sauvé, Fabrício A. B. Silva, Carla O. Barros, and Cirano Silveira, Running Bag-of-Tasks 
Applications on Computational Grids: The MyGrid Approach, Proceedings of the 2003 International Conference on Parallel Processing, October 2003, pp. 407-416.

[11] Dwaine Clarke, Jean-Emile Elien, Carl Ellison, Matt Fredette, Alexander Morcos, and Ronald L. Rivest, Certificate chain discovery in SPKI/SDSI, Journal of Compututer Security 9 (2001), no. 4, 285-322.

[12] F. Cohen, Computer viruses: theory and experiments, Computers and Security 6 (1987), no. 1, $22-35$.

[13] Raphael Y. de Camargo, Andrei Goldchleger, Marcio Carneiro, and Fabio Kon, Pattern languages of program design 5 (PloPD5), ch. The Grid Architectural Pattern: Leveraging Distributed Processing Capabilities, pp. 337-356, Addison Wesley Publishing Company, 2006.

[14] Raphael Y. de Camargo and Fabio Kon, Distributed Data Storage for Opportunistic Grids, Middleware Doctoral Symposium (MDS 2006) (Melbourne, Australia), November 2006.

[15] _ Design and implementation of a middleware for data storage in opportunistic grids, CCGRID '07: Proceedings of the Seventh IEEE International Symposium on Cluster Computing and the Grid (Washington, DC, USA), IEEE Computer Society, 2007, pp. 23-30.

[16] Emerson Ribeiro de Mello, Aad P. A. van Moorsel, and Joni da Silva Fraga, Evaluation of $p 2 p$ search algorithms for discovering trust paths, EPEW (Katinka Wolter, ed.), Lecture Notes in Computer Science, vol. 4748, Springer, 2007, pp. 112-124.

[17] A. Detsch, L. P. Gaspary, M. P. Barcellos, and G. G. H. Cavalheiro, Towards a flexible security framework for peer-to-peer based grid computing, Proceedings of the 2nd workshop on Middleware for grid computing (New York, NY, USA), ACM Press, 2004, pp. 52-56.

[18] T. Dierks and C. Allen, RFC 2246: The TLS protocol version 1, IETF RFC Publication, January 1999, Status: PROPOSED STANDARD.

[19] Whitfield Diffie and Martin E. Hellman, New directions in cryptography, IEEE Transactions on Information Theory IT-22 (1976), no. 6, 644-654.

[20] C. Ellison, B. Frantz, B. Lampson, R. Rivest, B. Thomas, Southwestern Bell, and T. Ylonen, SPKI Certificate Theory, Internet RFC \#2693, 1999.

[21] Ralf S. Engelschall, OpenSSL Project, http://www.openssl.org/, 2008.

[22] D.H.J. Epema, M. Livny, R. van Dantzig, X. Evers, and J. Pruyne, A worldwide flock of Condors: Load sharing among workstation clusters, Future Generation Computer Systems 12 (1996), 5365 . 
[23] I. Foster, C. Kesselman, J. Nick, and S. Tuecke, The Physiology of the Grid: An Open Grid Services Architecture for Distributed Systems Integration, June 2002, Global Grid Forum, Open Grid Service Infrastructure Working Group.

[24] Ian Foster and K. Czajkowski, Modeling and managing state in distributed systems: the role of OGSI and WSRF, Proceedings of the IEEE, vol. 93, March 2005, pp. 604-612.

[25] Ian Foster and Carl Kesselman, Globus: A Metacomputing Infrastructure Toolkit, International Journal of Supercomputer Applications 2 (1997), no. 11, 115-128.

[26] _ The Grid 2: Blueprint for a New Computing Infrastructure, Morgan Kaufmann Publishers Inc., 2003.

[27] Ian Foster, Carl Kesselman, Gene Tsudik, and Steven Tuecke, A Security Architecture for Computational Grids, Proceedings of the 5th ACM Conference on Computer and Communications Security, 1998, pp. 83-92.

[28] Ian Foster, Carl Kesselman, and Steven Tuecke, The Anatomy of the Grid: Enabling Scalable Virtual Organizations, The International Journal of Supercomputer Applications 15 (2001), no. 3, 200-222.

[29] Matthew H. Fredette, An implementation of sdsi - the simple distributed security infrastruture., Master thesis, Department of Electrical Engineering and Computer/MIT, May 1997.

[30] James Frey, Todd Tannenbaum, Ian Foster, Miron Livny, and Steve Tuecke, Condor-G: A computation management agent for multi-institutional grids, Cluster Computing 5 (2002), 237246.

[31] Simson Garfinkel and Gene Spafford, Practical UNIX 83 Internet Security, O Reilly \& Associates, Inc., 1996.

[32] Luciano Paschoal Gaspary, Marinho P. Barcellos, André Detsch, and Rodolfo S. Antunes, Flexible security in peer-to-peer applications: Enabling new opportunities beyond file sharing, Comput. Netw. 51 (2007), no. 17, 4797-4815.

[33] Globus, http://www. globus.org, 2004.

[34] Andrei Goldchleger, Integrade: Um sistema de middleware para computação em grade oportunista, Dissertação de mestrado, IME/USP, December 2004.

[35] Andrei Goldchleger, Fabio Kon, Alfredo Goldman, Marcelo Finger, and Germano Capistrano Bezerra, InteGrade: Object-Oriented Grid Middleware Leveraging Idle Computing Power of Desktop Machines, Concurrency and Computation: Practice and Experience 16 (2004), no. 5, 449-459. 
[36] Simson Grafinkel and Gene Spafford, Practical UNIX and Internet Security, O'Reilly \& Associates, Inc, 1996.

[37] Krishna P. Gummadi, Stefan Saroiu, and Steven D. Gribble, King: Estimating Latency Between Arbitrary Internet End Hosts, Proc. of the Second ACM SIGCOMM Workshop on Internet measurment (New York, NY, USA), 2002, pp. 5-18.

[38] P. Hallam-Baker and S. H. Mysore, Xml key management specification (xkms 2.0), W3C - Proposed Recommendation, May 2005.

[39] Joseph Y. Halpern and Ron Van der Meyden, A logical reconstruction of SPKI, CSFW '01: Proceedings of the 14th IEEE Workshop on Computer Security Foundations (Washington, DC, USA), IEEE Computer Society, 2001, pp. 59-70.

[40] Von Welch Ian, Globus toolkit version 4 grid security infraestruture: A standards perspective, www-unix.globus.org/toolkit/docs/4.0/security/GT4-GSI-Overview.pdf, Aug 2005.

[41] Audun Jøsang, Artificial reasoning with subjective logic, Second Australian Workshop on Commonsense Reasoning (Perth, Australia), 1997.

[42] _ An algebra for assessing trust in certification chains, Network and Distributed Systems Security Symposium (NDSS 99) (San Diego, USA), The Internet Society, 1999.

[43] Jose de Ribamar Braga Pinheiro Júnior and Fabio Kon, Representando opiniões em cadeias de confiança SPKI/SDSI, Simpósio Brasileiro de Segurança da Informação e de Sistemas Computacionais (Santos), SBC, September 2006.

[44] Jose de Ribamar Braga Pinheiro Júnior, Alexandre Cesar Tavares Vidal, and Fabio Kon, Repositório seguro de aplicações baseado em GSS (artigo curto), Simpósio Brasileiro de Segurança da Informação e de Sistemas Computacionais (Florianópolis), SBC, Setembro 2005.

[45] Jose de Ribamar Braga Pinheiro Júnior, Alexandre Cesar Tavares Vidal, Fabio Kon, and Marcelo Finger, Trust in large-scale computational grids: An SPKI/SDSI extension for representing opinion, 4th International Workshop on Middleware for Grid Computing - MGC 2006 (Melbourne, Australia), ACM/IFIP/USENIX, November 2006.

[46] José De Ribamar Braga Pinheiro Júnior and Fabio Kon, Minicurso de segurança em grades computacionais, pp. 66-111, Simpósio Brasileiro de Segurança de Informação e de Sistemas Computacionais - (SBSEG), Setembro 2005.

[47] J. Kabat and M. Upadhyay, RFC2853: Generic Security Service API Version 2: Java Bindings, Internet RFCs (2000).

[48] J. Kohl and C. Neuman, The Kerberos network authentication service (v5), Internet RFC \#1510, September 1993. 
[49] Phillip E. Krueger, Distributed scheduling for a changing environment, Ph.D. thesis, University of Wisconsin at Madison, Madison, WI, USA, 1988.

[50] James F. Kurose and Keith W. Ross, Redes de computadores e a internet: Uma abordagem top-down, trad. 3 ed. ed., Addison Wesley, São Paulo, 2006.

[51] Ulrich Lang and Rudolf Schreiner, Developing Secure Distributed Systems with CORBA, Artech House, Inc., Norwood, MA, USA, 2002.

[52] Michael J. Lewis and Andrew Grimshaw, The Core Legion Object Model, Proceedings of the Fifth IEEE International Symposium on High Performance Distributed Computing (HPDC '96) (Los Alamitos, California), IEEE Computer Society Press, August 1996, pp. 551-561.

[53] Kyung-Suk Lhee and Steve J. Chapin, Buffer overflow and format string overflow vulnerabilities, Software Practice and Experience 33 (2003), no. 5, 423-460.

[54] J. Linn, The Generic Security Service Application Program Interface (GSS API), Tech. Report Internet RFC 2078, Network Working Group, January 1997.

[55] Alfred J. Menezes, Scott A. Vanstone, and Paul C. Van Oorschot, Handbook of applied cryptography, CRC Press, Inc., Boca Raton, FL, USA, 1996.

[56] MyGrid/OurGrid, http: //www. ourgrid.org, 2005.

[57] An introduction to computer security: The NIST handbook, Special Publication SP 800-12, National Institute of Standards and Technology (NIST), October 1995.

[58] L. Pearlman, V. Welch, I. Foster, C. Kesselman, and S. Tuecke, A community authorization service for group collaboration, Proceedings of the 3rd International Workshop on Policies for Distributed Systems and Networks (POLICY'02) (Washington, DC, USA), IEEE Computer Society, 2002, pp. 50-59.

[59] J. Ramachandran, Designing security architecture solutions, John Wiley \& Sons, Inc., New York, NY, USA, 2002.

[60] Ronald L. Rivest and Butler Lampson, SDSI - A simple distributed security infrastructure, Presented at CRYPTO'96 Rumpsession, 1996.

[61] $\quad$ A simple distributed security infrastructure (SDSI), http://groups.csail.mit.edu/cis/sdsi.html, Dec 2007.

[62] Altair Santin, Joni Fraga, Frank Siqueira, and Emerson Mello, Federation WEB: A scheme to compound authorization chains on large-scale distributed systems, 22nd Symposium on Reliable Distributed Systems (SRDS 2003) (Florence, Italy), 2003. 
[63] Elizeu Santos-Neto and Walfredo Cirne, Minicurso: Livro texto, ch. Grids Computacionais: Da Computação de Alto Desempenho a Serviços sob Demanda, pp. 15-60, Sociedade Brasileira de Redes de Computadores, May 2005.

[64] Markus Schumacher, Eduardo Fernandez, Duane Hybertson, and Frank Buschmann, Security patterns: Integrating security and systems engineering, John Wiley \& Sons, 2005.

[65] Pradeep K. Sinha, Distributed operating systems: Concepts and design, Wiley-IEEE Press, 1996.

[66] William Stallings, Network security essentials: Applications and standards, Prentice Hall Professional Technical Reference, 2002.

[67] Routo Terada, Segurança de Dados. Criptografia em Redes de Computadores, Editora Edgard Blucher Ltda, 2000.

[68] S. Tuecke, V. Welch, D. Engert, L. Pearlman, and M. Thompson, Internet X.509 public key infrastructure (PKI) proxy certificate profile, Internet RFC \#3820, 2004.

[69] W3C, Simple object access protocol (SOAP) 1.1, 2000, URL: http://www.w3c.org/TR/SOAP.

[70] Michelle S. Wangham, Emerson Ribeiro de Mello, Joni da Silva Fraga, and Davi da Silva Boger, A model to support spki federations management through xkms, ICWS, 2007, pp. 338-345.

[71] Von Welch, Ian Foster, Carl Kesselman, Olle Mulmo, Laura Pearlman, Steven Tuecke, Jarek Gawor, Sam Meder, and Frank Siebenlist, X.509 proxy certificates for dynamic delegation, Apr 2004 . 